$$
\begin{gathered}
\text { Universidade de São Paulo } \\
\text { Instituto de Física de São Carlos }
\end{gathered}
$$

José Ricardo Furlan Ronqui

\title{
Medidas de centralidade em redes complexas: correlações, efetividade e caracterização de sistemas
}





\section{Medidas de centralidade em redes complexas: correlações, efetividade e caracterização de sistemas}

Dissertação apresentada ao Programa de PósGraduação em Física do Instituto de Física de São Carlos da Universidade de São Paulo, para obtenção do título de Mestre em Ciências.

Área de Concentração: Física Aplicada Opção: Física Computacional

Orientador: Prof. Dr. Gonzalo Travieso

\section{Versão Corrigida}

(versão original disponível na Unidade que aloja o Programa)

São Carlos 
AUTORIZO A REPRODUÇÃO E DIVULGAÇÃO TOTAL OU PARCIAL DESTE TRABALHO, POR QUALQÜER MEIO CONVENCIONAL OU ELETRÔNICO PARA FINS DE ESTUDO E PESQUISA, DESDE QUE CITADA A FONTE.

Ficha catalográfica elaborada pelo Serviço de Biblioteca e Informação do IFSC, com os dados fornecidos pelo(a) autor(a)

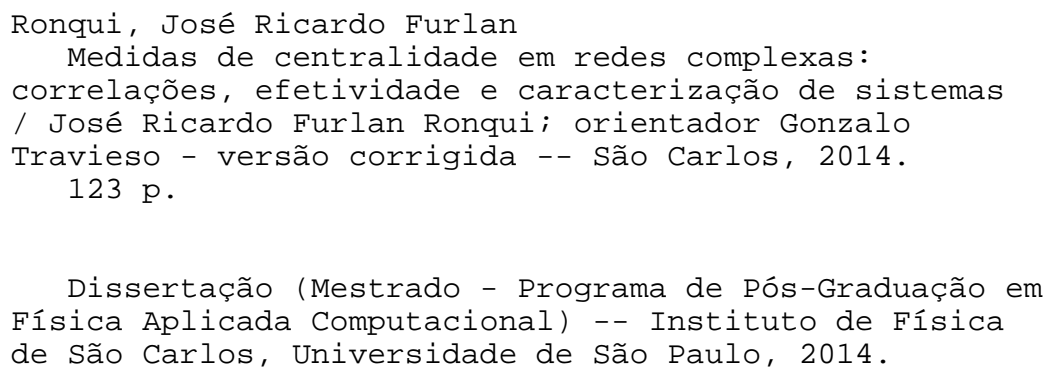

1. Redes complexas. 2. Medidas de centralidade. 3. Correlações. 4. Ataques. 5. Análise de componentes principais. I. Travieso, Gonzalo, orient. II. Título. 
Dedico esta dissertação aos meus pais Célia e Dari. 



\section{AGRADECIMENTOS}

Primeiramente gostaria de agradecer aos meus pais Célia e Dari, pelo apoio e pelos conselhos.

Agradeço também ao Prof. Dr. Gonzalo Travieso que me orientou na elaboração deste trabalho, nas correções do texto e outras diversas vezes durante o curso de graduação.

Aos meus amigos, muitos dos quais não vejo mais com tanta frequência, os de Pindorama e Catanduva com quem sempre tive discussões filosóficas sobre assuntos não acadêmicos; e também aos amigos que fiz ao longo da graduação que passaram pelo difícil processo (ou pelo menos por parte dele) de formação de um físico computacional.

Aos amigos da pós, pelas discussões sobre o avanço da ciência, produtividade, filmes, empreendedorismo, logística do bandejão e GNU/Linux.

Aos colegas de laboratório, pela ajuda com as redes e suas aplicações e pelas boas conversas.

Ao pessoal da secretaria de pós-graduação e da biblioteca que sempre me atenderam muito bem no esclarecimento das várias dúvidas que tive.

Agradeço ao Instituto de Física de São Carlos pela oportunidade, e as agências de fomento CAPES e CNPq que contribuíram com o estímulo financeiro.

Agradeço também ao amigo Thiago Mosqueiro, que desenvolveu o pacote de Latex utilizado para escrever este trabalho e pelas discussões sobre outros assuntos. $E$ aos amigos Jéssica, Krissia, Paulo, Raul e Daniel que me ajudaram nos ajustes finais da dissertação.

Finalmente agradeço a comunidade de software livre, em especial aos desenvolvedores das bibliotecas Igraph, NetworkX e graph-tool, que foram utilizadas no desenvolvimento deste trabalho; e também aos desenvolvedores do sistema operacional GNU/Linux. 

If you want to understand function, study structure.

Francis Crick.

Watson, you can see everything. You fail, however, to reason from what you see. You are too timid in drawing your inferences.

Frase do personagem Sherlock Holmes no livro "The Adventures of the Blue Carbuncle" escrito por Arthur Conan Doyle. 



\section{RESUMO}

RONQUI, J. R. F. Medidas de centralidade em redes complexas: correlações, efetividade e caracterização de sistemas. 2014. 123 p. Dissertação (Mestrado em Ciências) - Instituto de Física de São Carlos, Universidade de São Paulo, São Carlos, 2014.

Centralidades são medidas desenvolvidas para determinar a importância dos nós e ligações, utilizando as características estruturais das redes para esta finalidade. As medidas de centralidade são, portanto, essenciais no estudo de redes complexas pois os sistemas representados por elas geralmente são formados por muitos elementos, e com isso, torna-se inviável estudar individualmente cada um deles; dessa forma é necessário identificar os nós e ligações que são mais relevantes em cada situação. Todavia, com o surgimento de ideias diferentes de como esses elementos podem ser importantes, diversas medidas foram propostas com o intuito de evidenciar elementos que passam despercebidos pelas demais. Neste trabalho utilizamos a correlação de Pearson para avaliar o quão semelhantes são as classificações fornecidas pelas centralidades para redes representando sistemas reais e modelos teóricos. Para avaliar a efetividade das medidas e como elas afetam cada sistema, atacamos as redes usando as centralidades como indicadores para a ordem de remoção dos nós e ligações. Procurando caracterizar as redes usando suas diferenças estruturais, realizamos uma análise de componentes principais empregando as correlações entre os pares de centralidade como características de cada sistema. Nossos resultados mostraram que na maioria dos casos medidas distintas estão correlacionadas, o que indica que em geral os mesmos elementos são evidenciados pelas diferentes centralidades; também observamos que as correlações são mais fortes nos modelos do que nos sistemas reais. Os ataques mostraram que medidas fortemente correlacionadas podem influenciar as redes de maneiras distintas, evidenciando a importância do conjunto de elementos selecionados por cada medida. Nosso último resultado demonstra que as correlações entre os pares de centralidades podem ser utilizados tanto para a diferenciação e caracterização de redes quanto na avaliação de modelos que representem melhor a estrutura de um sistema específico.

Palavras-chave: Redes complexas. Medidas de centralidade. Correlações. Ataques. Análise de componentes principais. 



\section{ABSTRACT}

RONQUI, J. R. F. Centrality measures in complex networks: correlations, effectiveness and characterization of systems. 2014. 123 p. Dissertação (Mestrado em Ciências) - Instituto de Física de São Carlos, Universidade de São Paulo, São Carlos, 2014.

Centrality measures were developed to evaluate the importance of nodes and links based on the structure of networks. Centralities are essential in the study of networks because these systems are usually large, which make manual analysis of all nodes and links impossible; therefore recognizing such elements is a vital task. As nodes and links can be considered essential by different reasons, a large number of measures were proposed to identify important elements that were not highlighted by the other ones. In our study, we use Pearson's correlation coefficient to measure the similarity between rankings of nodes and links provided by different centralities for real and model based networks. We also perform attacks to networks, using these rankings to determine the order of removal of nodes and links, intending to evaluate and compare the efficiency and how the systems react to attacks guided by different centralities. Finally, we use the correlation coefficients between the pairs of centralities as properties of networks, and perform a principal component analysis with them, to evaluate if differences among network structures can be detected from correlations. Our results showed that centrality measures are frequently correlated, which means that the same elements can be highlighted by different centralities. We also noticed that the correlation coefficients are larger in models than in real world networks. The results of the attacks experiment showed that even when two measures are highly correlated, they can affect networks in distinct ways, meaning that the group of the nodes and links provided by each measure are relevant for the study of networks systems. Our last result evidenced that correlations among centrality measures can be used for characterization of networks and to evaluate how well models represent them.

Keywords: Complex networks. Centrality measures. Correlations. Attacks. Principal component analysis. 



\section{LISTA DE FIGURAS}

Figura 2.1 - Representação visual de um grafo simples. Os círculos azuis representam os nós do grafo e as linhas ligando os diferentes círculos representam as conexões entre eles. Devido à seu formato este grafo também é conhecido como grafo estrela. Fonte: Elaborada pelo autor.

Figura 2.2 - Representação da divisão da cidade de Königsberg no problema das 7 pontes. As áreas em verde representam a área onde a cidade se localizava e as linhas amarelas representam as 7 pontes que ligavam os diferentes pontos da cidade. Fonte: Figura retirada de SEVEN (23). . . 31

Figura 2.3 - Abstração feita por Euler para o problema das pontes de Königsberg. Esta abstração é a primeira representação conhecida dos grafos. Nesta representação, os nós do grafo representam os vários pontos da cidade, e as ligações são as diferentes pontes conectando-os. Fonte: Figura retirada de KÖNIGSBERG (27).

Figura 2.4 - Grafo completo com 21 nós e 210 ligações. Neste grafo todos os pares de nós possíveis são conectados, resultado em uma estrutura bastante regular. Fonte: Elaborada pelo autor.

Figura 2.5 - Rede real conhecida como clube de caratê do Zachary. Esta rede foi montada observando-se os membros de um clube de caratê de uma universidade e como eles se relacionavam. Fonte: Elaborada pelo autor.

Figura 2.6 - Grafo com 20 nós gerado utilizando-se o modelo de Erdős-Rényi. Neste grafo a probabilidade de conexão utilizada foi de $p=0.3$, podemos notar que existe uma homogeneidade na distribuição das ligações. Fonte: Elaborada pelo autor.

Figura 2.7 - Grafo com 20 nós gerado com o modelo de Watts e Strogatz, antes de se começar a fazer o rewiring. Neste grafo, cada nó era conectado com seus 4 vizinhos mais próximos. Fonte: Elaborada pelo autor.

Figura 2.8 - Mesmo grafo da figura 2.7, após algumas de suas ligações serem reconectadas a outros nós da rede com probabilidade $p=0.1$. Fonte:

Elaborada pelo autor. 
Figura 2.9 - Grafo gerado utilizando-se o modelo de Barabási e Albert. Este grafo possui 20 nós, nele podemos notar que um número pequeno de nós possui grande quantidade de conexões, enquanto os demais possuem poucas conexões. Fonte: Elaborada pelo autor

Figura 3.1 - Um grafo com 5 nós e 6 ligações, nele pode-se notar que A é o vértice que possui maior valor para a centralidade de grau e B o menor. Fonte: Elaborada pelo autor.

Figura 3.2 - Nesta figura pode-se notar que o nó 7 tem papel fundamental para a transmissão de informação entre nós distintos em uma das duas comunidades presentes (representadas pelos dois grafos completos), a centralidade de interposição tem um papel importante evidenciando este tipo de nó. Fonte: Elaborada pelo autor.

Figura 3.3 - A figura apresenta dois grafos completos que foram unidos pela ligação que liga os nós 6 e 7. Esta ligação possui um valor de centralidade de interposição alto, pois é a única que liga os dois conjuntos formados pelos grafos completos, e portanto todas as informações trocadas entre elementos desses dois grafos passam obrigatoriamente por esta ligação.

Fonte: Elaborada pelo autor. . . . . . . . . . . . . . . . . . . . . 50

Figura 4.1 - Pares de medidas centralidade com os maiores valores de correlação para a rede dos golfinhos. Fonte: Elaborada pelo autor.

Figura 4.2 - Pares de medidas centralidade com os maiores valores de correlação para a rede dos membros do clube de caratê. Fonte: Elaborada pelo autor.

Figura 4.3 - Pares de medidas centralidade com os maiores valores de correlação para a rede colaboração entre autores em artigos de física de altas energias. Fonte: Elaborada pelo autor.

Figura 4.4 - Pares de medidas centralidade com os maiores valores de correlação para a rede colaboração entre autores em artigos de redes complexas. Fonte: Elaborada pelo autor.

Figura 4.5 - Pares de medidas centralidade com os maiores valores de correlação para a rede de livros de politica. Fonte: Elaborada pelo autor.

Figura 4.6 - Pares de medidas centralidade com os maiores valores de correlação para a rede de distribuição de energia. Fonte: Elaborada pelo autor. 
Figura 4.7 - Pares de medidas centralidade com os maiores valores de correlação para as redes geradas utilizando-se o modelo de Erdős-Rényi. Fonte: Elaborada pelo autor.

Figura 4.8 - Pares de medidas centralidade com os maiores valores de correlação para as redes geradas utilizando-se o modelo de Barabási-Albert. Fonte: Elaborada pelo autor.

Figura 4.9 - Pares de medidas centralidade com os menores valores de correlação para a rede dos golfinhos. Fonte: Elaborada pelo autor.

Figura 4.10 -Pares de medidas centralidade com os menores valores de correlação para a rede dos membros do clube de caratê. Fonte: Elaborada pelo autor.

Figura 4.11 -Pares de medidas centralidade com os menores valores de correlação para a rede colaboração entre autores em artigos de física de altas energias. Fonte: Elaborada pelo autor.

Figura 4.12 -Pares de medidas centralidade com os menores valores de correlação para a rede colaboração entre autores em artigos de redes complexas. Fonte: Elaborada pelo autor.

Figura 4.13 -Pares de medidas centralidade com os menores valores de correlação para a rede de livros de politica. Fonte: Elaborada pelo autor.

Figura 4.14 -Pares de medidas centralidade com os menores valores de correlação para a rede de distribuição de energia. Fonte: Elaborada pelo autor.

Figura 4.15 -Pares de medidas centralidade com os menores valores de correlação para as redes geradas utilizando-se o modelo de Erdős-Rényi. Fonte: Elaborada pelo autor.

Figura 4.16 -Pares de medidas centralidade com os menores valores de correlação para as redes geradas utilizando-se o modelo de Barabási-Albert. Fonte: Elaborada pelo autor.

Figura 4.17 -Pares de medidas centralidade de ligações com os maiores valores de correlação para a rede dos golfinhos. Fonte: Elaborada pelo autor.

Figura 4.18 -Pares de medidas centralidade de ligações com os maiores valores de correlação para a rede do clube de caratê. Fonte: Elaborada pelo autor. 
Figura 4.19 - Pares de medidas centralidade de ligações com os maiores valores de correlação para a rede de colaboração entre autores em física de altas energias. Fonte: Elaborada pelo autor. . . . . . . . . . . . . . . . 79

Figura 4.20 -Pares de medidas centralidade de ligações com os maiores valores de correlação para a rede de colaboração entre autores em redes complexas. Fonte: Elaborada pelo autor.

Figura 4.21 -Pares de medidas centralidade de ligações com os maiores valores de correlação para a rede de livros de política. Fonte: Elaborada pelo autor. 80

Figura 4.22 -Pares de medidas centralidade de ligações com os maiores valores de correlação para a rede de distribuição de energia. Fonte: Elaborada pelo autor.

Figura 4.23 -Pares de medidas centralidade de ligações com os maiores valores de correlação para as redes geradas utilizando-se o modelo de Erdős-Rényi. Fonte: Elaborada pelo autor.

Figura 4.24 -Pares de medidas centralidade de ligações com os maiores valores de correlação para as redes geradas utilizando-se o modelo de BarabásiAlbert. Fonte: Elaborada pelo autor.

Figura 4.25 -Pares de medidas centralidade de ligações com os menores valores de correlação para a rede dos golfinhos. Fonte: Elaborada pelo autor.

Figura 4.26 -Pares de medidas centralidade de ligações com os menores valores de correlação para a rede do clube de caratê. Fonte: Elaborada pelo autor.

Figura 4.27 -Pares de medidas centralidade de ligações com os menores valores de correlação para a rede de colaboração entre autores em física de altas energias. Fonte: Elaborada pelo autor.

Figura 4.28 -Pares de medidas centralidade de ligações com os menores valores de correlação para a rede de colaboração entre autores em redes complexas. Fonte: Elaborada pelo autor.

Figura 4.29 -Pares de medidas centralidade de ligações com os menores valores de correlação para a rede de livros de política. Fonte: Elaborada pelo autor.

Figura 4.30 -Pares de medidas centralidade de ligações com os menores valores de correlação para a rede de distribuição de energia. Fonte: Elaborada pelo autor. 
Figura 4.31 -Pares de medidas centralidade de ligações com os menores valores de correlação para as redes geradas utilizando-se o modelo de Erdős-Rényi. Fonte: Elaborada pelo autor.

Figura 4.32 -Pares de medidas centralidade de ligações com os menores valores de correlação para as redes geradas utilizando-se o modelo de BarabásiAlbert. Fonte: Elaborada pelo autor.

Figura 4.33 -Ataques realizados na rede golfinhos. Os gráficos mostram como o tamanho da maior componente e eficiência da rede decaem com a remoção de seus nós para as diferentes medidas de centralidade consideradas. Fonte: Elaborada pelo autor.

Figura 4.34 -Ataques realizados na rede do clube de caratê. Os gráficos mostram como o tamanho da maior componente e eficiência da rede decaem com a remoção de seus nós para as diferentes medidas de centralidade consideradas. Fonte: Elaborada pelo autor.

Figura 4.35 -Ataques realizados na rede de colaboradores em física de altas energias. Os gráficos mostram como o tamanho da maior componente e eficiência da rede decaem com a remoção de seus nós para as diferentes medidas de centralidade consideradas. Fonte: Elaborada pelo autor.

Figura 4.36 -Ataques realizados na rede de colaboradores em redes complexas. Os gráficos mostram como o tamanho da maior componente e eficiência da rede decaem com a remoção de seus nós para as diferentes medidas de centralidade consideradas. Fonte: Elaborada pelo autor.

Figura 4.37 -Ataques realizados na rede dos livros sobre política. Os gráficos mostram como o tamanho da maior componente e eficiência da rede decaem com a remoção de seus nós para as diferentes medidas de centralidade consideradas. Fonte: Elaborada pelo autor.

Figura 4.38 -Ataques realizados na rede de distribuição de energia. Os gráficos mostram como o tamanho da maior componente e eficiência da rede decaem com a remoção de seus nós para as diferentes medidas de centralidade consideradas. Fonte: Elaborada pelo autor. 
Figura 4.39 -Ataques realizados na rede golfinhos. Os gráficos mostram como o tamanho da maior componente e eficiência da rede decaem com a remoção de suas ligações para as diferentes medidas de centralidade consideradas. Fonte: Elaborada pelo autor.

Figura 4.40 -Ataques realizados na rede do clube de caratê. Os gráficos mostram como o tamanho da maior componente e eficiência da rede decaem com a remoção de suas ligações para as diferentes medidas de centralidade consideradas. Fonte: Elaborada pelo autor.

Figura 4.41 -Ataques realizados na rede de colaboradores em física de altas energias. Os gráficos mostram como o tamanho da maior componente e eficiência da rede decaem com a remoção de suas ligações para as diferentes medidas de centralidade consideradas. Fonte: Elaborada pelo autor.

Figura 4.42 -Ataques realizados na rede de colaboradores em redes complexas. Os gráficos mostram como o tamanho da maior componente e eficiência da rede decaem com a remoção de suas ligações para as diferentes medidas de centralidade consideradas. Fonte: Elaborada pelo autor.

Figura 4.43 -Ataques realizados na rede dos livros sobre política. Os gráficos mostram como o tamanho da maior componente e eficiência da rede decaem com a remoção de suas ligações para as diferentes medidas de centralidade consideradas. Fonte: Elaborada pelo autor.

Figura 4.44 -Ataques realizados na rede de distribuição de energia. Os gráficos mostram como o tamanho da maior componente e eficiência da rede decaem com a remoção de suas ligações para as diferentes medidas de centralidade consideradas. Fonte: Elaborada pelo autor.

Figura 4.45 -Projeção das redes reais e modelos nas duas componentes principais mais significativas. Notamos que a maioria das redes reais pôde ser diferenciada dos modelos. Fonte: Elaborada pelo autor. . . . . . . . 106

Figura 4.46 -Projeção das correlações entre os pares das medidas de centralidade dos nós da rede dos golfinhos nas duas componentes principais. Nesta figura também mostramos as projeções de redes geradas pelos modelos de Erdős-Rényi, Barabási-Albert e reconexão, utilizando características da rede real. Fonte: Elaborada pelo autor. 
Figura 4.47 -Projeção das correlações entre os pares das medidas de centralidade dos nós da rede de colaboração em física de altas energias nas duas componentes principais. Nesta figura também mostramos as projeções de redes geradas pelos modelos de Erdős-Rényi, Barabási-Albert e reconexão, utilizando características da rede real. Fonte: Elaborada pelo autor

Figura 4.48 -Projeção das correlações entre os pares das medidas de centralidade dos nós da rede do clube de caratê nas duas componentes principais. Nesta figura também mostramos as projeções de redes geradas pelos modelos de Erdős-Rényi, Barabási-Albert e reconexão, utilizando características da rede real. Fonte: Elaborada pelo autor.

Figura 4.49 -Projeção das correlações entre os pares das medidas de centralidade dos nós da rede de colaboração entre autores de redes complexas nas duas componentes principais. Nesta figura também mostramos as projeções de redes geradas pelos modelos de Erdős-Rényi, Barabási-Albert e reconexão, utilizando características da rede real. Fonte: Elaborada pelo autor

Figura 4.50 -Projeção das correlações entre os pares das medidas de centralidade dos nós da rede de livros sobre política nas duas componentes principais. Nesta figura também mostramos as projeções de redes geradas pelos modelos de Erdős-Rényi, Barabási-Albert e reconexão, utilizando características da rede real. Fonte: Elaborada pelo autor.

Figura 4.51 -Projeção das correlações entre os pares das medidas de centralidade dos nós da rede de distribuição de energia nas duas componentes principais. Nesta figura também mostramos as projeções de redes geradas pelos modelos de Erdős-Rényi, Barabási-Albert e reconexão, utilizando características da rede real. Fonte: Elaborada pelo autor

Figura 4.52 -Projeção das redes reais e modelos nas duas componentes principais mais significativas. Notamos que todas as redes reais foram diferenciadas dos modelos. Fonte: Elaborada pelo autor. 
Figura 4.53 -Projeção das correlações entre os pares das medidas de centralidade das ligações da rede dos golfinhos nas duas componentes principais. Nesta figura também mostramos as projeções de redes geradas pelos modelos de Erdős-Rényi, Barabási-Albert e reconexão, utilizando características da rede real. Fonte: Elaborada pelo autor.

Figura 4.54 -Projeção das correlações entre os pares das medidas de centralidade das ligações da rede do clube de caratê nas duas componentes principais. Nesta figura também mostramos as projeções de redes geradas pelos modelos de Erdős-Rényi, Barabási-Albert e reconexão, utilizando características da rede real. Fonte: Elaborada pelo autor.

Figura 4.55 -Projeção das correlações entre os pares das medidas de centralidade das ligações da rede de colaboração entre autores de redes complexas nas duas componentes principais. Nesta figura também mostramos as projeções de redes geradas pelos modelos de Erdős-Rényi, Barabási-Albert e reconexão, utilizando características da rede real. Fonte: Elaborada pelo autor.

Figura 4.56 -Projeção das correlações entre os pares das medidas de centralidade das ligações da rede de livros sobre política nas duas componentes principais. Nesta figura também mostramos as projeções de redes geradas pelos modelos de Erdős-Rényi, Barabási-Albert e reconexão, utilizando características da rede real. Fonte: Elaborada pelo autor.

Figura 4.57 -Projeção das correlações entre os pares das medidas de centralidade das ligações da rede de distribuição de energia nas duas componentes principais. Nesta figura também mostramos as projeções de redes geradas pelos modelos de Erdős-Rényi, Barabási-Albert e reconexão, utilizando características da rede real. Fonte: Elaborada pelo autor.

Figura 4.58 -Diferenciação entre uma rede de interação de proteínas e os modelos de Barabási-Albert e Pastor-Satorras, utilizando as correlações entre as medidas de centralidade dos nós como características das redes. Fonte: Elaborada pelo autor. 


\section{LISTA DE TABELAS}

Tabela 3.1 - Exemplo de matriz de adjacências para o grafo da figura 3.1

Tabela 4.1 - Tabela com informações estruturais das redes reais utilizadas no trabaIho. $\mathrm{N}$ indica o número de nós da rede, $\langle k\rangle$ o grau médio, $\langle C\rangle$ representa o coeficiente de clusterização médio e $\langle L\rangle$ indica o comprimento médio do menor caminho entre todos os pares de nós da rede. Redes que possuem o símbolo * ao lado do nome, indicam que os dados são referentes à maior componente da rede.

Tabela 4.2 - Correlação de Pearson para as redes: golfinhos (GF), clube de caratê (CT), colaboração em artigos de física de altas energias (CF), colaboração em redes complexas (CR), livros de política (LP), rede de distribuição de energia (DE), modelo de Erdős-Rényi (ER), e modelo Barabási-Albert (BA). As centralidades Proximidade FC e Interposição $C A$ significam proximidade utilizando o modelo de fluxo de corrente e interposição baseada em caminhada aleatória, respectivamente.

Tabela 4.3 - Tabela com os expoentes das leis de potência encontradas encontrados entre as medidas de centralidade de nós das redes: golfinhos (GF), clube de caratê (CT), colaboração em artigos de física de altas energias (CF), colaboração em redes complexas (CR), livros de política (LP), rede de distribuição de energia (DE), modelo de Erdős-Rényi (ER), e modelo Barabási-Albert (BA).

Tabela 4.4 - Correlação de Pearson para as redes: golfinhos (GF), clube de caratê $(C T)$, colaboração em artigos de física de altas energias (CF), colaboração em redes complexas (CR), livros de política (LP), rede de distribuição de energia (DE), modelo de Erdős-Rényi (ER), e modelo Barabási-Albert (BA). Nas medidas de centralidade as abreviações Interp $L$ significam Interposição para ligação, Interp $L C A$ interposição para ligação baseada em caminhada aleatória, Interp interposição, Interp CA interposição baseada em caminhada aleatória e Proximidade FC proximidade utilizando o modelo do fluxo de corrente. 
Tabela 4.5 - Tabela com os expoentes das leis de potência encontradas entre as medidas de centralidade de ligação das redes: golfinhos (GF), clube de caratê (CT), colaboração em artigos de física de altas energias (CF), colaboração em redes complexas (CR), livros de política (LP), rede de distribuição de energia (DE), modelo de Erdős-Rényi (ER), e modelo Barabási-Albert (BA) . . . . . . . . . . . . . . . . . 77 


\section{SUMÁRIO}

1 Introdução

2 Redes Complexas $\quad 29$

2.1 O que são redes complexas . . . . . . . . . . . . . . . . . . . . . . . . . . 29

2.2 Um pouco de história sobre redes complexas . . . . . . . . . . . . . . . 30

2.3 Alguns exemplos de redes complexas . . . . . . . . . . . . . . . . . . . . 32

2.3.1 Redes sociais . . . . . . . . . . . . . . . . . . . . . . 33

2.3.2 Redes tecnológicas . . . . . . . . . . . . . . . . . . . . 33

2.3.3 Redes de informação . . . . . . . . . . . . . . . . . . . . . . . . . 34

2.3.4 Redes biológicas . . . . . . . . . . . . . . . . . . . . . . . . . . . . 34

2.4 Por que complexas? . . . . . . . . . . . . . . . . . . . . . . . . . 35

2.5 Características estruturais das redes complexas . . . . . . . . . . . . . . . . 37

2.6 Modelos de redes complexas . . . . . . . . . . . . . . . . . . . . . . . . . . . . 39

2.6.1 Redes Erdős-Rényi . . . . . . . . . . . . . . . . . . . . . . . . . . . . . 39

2.6.2 Redes Watts-Strogatz . . . . . . . . . . . . . . . . . . . . . 40

2.6.3 Redes Barabási-Albert . . . . . . . . . . . . . . . . . . . . . . . . . 41

3 Medidas de Centralidade $\quad 43$

3.1 Centralidade de grau . . . . . . . . . . . . . . . . . . . 43

3.2 Centralidade de autovetor . . . . . . . . . . . . . . . . 45

3.3 Centralidade de interposição . . . . . . . . . . . . . . . . . . . 47

3.3.1 Centralidade de interposição para nós . . . . . . . . . . . . . . . . 48

3.3.2 Centralidade de interposição para ligações . . . . . . . . . . . . . . . 49

3.4 Centralidade de proximidade . . . . . . . . . . . . . . . . 50 
3.5 Centralidade de interposição usando caminhada aleatória . . . . . . . . . . . 51

3.5.1 O Modelo do Fluxo de corrente . . . . . . . . . . . . . . . . . . . . 51

3.5.2 O modelo da caminhada aleatória . . . . . . . . . . . . . . . 54

3.5.3 Centralidade de interposição de caminhada aleatória para ligações . . . 56

3.6 Centralidade de proximidade utilizando o modelo do fluxo de corrente . . . . . 56

3.7 Centralidade de subgrafo . . . . . . . . . . . . . . . . . . . . . . . . . . 57

3.8 Considerações Finais . . . . . . . . . . . . . . . . . . . . . . . . . . . . . . . 58

4 Metodologia e resultados $\quad 59$

4.1 Redes utilizadas . . . . . . . . . . . . . . . . . . . . . . . . . . . . 59

4.1.1 Redes baseadas em modelos . . . . . . . . . . . . . . . . . . . . . 59

4.1 .2 Redes reais . . . . . . . . . . . . . . . . . . . . . 60

4.2 Correlações entre as medidas de centralidade . . . . . . . . . . . . . . . 60

4.2.1 Correlações das centralidades dos nós . . . . . . . . . . . . . . . . . . 61

4.2.1.1 Centralidades de nós mais correlacionadas . . . . . . . . . 64

4.2.1.2 Centralidades de nós menos correlacionadas . . . . . . . 70

4.2.2 Correlações das centralidades das ligações . . . . . . . . . . . . . . 75

4.2.2.1 Centralidades de ligação mais correlacionadas . . . . . . . . 78

4.2.2.2 Centralidades de ligação menos correlacionadas . . . . . . . 83

4.3 Diferenças entre medidas de centralidades . . . . . . . . . . . . . . . . . . . 88

4.3.1 Ataques utilizando centralidades dos nós . . . . . . . . . . . . . . 88

4.3.2 Ataques utilizando centralidades das ligações . . . . . . . . . . . . . . 96

4.4 Caracterização de redes usando centralidades . . . . . . . . . . . . . . . . . 104

4.4.1 Análise de componentes principais utilizando centralidades dos nós . . 105

4.4.2 Análise de componentes principais utilizando centralidades de ligações . 110

4.4.3 Avaliação de modelos com medidas de centralidades . . . . . . . . . 114 
REFERÊNCIAS 



\section{Capítulo 1}

\section{Introdução}

Redes complexas (1-8) são modelos matemáticos notáveis devido a sua simplicidade e aos diversos sistemas representados por elas (9). Essa variedade faz com que pesquisadores de diferentes áreas da ciência as estudem sob perspectivas distintas, por exemplo biologia (1012), ciências sociais (13-15), transporte (16), meteorologia (17), Internet (18), linguística (19) entre outras, contribuindo para que várias propriedades sejam descobertas; fatores esses que cooperam para o crescimento do campo. Todas as características, mesmo que indiretamente, dependem dos elementos que compõem as redes e de como se relacionam. Estrutura e função, portanto, são intimamente dependentes $(3,4)$. Estudar um sistema real modelando-o como uma rede não é algo trivial já que, usualmente são compostos por milhares ou em alguns casos milhões de nós e ligações, o que torna inviável analisar individualmente todos os elementos. Também existem casos em que não podemos desconsiderar a coletividade, onde um fenômeno não depende unicamente do nó ou ligação analisados, mas também de seus vizinhos e como são essas conexões.

Por esta razão, a solução encontrada para compreender as redes, foi selecionar as estruturas mais importantes para o processo estudado e avaliar como e com quais outras elas se relacionam. Dessa necessidade surgiram entre outras medidas que hoje são chamadas de centralidades, que utilizam as propriedades estruturais da rede para diferenciação de seus elementos (20). Porém, como existem vários motivos para um deles ser considerado essencial, uma variedade de maneiras de classificá-los emergiu. Sabemos que devido a sua definição, algumas medidas fornecem bons resultados para estudos específicos como a de grau, que frequentemente é empregada na realização de ataques (21), ou a de interposição que é usada na detecção de comunidades (22). Assim, a busca por melhores métodos de classificação de nós e ligações da rede, que iniciou-se com os estudos com grafos, continua até os dias atuais. Quando novas maneiras de caracterizar esses elementos são apresentadas, espera-se que elas forneçam resultados distintos dos que são obtidos com os métodos já existentes, possibilitando analisar o sistema de novos pontos de vista.

Dessa forma a escolha das centralidades em um problema específico é essencial pois nos permitem compreender o funcionamento da rede. Logo, estudos sobre como elas se relacionam podem indicar quais medidas devem ser utilizadas em cada caso. Porém não encontramos 
muitos trabalhos em que elas são comparadas. Devido a essa necessidade e buscando compreender melhor as centralidades, neste trabalho comparamos as classificações fornecidas pelas diferentes medidas e se seus resultados são redundantes. Da mesma forma que existem fenômenos que dependem da coletividade, a classificação que um elemento recebe pelas várias medidas pode não ser suficiente. Portanto também verificamos como os resultados fornecidos por diferentes medidas afetam os sistemas, o que pode fornecer informações sobre como o conjunto de elementos selecionados por elas são importantes para as redes. Finalmente, as medidas de centralidade estão associadas a estrutura e aos motivos pelos quais os elementos dos sistemas se relacionam. Essas conexões provavelmente acontecem por razões distintas em cada sistema, e com isso esperamos que as relações entre as medidas devem mudar. Investigamos, então, se é possível perceber essas diferenças entre as medidas de redes distintas e assim descrever os diferentes sistemas considerados.

Para responder essas questões, em nossos estudos realizamos três experimentos: primeiro calculamos as correlações entre os pares de centralidades e analisamos os gráficos apresentando seu relacionamento para avaliar o quão semelhantes ou diferentes são os resultados obtidos pelas diversas medidas; para avaliar a importância do conjunto de elementos selecionados por cada medida, realizamos ataques aos sistemas considerados removendo seus elementos segundo a importância obtida por cada centralidade e comparamos os desempenhos; finalmente usamos os valores das correlações como características de cada sistema e realizamos uma análise de componentes principais para avaliar se as diferenças entre a correlação dos pares de centralidade pode ser utilizada para caracterizar e diferenciar as redes complexas.

Nos capítulos 2 e 3, respectivamente, fornecemos maiores informações e referências sobre as redes complexas e as medidas de centralidade utilizadas em nosso trabalho. Os sistemas e modelos utilizados em cada um de nossos experimentos bem como os resultados obtidos em cada um deles são apresentados no capítulo 4. O capítulo 5 contém nossas conclusões e discussões sobre novas pesquisas que podem ser desenvolvidas a partir dos resultados e metodologia aqui apresentados. 


\section{Redes Complexas}

\subsection{O que são redes complexas}

Redes complexas são modelos utilizados para representar elementos principais (também chamados de atores), e como eles se relacionam. Esses modelos a que nos referimos são conhecidos matematicamente como grafos. Um grafo é um conjunto de nós (também chamados de vértices) conectados por ligações (ou arestas); no caso das redes complexas os nós da rede representam os atores e suas ligações os relacionamentos entre esses atores. Na figura 2.1, apresentamos um grafo simples, nele os círculos azuis representam os nós do grafo e as linhas ligando os diferentes círculos representam as ligações entre os nós da rede.

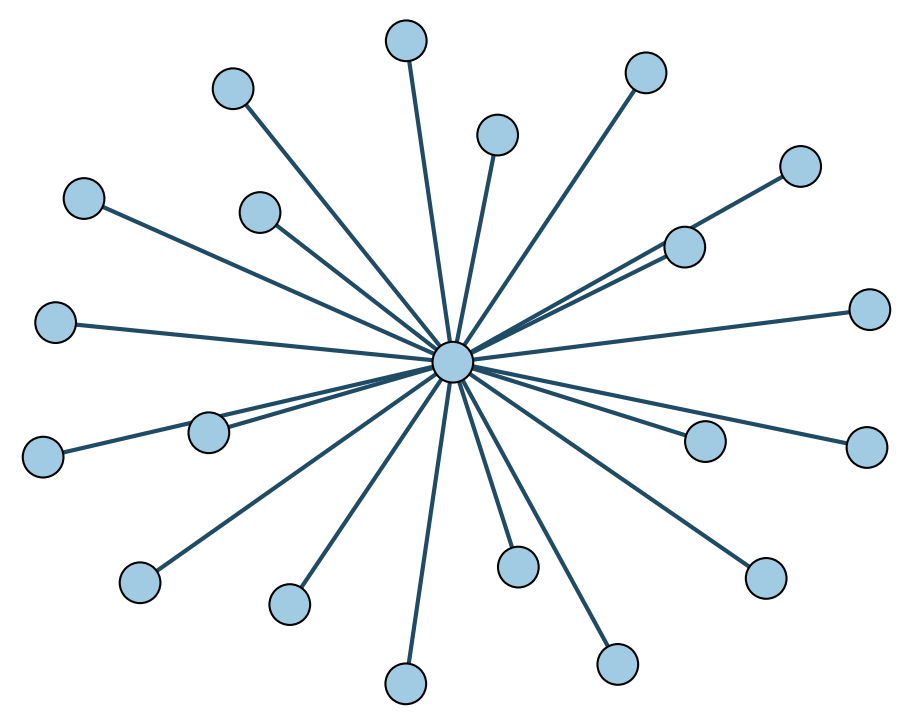

Figura 2.1 - Representação visual de um grafo simples. Os círculos azuis representam os nós do grafo e as linhas ligando os diferentes círculos representam as conexões entre eles. Devido à seu formato este grafo também é conhecido como grafo estrela. Fonte: Elaborada pelo autor.

Um exemplo de sistema que pode ser imaginado como um grafo, é o de um grupo de amigos. Nesse caso os nós do grafo representam as pessoas, e as ligações entre nós diferentes 
representam os laços de amizade entre as pessoas da rede. A grande vantagem das redes complexas, é que como grafos são modelos simples, todo sistema que seja composto de elementos principais que apresentem algum tipo de relacionamento entre si, podem ser representados utilizando-se um grafo. Dessa forma, uma grande variedade de aplicações diferentes de redes complexas surgiu e a área está hoje em grande crescimento. Além disso, ao analisar novos sistemas utilizando redes complexas, podemos desenvolver ferramentas que serão úteis para outros sistemas.

No início do desenvolvimento da área de grafos, muitos estudos eram realizados com relação à sua estrutura e essa tarefa mostrou-se bastante difícil para grafos grandes. Entretanto, com o surgimento dos computadores e seu crescente poder de processamento, tornou-se possível analisar grafos que antes eram inviáveis e obter novos resultados, além de viabilizar o estudo de redes que não são mais estáticas, mas que evoluem no tempo, seguindo algumas regras para essa dinâmica. Desde o início, os estudos de redes complexas sempre aplicaram o conceito matemático dos grafos em diversas áreas do conhecimento, como por exemplo, sociologia, computação, física, biologia, química entre outras. Essa interdisciplinaridade inerente ao desenvolvimento das redes complexas junto com a grande quantidade de dados disponíveis faz com que as redes estejam cada dia mais presentes em nossa vida cotidiana.

\subsection{Um pouco de história sobre redes complexas}

Como já mencionamos, as redes complexas são os elementos matemáticos conhecidos como grafos. O primeiro registro que se tem da utilização de grafos foi para resolver o problema das pontes de Königsberg. O problema consiste no seguinte: a cidade de Königsberg na Prússia era dividida por um rio, assim a cidade se estendia pelas duas margens do rio e em duas ilhas que ficavam dentro dele. No total, existiam sete pontes ligando as diferentes ilhas e margens da cidade, como representado na figura 2.2. Entre os habitantes da cidade surgiu a dúvida se seria possível, estando em uma determinada ilha ou margem, atravessar todas as pontes uma única vez e voltar para a mesma parte da cidade. O problema permaneceu sem solução até que, no ano de 1736, o matemático Leonard Euler demonstrou que tal travessia seria impossível. Para resolvê-lo ele abstraiu as ilhas e margens e as pontes em uma estrutura matemática como está representado na figura 2.3. Com o tempo, este tipo de estrutura matemática ficou conhecida como grafo. Assim em 1736 surgia uma nova área na matemática, a área dos grafos. Um ponto interessante sobre o trabalho de Euler na resolução deste tipo de problema, é que na época ele encontrou um grupo de problemas do mundo real que dependiam apenas do padrão 
de conexão entre seus elementos para ser resolvido (2).

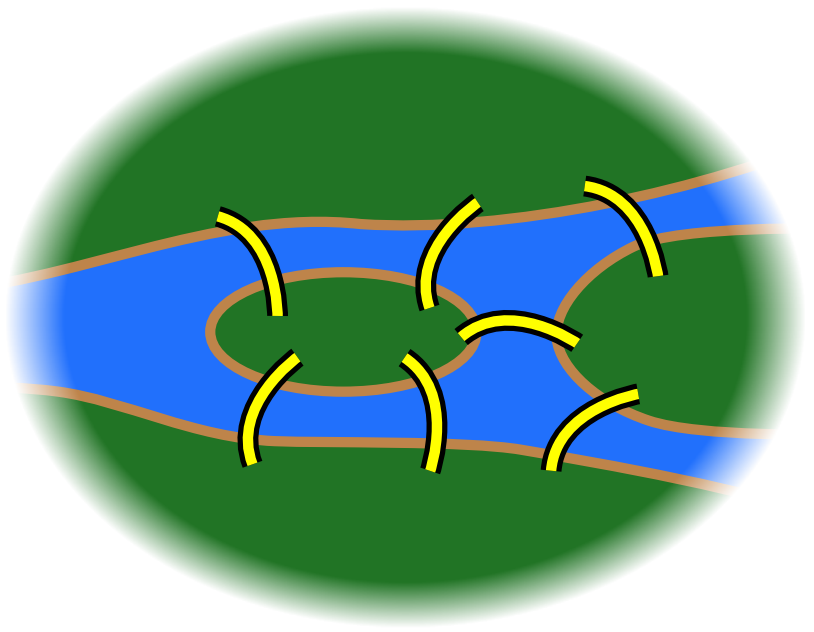

Figura 2.2 - Representação da divisão da cidade de Königsberg no problema das 7 pontes. As áreas em verde representam a área onde a cidade se localizava e as linhas amarelas representam as 7 pontes que ligavam os diferentes pontos da cidade. Fonte: Figura retirada de SEVEN (23).

Posteriormente vários trabalhos foram realizados, explorando em grande parte a topologia dos grafos e introduzindo novos conceitos (24), e diferentes tipos de grafos. Também é interessante ressaltar que desde o início dos estudos envolvendo grafos, eles foram utilizados de maneira interdisciplinar em várias áreas (25). A próxima grande mudança na teoria dos grafos ocorreu com o início dos estudos do grafos aleatórios (26), entretanto o modelo mais conhecido de grafos aleatórios foi o de Erdös e Rényi descrito na seção 2.6. Outro aspecto interessante dos grafos aleatórios é que como eles se baseiam unicamente em probabilidades, várias de suas propriedades podem ser obtidas analiticamente com o uso de estatística, como por exemplo a distribuição de graus que segue uma lei de Poisson. Infelizmente, como veremos a seguir, esse modelo não representa com fidelidade a grande maioria das redes complexas presentes na natureza.

A próxima mudança de paradigma que foi realizada na área, é a que estamos vivendo hoje. Apesar dos conceito de grafos ser antigo, devido ao tamanho dos sistemas representados por eles, em poucos casos era possível analisá-los detalhadamente, o que inviabilizava estudos sobre sua topologia e dinâmica. Porém, com o aumento da capacidade computacional e a grande quantidade e acessibilidade aos dados nos últimos anos, tornou-se possível montar novas redes que representam sistemas reais, e que por isso, ficaram conhecidas como redes reais. Das análises dessas redes reais, ficou claro que elas diferiam das redes regulares ou aleatórias que eram as mais amplamente estudadas, e por isso vários modelos e medidas que possibilitaram a observação da complexidade (ver seção 2.4) presente nas redes reais - 


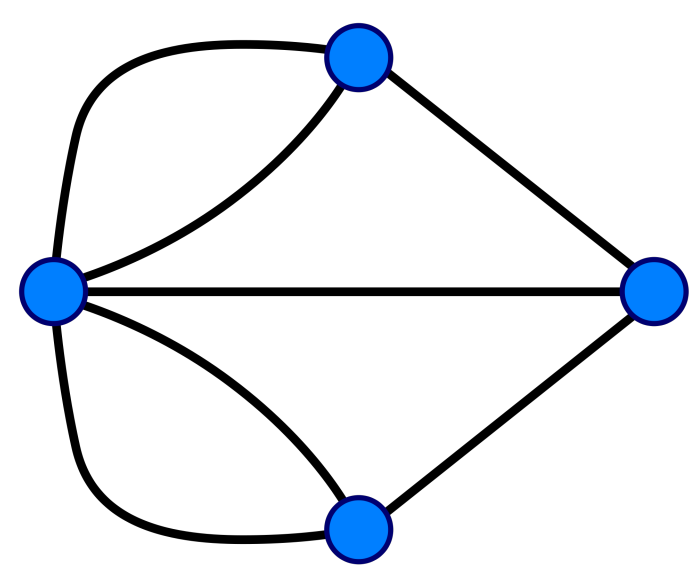

Figura 2.3 - Abstração feita por Euler para o problema das pontes de Königsberg. Esta abstração é a primeira representação conhecida dos grafos. Nesta representação, os nós do grafo representam os vários pontos da cidade, e as ligações são as diferentes pontes conectando-os. Fonte: Figura retirada de KÖNIGSBERG (27).

foram desenvolvidos para representar as novas características observadas, e descrever melhor as redes estudadas. Na seção 2.5, abordaremos um pouco melhor algumas dessas características e os modelos utilizados para representá-las. Outra vantagem que surgiu da possibilidade de se estudar redes representando sistemas reais, é que as mais diversas áreas puderam fazer uso dos resultados obtidos para as redes complexas, e trazer também seu ponto de vista, o que deu origem a diversas novas aplicações. Na seção 2.3, comentaremos sobre algumas das aplicações atuais de redes complexas.

\subsection{Alguns exemplos de redes complexas}

Nesta seção escreveremos um pouco sobre algumas das diversas aplicações das redes complexas, com objetivo de demonstrar o grande número de aplicações em que as redes complexas podem ser utilizadas, o quão comumente elas ocorrem nos dias atuais e a grande interdisciplinaridade da área. Não abordaremos, entretanto, como os dados para montar tais redes são obtidos; maiores informações sobre como as elas são montadas podem ser obtidas nas referências bibliográficas $(1,2)$. 


\subsubsection{Redes sociais}

Talvez uma das primeiras áreas em que utilizou-se o conceito das redes, depois da matemática, foi na sociologia. Apesar de hoje o termo redes sociais estar associado à grandes redes geradas por computadores, como por exemplo o Facebook, a origem da ideia de utilizar grafos para representar as relações entre pessoas ou grupo de pessoas, é de Moreno em 1934 (28), que posteriormente originou a área que atualmente é conhecida como análise de redes sociais. Entretanto, nos trabalhos iniciais, as redes eram chamadas de sociogramas, ao invés de redes sociais. Outro ponto interessante é que as ligações neste tipo de rede, podem ter diferentes definições dependendo do que se está estudando. As ligações, por exemplo, poderiam representar laços de amizade entre os as pessoas da rede, ou relações profissionais, ou ainda, comunicação entre as pessoas ou o fluxo monetário entre elas. Um dos resultados interessantes no início dos estudos do trabalho de Moreno foi quando, analisando um grupo de crianças de uma escola e suas amizades, ele descobriu que existiam poucos laços de amizade entre meninos e meninas, o que hoje é conhecido como homofilia ou mistura seletiva (também conhecido como assortative mixing) que é a tendência de indivíduos com alguma característica em comum terem um número maior de conexões entre si (29).

\subsubsection{Redes tecnológicas}

Talvez uma das redes tecnológicas mais estudadas recentemente seja a Internet. A Internet a que nos referimos aqui é composta pelos servidores ou computadores que são os nós da rede complexa e as ligações feitas por cabos entre eles que são as ligações. Existem várias maneiras diferentes de se obter a topologia da Internet, e várias camadas diferentes em que ela pode ser analisada (para maiores informações ver (1)). Um resultado interessante foi o de Faloutsos et al. (18), que analisou a distribuição de graus da Internet e descobriu que ela segue aproximadamente uma lei de potência, que como veremos na seção 2.5 é uma característica frequentemente presente nas redes reais.

Outro tipo bastante interessante de rede tecnológica são as redes de distribuição de energia, onde mapeiam-se as linhas e estações de energia de alta voltagem $(30,31)$. Essas redes apresentam uma característica interessante: seus nós estão distribuídos geograficamente de maneira que a distribuição de energia seja satisfatória, e que a construção da rede seja economicamente viável. Nestas redes também foi observada a distribuição do tipo lei de potência (32). 


\subsubsection{Redes de informação}

Os dois tipos de redes de informação que citaremos aqui são as redes formadas pelas página de internet e as redes de citação entre artigos científicos. A primeira é uma rede direcional formada pelas páginas da internet, nesse caso os nós da rede complexa são as webpages e as ligações são formadas pelos links presentes em cada página. Reconhecer e estudar esta estrutura de rede complexa da World Wide Web é bastante importante, principalmente para os buscadores de páginas, pois esta é uma maneira deles retornarem as webpages mais relevantes para cada pesquisa.

$\mathrm{Na}$ rede de citações entre artigos científicos, os artigos são os nós da rede e se o artigo $A$ cita $O$ artigo $B$ em suas referências, uma ligação direcionada é feita de $A$ para $B$, onde os outros artigos citados geralmente contém informações relevantes para o primeiro. Estas redes permitem identificar os artigos e autores mais relevantes em uma determinada área do conhecimento, utilizando seu número de citações. Recentemente, a estrutura formada neste tipo de rede também foi útil para detectar um acordo feito entre revistas brasileiras, para aumentar seu fator de impacto (33). Nas redes de citação entre artigos científicos também foi observado o comportamento lei de potência na distribuição de grau de seus nós (34).

\subsubsection{Redes biológicas}

Biologia é talvez a área da ciência em que redes complexas podem ser empregadas mais facilmente, devido à importância das relações entre os diversos elementos estudados, que na maioria dos casos também está associada ao funcionamento do sistema biológico. Podemos citar por exemplo, as conexões entre as células cerebrais na área da neurociência (35), ou ainda as relações entre diferentes espécies em ecossistemas (36), ou ainda a interação entre proteínas (37) ou redes de co-expressão gênica (38), dentre outros. Em todos esses tipos de redes várias características estruturais interessantes foram obtidas, como por exemplo, comportamento lei de potência na distribuição de grau de algumas redes (2). Outro resultado interessante foi o obtido por Milo (39), que encontrou padrões de conexão chamados de motifs que aparecem mais frequentemente em redes reais do que em redes aleatórias, além disso os padrões diferem entre redes reais e parecem estar intimamente relacionados com funções específicas desempenhadas pelo sistema analisado. Podemos citar também o trabalho de Jeong (10) que mostra que a remoção das proteínas mais conectadas (ou mais centrais), 
apresentam um impacto maior para o sistema.

\subsection{Por que complexas?}

Uma pergunta que podemos nos fazer é: "Por que as redes são consideradas complexas?". Essencialmente a resposta para esta pergunta não é trivial pois, a definição de complexidade não é única (40) e é bastante discutida na literatura e o que é considerado complexo por uma definição pode não o ser por uma definição diferente. Aqui empregaremos o mesmo conceito de complexidade presente no livro de Estrada (2), que usa a ideia de quantidade de informação necessária para descrever um sistema como definição de complexidade, ou seja, redes complexas são redes que necessitam de uma grande quantidade de informação para serem descritas de uma forma precisa.

Para ilustrar melhor esta ideia, usaremos alguns exemplos. No grafo da figura 2.4, apresentamos um grafo completo. Neste tipo de grafo todos os pares de nós possíveis são conectados. Como podemos notar a estrutura gerada por este tipo de grafo é bastante regular e pode ser facilmente descrita. Neste tipo de grafo, não podemos diferenciar um nó $i$ de um nó $j$ utilizando apenas a estrutura do grafo, ou seja, todos os nós acabam sendo iguais.

Outro exemplo é o da figura 2.1, presente na primeira seção deste capítulo. Esse grafo pode ser facilmente descrito como sendo um grafo de $n=21$ nós e $m=n-1=20$ ligações, conectando 20 dos nós a um nó central. Entretanto, se o compararmos com o primeiro exemplo, notamos que é preciso uma quantidade um pouco maior de informação para descrever este grafo, logo, se comparado com o grafo completo e utilizando nossa definição de complexidade, o grafo estrela é um pouco mais complexo que o primeiro grafo. Além disso, no caso do grafo tipo estrela fica claro que o nó central, ao qual todos os outros estão conectados, é diferente pois ele é mais importante que os demais - sua remoção, por exemplo, causaria a destruição de todas a relações (ligações) da rede, além de transformar uma rede com apenas uma componente contendo todos os nós em uma rede com 20 componentes contendo um nó.

Tanto o grafo completo quanto o grafo estrela apresentados anteriormente, são redes geradas utilizando-se modelos específicos. Entretanto, em uma rede real, que é gerada observandose os atores do sistema estudado e como se relacionam, por exemplo, a rede representada na figura 2.5, gerada por Zachary (41), torna-se difícil realizar uma descrição sucinta da mesma, logo, precisa-se de uma quantidade de informação muito grande para descrevê-la, e essa necessidade de informação levou ao desenvolvimento de várias ideias diferentes que podem ser 


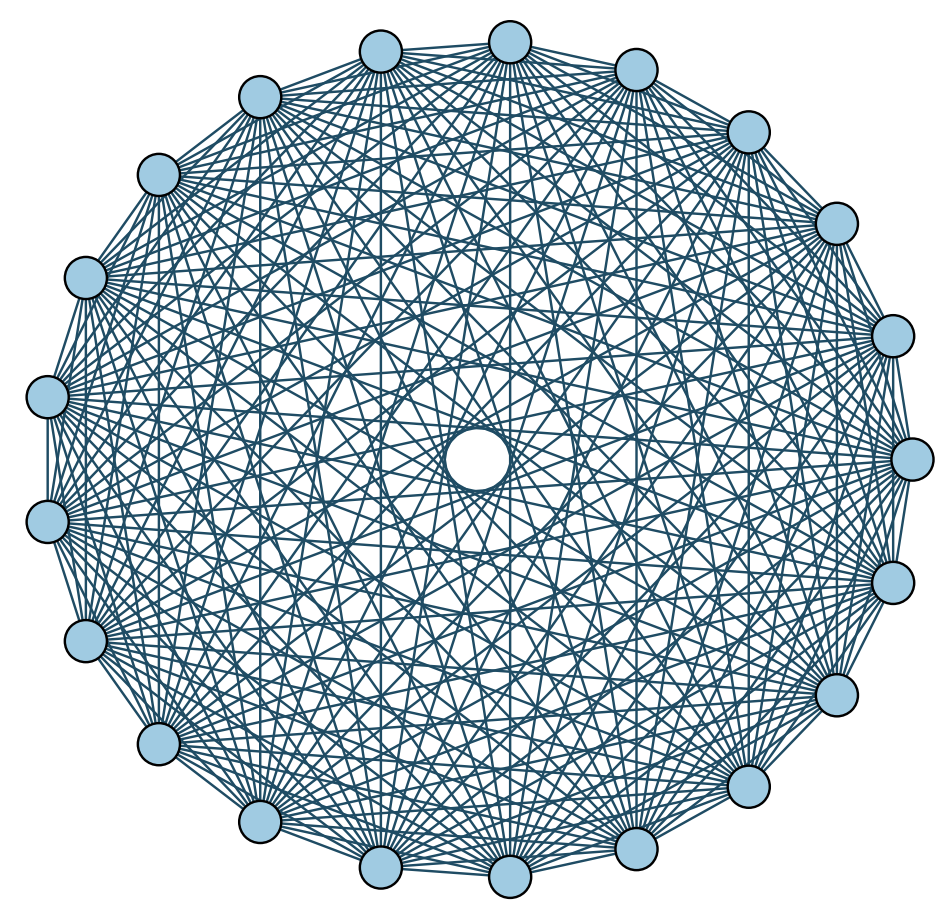

Figura 2.4 - Grafo completo com 21 nós e 210 ligações. Neste grafo todos os pares de nós possíveis são conectados, resultado em uma estrutura bastante regular. Fonte: Elaborada pelo autor.

utilizadas para caracterização de uma rede complexa. Podemos dizer por exemplo que a rede da figura 2.5 possui 34 nós e 78 ligações, ou ainda, poderíamos dizer que esta rede possui duas comunidades (42). Entretanto, seria preciso uma quantidade muito maior de informação para poder descrever esta rede de maneira única. Além disso, observando-se essas medidas de distinção, foi possível notar que algumas das características estiveram presentes em várias redes reais estudadas. Na seção 2.5 deste capítulo abordaremos um pouco mais as estruturas observadas.

Outro ponto que podemos notar sobre a complexidade presente nas redes, é que ela acaba fazendo com que alguns nós e ligações sejam mais importantes do que os demais, da mesma forma como destacamos o nó central do grafo estrela que acaba sendo vital para a rede. Esse tipo de informação é imprescindível para estudos topológicos sobre a estrutura das redes ou aplicações que utilizam redes complexas, como por exemplo identificar uma página de maior relevância nas pesquisas realizadas em uma máquina de buscas na internet (43), ou identificar gargalos na distribuição de produtos em redes transporte. Logo, tornou-se essencial 


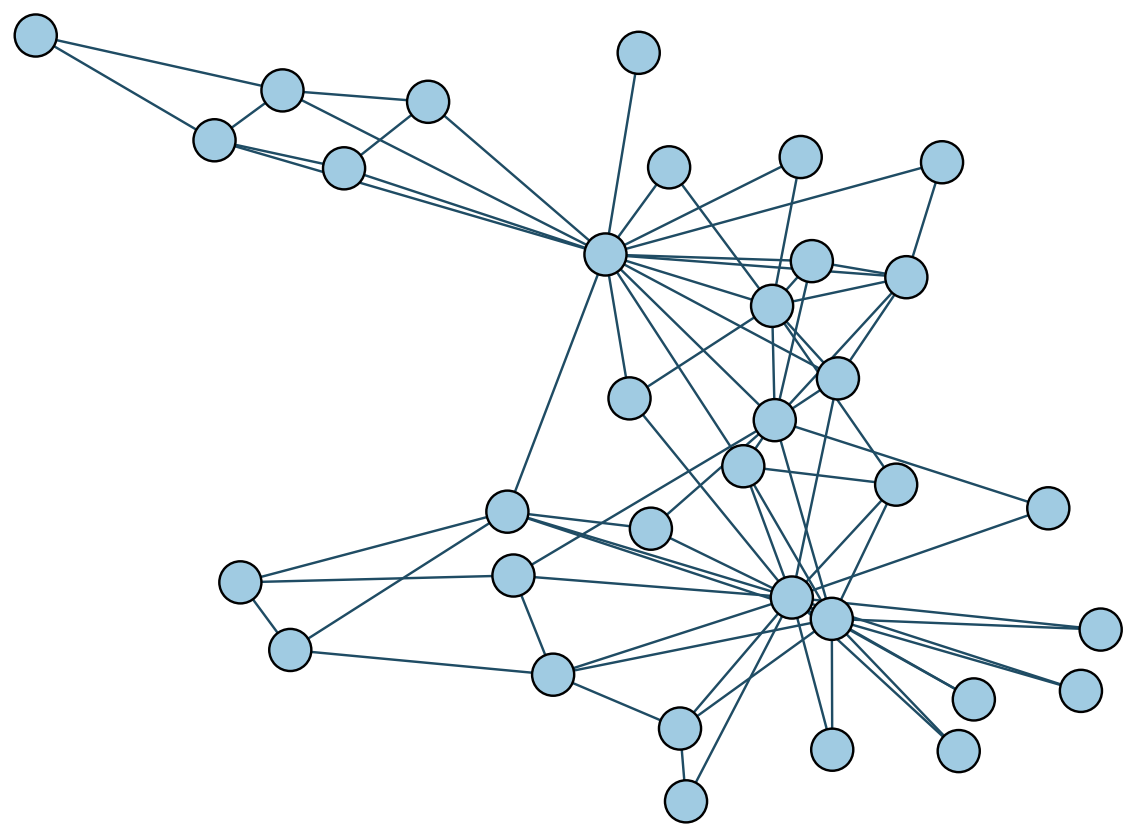

Figura 2.5 - Rede real conhecida como clube de caratê do Zachary. Esta rede foi montada observando-se os membros de um clube de caratê de uma universidade e como eles se relacionavam. Fonte: Elaborada pelo autor.

desenvolver métricas para evidenciar os elementos (nós e ligações) mais importantes dentro de uma rede complexa - as chamadas medidas de centralidade. Existem diferentes formas de se considerar os elementos das redes importantes, o que leva a diversidade de medidas de centralidade. No capítulo 3, apresentamos maiores informações sobre medidas de centralidade consideradas nesse trabalho e descreveremos suas ideias principais.

\subsection{Características estruturais das redes complexas}

Nesta seção discutiremos algumas propriedades estruturais observadas nas redes reais. Duas delas são: o elevado valor para a transitividades e o fenômeno conhecido como mundo pequeno.

O fenômeno mundo pequeno, primeiro observado por Milgram (44), é o fato de que o menor caminho entre dois nós da rede complexa é pequeno se comparado com a quantidade total de nós da rede, sendo proporcional ao logaritmo deste número. A transitividade é a 
propriedade de que dois vizinhos de um dado nó da rede também sejam vizinhos entre si, ou seja, o amigo do meu amigo tem uma grande probabilidade de ser meu amigo; para mensurá-la, utiliza-se o chamado coeficiente de clusterização. Esse fenômeno é muito presente em redes sociais. Maiores informações tanto sobre a transitividade quanto sobre o fenômeno mundo pequeno podem ser encontrados em (31). Neste artigo, também é proposto um modelo conhecido como modelo de Watts-Strogatz - que apresenta ambas as características citadas e é descrito na seção 2.6 .

Outro fenômeno que aparece frequentemente em redes reais, é a distribuição de graus livre de escala. Quando começou-se a estudar as redes reais, os cientistas perceberam que em vários casos existiam poucos nós com um grande número de conexões e muitos nós com poucas conexões. Assim, passou-se a estudar a distribuição de grau de várias redes reais, e em vários dos casos estudados notou-se que essa distribuições seguiam uma lei de potência $p(k) \sim k^{-\gamma}$, onde $p(k)$ é a probabilidade de encontrar um nó com grau $k$ e geralmente $2 \leq \gamma \leq 3$. Maiores informações sobre leis de potência e suas propriedades podem ser encontradas em (45).

Alguns modelos foram elaborados tentando representar a característica livre de escala das redes reais, como por exemplo o proposto por Price que inspirado pelos trabalhos de Simon $(1,46)$, propôs um modelo que gera redes livre de escala, que ele havia observado anteriormente entre citações de artigos científicos (34). Entretanto de todos os modelos propostos para representar o fenômeno livre de escala em redes complexas, o mais famoso é o modelo proposto por Barabási e Albert, descrido na seção 2.6.

Entender a estrutura das redes complexas é essencial, pois como vimos na seção 2.4 , a complexidade das redes torna difícil uma descrição da mesma. Além disso, um estudo da estrutura pode, por exemplo, fornecer informações sobre a evolução ou função e sobre os fenômenos que acontecem no sistema que está sendo representado pela rede. Assim, uma série de medidas diferentes foram desenvolvidas para se obter um conjunto de informações da rede, como por exemplo o conceito de eficiência local e global das redes (47), ou a modularidade $(42,48)$ que mede a tendência dos nós se associarem àqueles que são, de alguma forma, mais parecidos com eles, ou ainda a frequência que os motifs, que são pequenos subgrafos associados a funções especializadas (39), estarem presentes. Além dessas medidas, para se identificar os nós e ligações mais importantes da rede, uma série de métricas (também conhecidas como medidas de centralidade) foram desenvolvidas, a fim de classificar os nós e ligações seguindo conceitos diferentes de como estes elementos podem ser importantes para a rede. No capítulo 3 fazemos uma descrição das medidas de centralidade utilizadas neste trabalho, como elas podem ser obtidas e onde foram propostas. 


\subsection{Modelos de redes complexas}

Descreveremos agora alguns dos modelos mais utilizados e conhecidos em redes complexas. Esses modelos são importantes pois além de gerar, de maneira simples, redes que apresentam características que são observadas com frequência nas redes reais, eles também são necessários para gerar uma grande diversidade de redes contendo características bem definidas.

\subsubsection{Redes Erdős-Rényi}

O modelo proposto por Erdős e Rényi $(49,50)$, visa estudar as características e propriedades de redes geradas utilizando-se apenas probabilidades e estatística. Muitas propriedades deste modelo foram obtidas nas referências $(51,52)$. Além disso como este modelo baseia-se em probabilidades para gerar as redes, ele foi essencial para o estudo de redes grandes no passado, e por isso este é um dos modelos de rede mais amplamente estudados na literatura. No modelo proposto por Erdős e Rényi, o grafo começa com $n$ nós sem nenhuma conexão e então começa-se a fazer ligações com uma probabilidade $p>0$ entre todos os pares possíveis de nós da rede. Este modelo gera redes complexas em que a distribuição de grau segue uma lei de Poisson. Na figura 2.6, apresentamos um grafo gerado utilizando-se este modelo.

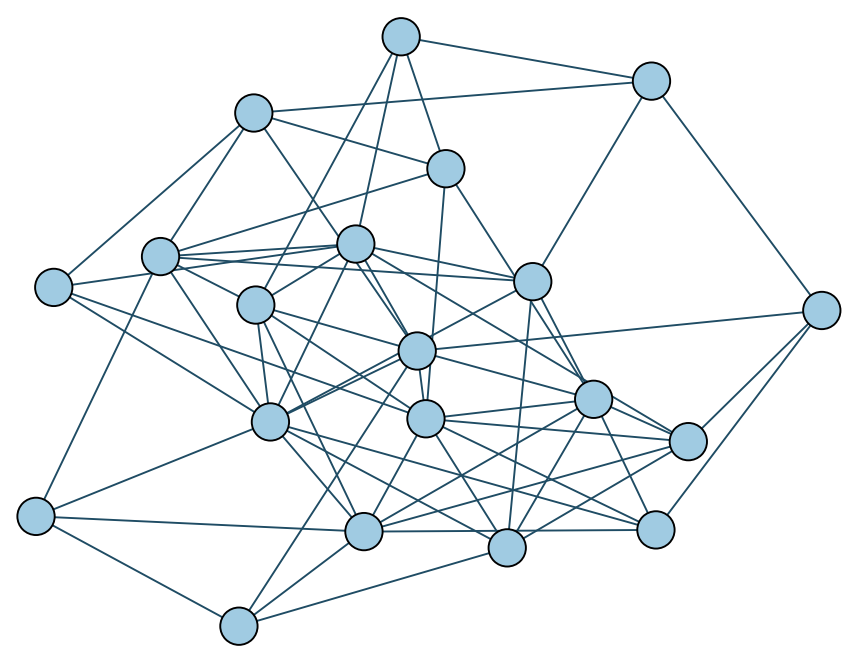

Figura 2.6 - Grafo com 20 nós gerado utilizando-se o modelo de Erdôs-Rényi. Neste grafo a probabilidade de conexão utilizada foi de $p=0.3$, podemos notar que existe uma homogeneidade na distribuição das ligações. Fonte: Elaborada pelo autor. 
Apesar deste modelo ser vastamente estudado, um problema aparente com ele é que ele não representa bem as características observadas nas redes reais (ver seção 2.5). Por exemplo em um grupo de pessoas, é difícil que os indivíduos se conheçam aleatoriamente como proposto no modelo, o mais natural é que pessoas com interesses em comum ou que convivam em um mesmo ambiente criem laços de amizade. Assim, outros modelos que tentavam entender e explicar melhor os fenômenos observados nas redes reais precisaram ser propostos.

\subsubsection{Redes Watts-Strogatz}

O modelo de Watts-Strogatz foi desenvolvido para representar o fenômeno small-world ou mundo pequeno observado nas redes reais, descrito na seção 2.5. O modelo consiste em criar uma rede regular, em formato de anel, onde cada nó está conectado com $n$ nós mais próximos, como a rede representada na figura 2.7, onde por conveniência $n$ é um número par, assim cada nó é conectado com o mesmo número de vizinhos em ambas as direções do anel.

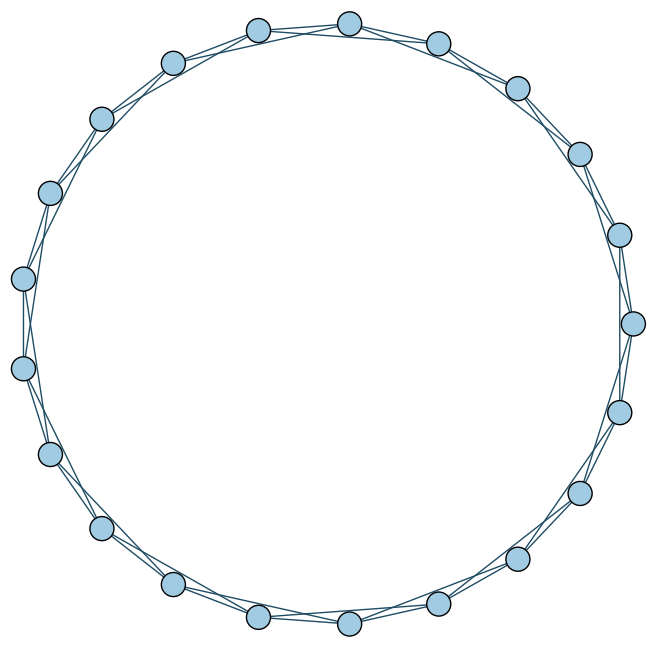

Figura 2.7 - Grafo com 20 nós gerado com o modelo de Watts e Strogatz, antes de se começar a fazer o rewiring. Neste grafo, cada nó era conectado com seus 4 vizinhos mais próximos. Fonte: Elaborada pelo autor.

Em seguida, todas as ligações da rede podem ser refeitas aleatoriamente a algum nó da rede, com uma probabilidade $p$. É interessante ressaltar que este modelo começa com uma complexidade relativamente pequena, e após a realização dos sorteios para reconectar as ligações, que adicionam atalhos na rede reduzindo a distância média entre os nós e também 
aumentam a complexidade da rede, tanto a transitividade quanto a característica mundo pequeno (descritas na seção 2.5) são obtidas. Na figura 2.8 apresentamos a mesma rede da figura 2.7, quando algumas de suas ligações são refeitas com outros nós da rede com probabilidade $p=0.1$. Como pode-se imaginar, se a probabilidade for $p=1$ então obtemos uma rede completamente aleatória, e se $p=0$ então a rede continua sendo a rede regular inicial, logo as características observadas de transitividade e pequeno mundo são obtidas quando a rede encontra-se em algum lugar no meio do caminho entre esses dois extremos.

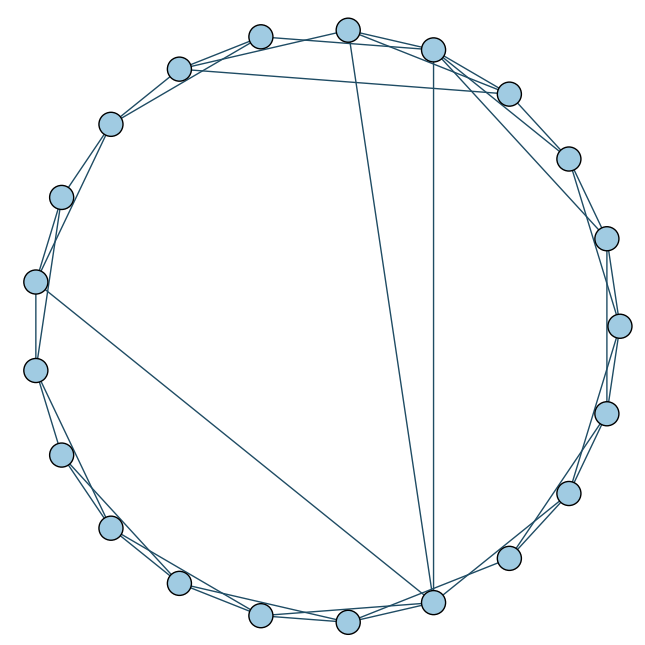

Figura 2.8 - Mesmo grafo da figura 2.7, após algumas de suas ligações serem reconectadas a outros nós da rede com probabilidade $p=0.1$. Fonte: Elaborada pelo autor.

\subsubsection{Redes Barabási-Albert}

Este modelo foi proposto por Barabási e Albert em (53). O modelo de Barabási e Albert gera redes que apresentam uma distribuição de graus livre de escala, observada em diversas redes reais e discutida na seção 2.5. O modelo gera as redes da maneira a seguir, inicialmente a rede começa com um pequeno número do total de nós $m_{0}$. A cada passo no tempo um novo nó $u$ é adicionado a rede, sendo conectado a $m \leq m_{0}$ dos nós existentes com probabilidade $p_{u}=\frac{k_{v}}{\sum_{w} k_{w}}$. Esse método de conexão faz com que as redes geradas apresentem a característica livre de escala, pois a probabilidade de conexão é maior para os nós que possuem um grande número de primeiros vizinhos. Na figura 2.9, apresentamos uma rede gerada utilizando-se este modelo. 


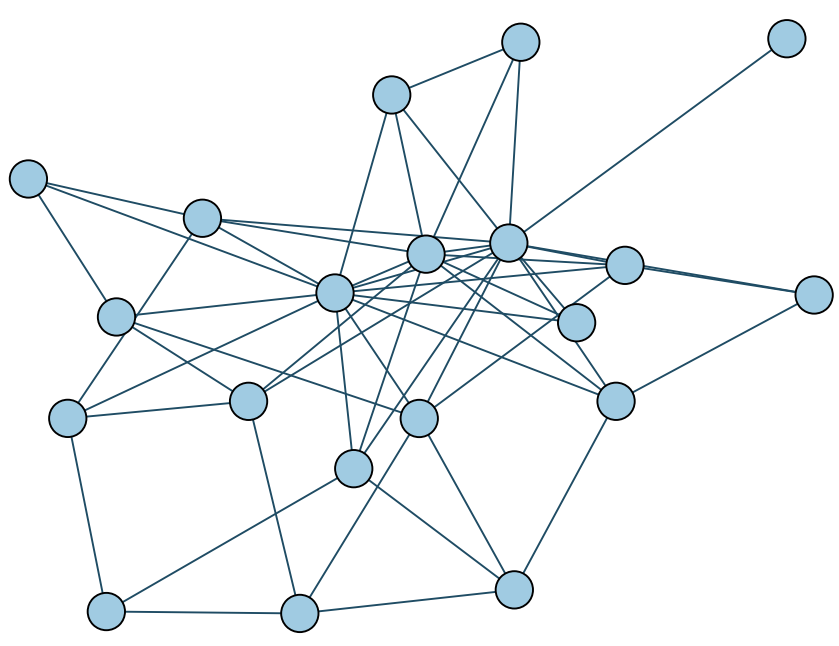

Figura 2.9 - Grafo gerado utilizando-se o modelo de Barabási e Albert. Este grafo possui 20 nós, nele podemos notar que um número pequeno de nós possui grande quantidade de conexões, enquanto os demais possuem poucas conexões. Fonte: Elaborada pelo autor. 


\section{Medidas de Centralidade}

Com o desenvolvimento dos estudos baseados em grafos na área das ciências sociais, um dos primeiros problemas encontrados foi o de como seria possível avaliar quais pessoas possuíam uma maior importância dentro do grupo analisado, afinal como vimos anteriormente, redes reais geralmente apresentam grande complexidade e esta complexidade faz com que alguns nós da rede e algumas de suas relações sejam mais importantes que os demais.

Várias medidas baseadas na estrutura da rede foram então propostas, para que assim fosse possível uma melhor caracterização das redes sociais. Utilizando-se uma determinada característica, como por exemplo o número de amigos que um indivíduo possui ou ainda a quantidade de pessoas importantes que uma pessoas conhece, foi possível determinar o quão central um indivíduo era para o grupo analisado. Além disso diferentes ideias de como um nó ou uma ligação podiam ser consideradas importantes para rede surgiram, dando origem aos mais variados tipos de medidas. Tais medidas posteriormente ficaram conhecidas na literatura como medidas de centralidade e passaram a ser utilizadas em tipos diferentes de redes, além das sociais, que modelavam, por exemplo, redes de comunicação, biológicas, metabólicas, ou qualquer outro sistema que possa ser representado como uma rede complexa. Notou-se que tal ideia poderia ser estendida para as ligações da rede, podendo-se então avaliar a importância das conexões entre seus nós.

Nas seções seguintes descreveremos as medidas de centralidade utilizadas em nosso trabalho e também quais características elas levam em conta e como calculá-las.

\subsection{Centralidade de grau}

A centralidade de grau ou degree centrality é talvez a mais simples de todas as medidas de centralidade, esta métrica avalia a importância de um nó analisando a quantidade de nós a que ele é ligado, ou seja, quanto maior o número de nós ligados a este, maior a importância do nó para a rede e, portanto, maior o valor atribuído para este vértice pela centralidade. Na figura 3.1 apresentamos um grafo simples com cinco nós e seis ligações; nele, o vértice A possui 
maior centralidade de grau devido ao número de vizinhos a que está conectado. Na segunda colocação encontra-se o vértice $D$, seguido de $C$ e $E$ que empatam na terceira posição. $B$ fica em último lugar com apenas uma ligação. O grau de um nó pode ser calculado utilizando-se

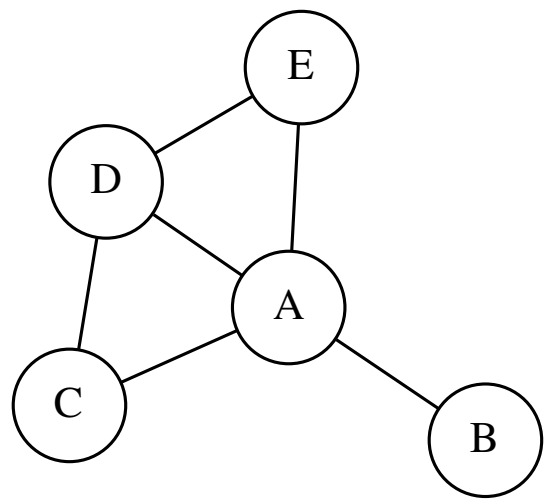

Figura 3.1 - Um grafo com 5 nós e 6 ligações, nele pode-se notar que A é o vértice que possui maior valor para a centralidade de grau e B o menor. Fonte: Elaborada pelo autor.

a seguinte expressão:

$$
k_{i}=\sum_{j=1}^{n} A_{i j}
$$

onde $k_{i}$ é o grau do nó $i$ e $A_{i j}$ são os elementos da matriz de adjacências da rede complexa e $n$ é o número de vértices na rede complexa. A matriz de adjacências é uma das maneiras de se representar o grafo. Nessa matriz, as linhas e colunas estão associadas aos nós da rede. Quando exite uma ligação entre dois nós da rede, o campo correspondente da matriz é preenchido com valor 1 . No caso de redes sem direção a matriz de adjacências sempre é simétrica. Quando as ligações presentes nas redes possuem pesos, então utilizamos duas matrizes par representá-la, a matriz de adjacências que indica se existem ligações entre os nós da rede e a matriz de pesos, contendo os pesos daquelas ligações. Na tabela 3.1 apresentamos a matriz de adjacências do grafo da figura 3.1.

Em alguns casos (e também neste trabalho) pode-se utilizar uma variação da centralidade de grau, onde divide-se o valor de $k_{i}$ pelo maior grau possível, garantindo-se assim que o valor da centralidade de cada nó esteja entre 0 e 1. Na equação (3.1.2) apresentamos a fórmula para o cálculo da medida de centralidade de grau, quando normalizada pelo grau máximo. 
Tabela 3.1 - Exemplo de matriz de adjacências para o grafo da figura 3.1

\begin{tabular}{c|ccccc}
\hline & $\mathrm{A}$ & $\mathrm{B}$ & $\mathrm{C}$ & $\mathrm{D}$ & $\mathrm{E}$ \\
\hline $\mathrm{A}$ & 0 & 1 & 1 & 1 & 1 \\
$\mathrm{~B}$ & 1 & 0 & 0 & 0 & 0 \\
$\mathrm{C}$ & 1 & 0 & 0 & 1 & 0 \\
$\mathrm{D}$ & 1 & 0 & 1 & 0 & 1 \\
$\mathrm{E}$ & 1 & 0 & 0 & 1 & 0 \\
\hline
\end{tabular}

Fonte: Elaborada pelo autor.

$$
k_{i}=\frac{\sum_{j=1}^{n} A_{i j}}{n-1}
$$

É importante ressaltar que na equação (3.1.2) assumimos que a rede seja um grafo simples, ou seja, consideramos que na rede não existem ligações de um nó com ele mesmo (loops) ou ligações paralelas (o que implicaria que o grau máximo de cada nó pudesse ser maior que $n-1)$. Caso tais ligações existam, a expressão da equação (3.1.2) continua válida, entretanto seus valores não estarão mais limitados entre 0 e 1 . Outro fato que pode ser destacado é que para redes com direção deve-se levar em consideração ainda a existência de duas centralidades de grau, as de grau de entrada (in degree) e de saída (out degree), sendo que a primeira delas leva em conta quantas ligações chegam em um nó $i$ e a última, quantas ligações o nó $i$ possuí para outros nós. Avaliar qual dessas duas métricas deve ser levada em consideração para as redes com direção depende intrinsecamente do que a rede representa e quais as características estão sendo analisadas. Como no presente trabalho utilizamos apenas redes sem direção, não entraremos em maiores detalhes sobre as centralidades de grau de entrada e saída.

\subsection{Centralidade de autovetor}

Proposta primeiramente por Bonacich em (54), a centralidade de autovetor estende o conceito da centralidade de grau, da seguinte maneira: um nó é importante para a rede complexa se ele possuir muitas ligações com outros nós, ou se tiver algumas conexões com nós que são altamente conectados na rede. Desta maneira, a centralidade de autovetor leva em consideração não apenas as conexões que o nó $i$ possuí como também quantas os seus vizinhos possuem. Pensando em uma rede social, a ideia seria que uma pessoa é importante se possui muitos amigos ou se conhece alguns com muitos contatos, ou ainda se estiver em 
um ponto intermediário entre as duas situações.

Para obter a expressão para a centralidade de autovetor, utilizaremos um desenvolvimento parecido com o que foi feito por Newman (1). Imaginemos que no início todos os vértices possuam uma centralidade $x_{i}=1$. Dessa maneira podemos calcular as centralidades $x_{i}^{\prime}$ de todos os vértices como sendo a soma das centralidades de todos os seus vizinhos ou seja:

$$
x_{i}^{\prime}=\sum_{j} A_{i j} x_{j}
$$

onde $A_{i j}$ são os elementos da matriz de adjacências representando a rede estudada. Notemos ainda que a expressão (3.2.1) também pode ser escrita utilizando-se notação matricial da seguinte maneira $\mathbf{x}^{\prime}=\mathbf{A x}$, onde $\mathbf{x}$ é o vetor com os elementos $x_{i}$. Repetindo-se o processo da (3.2.1) $t$ vezes, obtemos:

$$
\mathbf{x}(t)=\mathbf{A}^{\mathbf{t}} \mathbf{x}(0)
$$

onde $\mathbf{x}(t)$ é o vetor com as centralidades para todos os nós após $t$ iterações e $\mathbf{x}(0)$ é o valor inicial atribuído a cada nó. Podemos escrever $\mathbf{x}(0)$ como uma combinação linear dos autovetores $\mathbf{v}_{\mathbf{i}}$ da matriz de adjacências, de forma que:

$$
\mathbf{x}(0)=\sum_{i} c_{i} \mathbf{v}_{i}
$$

Substituindo-se a equação (3.2.3) na (3.2.2), obtemos:

$$
\mathbf{x}(t)=\mathbf{A}^{\mathbf{t}} \sum_{i} c_{i} \mathbf{v}_{i}=\sum_{i} c_{i} \kappa_{i}^{t} \mathbf{v}_{i}=\kappa_{1}^{t} \sum_{i} c_{i}\left[\frac{\kappa_{i}}{\kappa_{1}}\right]^{t} \mathbf{v}_{i},
$$

onde os $\kappa_{i}$ são os autovalores da matriz de adjacências $\mathbf{A}$ e $\kappa_{1}$ é o maior autovalor. Para um número de iterações grande o suficiente, os valores de $\mathbf{x}(t)$ entrarão em um situação estacionária onde todos os valores de suas componentes não irão mais variar, logo utilizandose a (3.2.4) nota-se que no limite de $t \rightarrow \infty$ obtêm-se $\mathbf{x}(t) \rightarrow c_{1} \kappa_{1} \mathbf{v}_{1}$. Portanto podemos dizer que o valor da centralidade de autovetor no caso em que os valores da centralidade parem de variar pode ser escrita como:

$$
\mathbf{A x}=\kappa_{1} \mathbf{x}
$$

Que é a centralidade de autovetor proposta por Bonacich em 1987 em (54). Da equação (3.2.5) pode-se notar que a centralidade do nó $i$ depende de todos os seus vizinhos:

$$
x_{i}=\kappa_{1}^{-1} \sum_{j} A_{i j} x_{j}
$$

Demonstrando que a centralidade de autovetor leva em consideração o valor da centralidade 
de todos os vizinhos conectados com o nó $i$ como discutido no início desta seção.

\subsection{Centralidade de interposição}

Originalmente esta medida é conhecida como betweenness centrality, entretanto devido à falta de uma tradução amplamente utilizada em português, a chamaremos de centralidade de interposição. A ideia desta centralidade foi proposta nos artigos $(55,56)$ e consiste em avaliar a importância de um nó na transmissão de mensagens ou eventos entre os demais, ou, de maneira equivalente, como um ele encontra-se no caminho entre os outros nós da rede se estes quiserem trocar informações. Uma grande vantagem dessa medida, como veremos adiante nesta seção é que, seu conceito pode ser utilizado para avaliar a importância tanto de vértices quanto de ligações da rede complexa.

Imaginemos uma rede onde exista alguma informação sendo transmitida entre seus diversos nós. No caso de uma rede social, podemos imaginar esta informação como sendo uma notícia, uma mensagem ou um rumor sendo espalhado entre os vários indivíduos da rede. No caso de um grafo representando a internet essas informações poderiam ser os pacotes de dados transmitidos entre os computadores e roteadores da rede. Assumiremos que cada mensagem sempre escolha percorrer um dos menores caminhos entre o nó que emite a informação e o nó que a receberá, sendo que a probabilidade de escolha entre eles é igual. A vantagem dos menores caminhos entre dois elementos, é que quando as mensagens os utilizam, elas chegam ao seu destino passando pelo menor número de elementos intermediários possível. Entretanto, existem casos em que é interessante considerar não apenas os menores caminhos, mas sim todos os caminhos existentes entre dois. A Internet é um exemplo desse último caso pois, raramente os pacotes trafegam unicamente pelos menores caminhos. Dessa forma torna-se mais fácil lidar com problemas, como o congestionamento ou sobrecarga de alguns elementos da rede. Na seção 3.5 apresentamos uma medida que realmente tenta simular a transmissão de mensagens, usando todos os caminhos entre dois nós. Para a centralidade de interposição, faremos também a suposição que cada par de nós troca mensagens com a mesma probabilidade por unidade de tempo, portanto, após uma quantidade de tempo razoável para que um volume de mensagens seja transmitido, a quantidade média de informações que passa por um determinado nó ou ligação será proporcional ao número de menores caminhos que eles participam. 


\subsubsection{Centralidade de interposição para nós}

Assim, podemos definir a centralidade de interposição para nós como:

$$
x_{i}=\sum_{s t} \frac{n_{s t}^{i}}{g_{s t}}
$$

onde $n_{s t}^{i}$ é o número de menores caminhos entre os vértices $s$ e $t$ que passa pelo vértice $i$ e $g_{s t}$ é o número total de menores caminhos entre os vértices $s$ e $t$. Existem casos em que uma rede pode possuir mais de uma componente. Uma componente, é um conjunto de nós tal que sempre exista um caminho entre eles. Dessa forma, se não existe nenhum caminho ligando os nós $A$ e $B$ por exemplo, dizemos que eles encontram-se em componentes distintas. Caso a rede seja composta por mais de uma componente a soma considera apenas os nós pertencentes a mesma componente do nó $i$, pois na maioria dos casos, a comparação de centralidade de interposição entre nós de componentes diferentes não tem sentido, visto que não existem caminhos entre nós de componentes distintos.

Na figura 3.2 pode-se notar que existem dois grafos completos (o primeiro formado pelos nós $\{1,2,3,4,5,6\}$ e o segundo formado por $\{8,9,10,11,12,13\})$, que foram conectados pelo nó 7. Esses dois subgrafos podem ser imaginados como comunidades em uma rede real e todas as trocas de mensagens entre dois nós presentes em um dos dois conjuntos distintos necessariamente passam pelos nós 6,7 e 8, logo é de se esperar que estes tenham um valor alto para a centralidade de interposição e, portanto, são essenciais para a rede. Observamos que a remoção de qualquer um dos nós citados e suas ligações faria com que a rede passasse a ter 2 componentes. Outro fato interessante que se destaca é a existência de apenas um caminho ligando os dois conjuntos de nós; assim, caso exista um grande fluxo de informações entre todos os nós da rede é de se esperar que este esteja congestionado.

Os nós que possuem um alto valor para a centralidade de interposição são essenciais pois, além de terem acesso a grande quantidade de informação transmitida também fazem a comunicação entre elementos da rede em comunidades distintas. Se por algum motivo eles forem removidos ou danificados a troca de informações na rede será prejudicada, uma vez que a remoção de nós com alto valor de interposição implica no aumento da distância média entre os nós da rede complexa. 


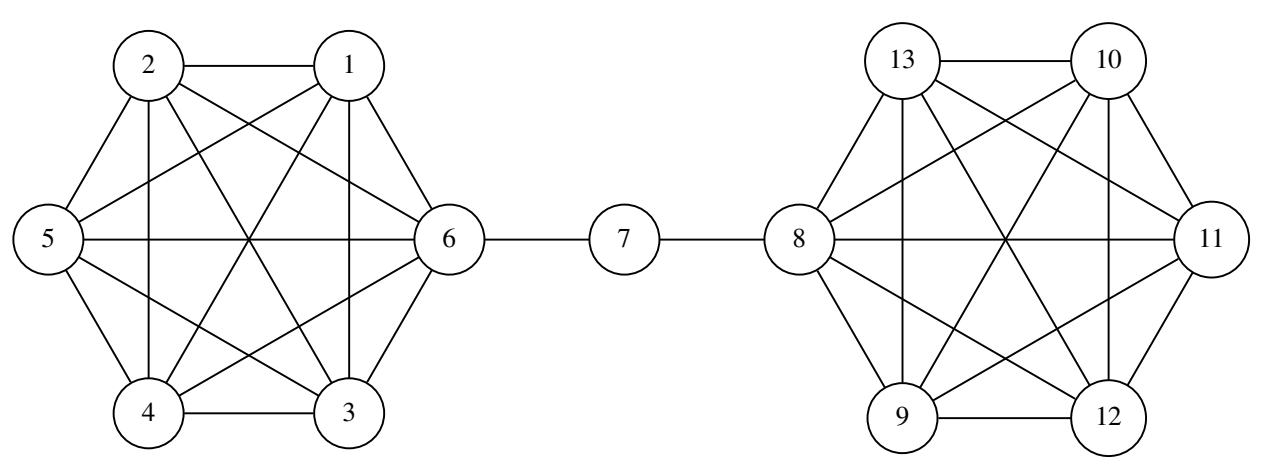

Figura 3.2 - Nesta figura pode-se notar que o nó 7 tem papel fundamental para a transmissão de informação entre nós distintos em uma das duas comunidades presentes (representadas pelos dois grafos completos), a centralidade de interposição tem um papel importante evidenciando este tipo de nó. Fonte: Elaborada pelo autor.

\subsubsection{Centralidade de interposição para ligações}

Da mesma maneira que podemos definir a centralidade de interposição para nós, seu conceito pode ser estendido para as ligações da rede complexa. A ideia desta medida, que também é conhecida por edge betweenness centrality, é conseguir distinguir quais ligações são mais importantes para a rede complexa, utilizando-se as mesmas ideias apresentadas no início desta seção para a centralidade de interposição. Sua expressão matemática é bastante similar àquela da centralidade de interposição para nós:

$$
x_{e}=\sum_{s t} \frac{n_{s t}^{e}}{g_{s t}}
$$

onde, as únicas diferenças para a equação (3.3.1), é o $n_{s t}^{e}$ que representa o número de menores caminhos entre os vértices $s$ e $t$ que passam pela ligação $e$, e $x_{e}$ é o valor da centralidade de interposição para a ligação $e$.

Na figura 3.3, pode-se notar novamente dois grafos completos que, em uma rede real, poderiam ser comunidades. Ambos os grafos foram conectados por apenas uma ligação que liga os nós 6 e 7. É interessante ressaltar que em uma situação de tráfego pesado de mensagens entre todos os nós da rede, esta ligação provavelmente estaria congestionada. 


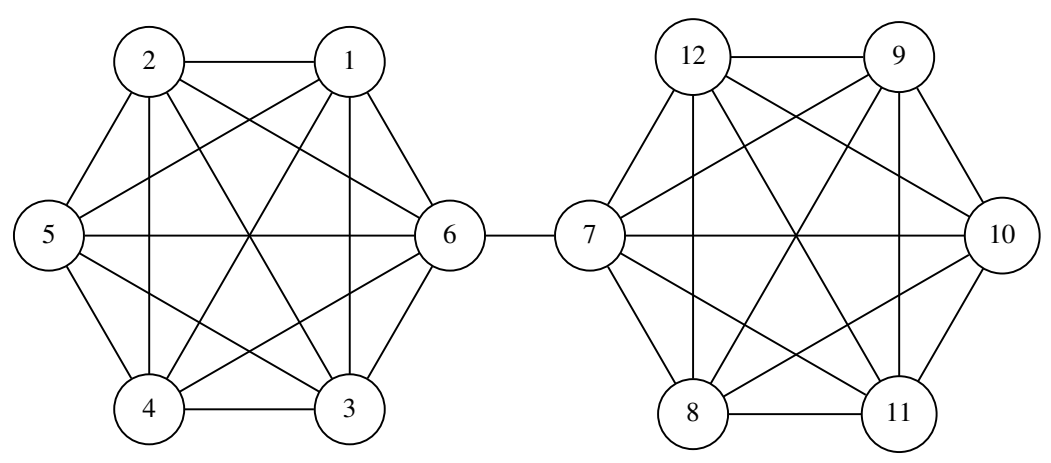

Figura 3.3 - A figura apresenta dois grafos completos que foram unidos pela ligação que liga os nós 6 e 7. Esta ligação possui um valor de centralidade de interposição alto, pois é a única que liga os dois conjuntos formados pelos grafos completos, e portanto todas as informações trocadas entre elementos desses dois grafos passam obrigatoriamente por esta ligação. Fonte: Elaborada pelo autor.

\subsection{Centralidade de proximidade}

Esta centralidade também conhecida como closeness centrality e definição que utilizaremos é a mesma que foi proposta no artigo (57). O objetivo desta medida é avaliar o quanto um determinado nó está distante dos demais. Assim, os nós que possuírem uma menor distância média comparados com os demais, receberão um valor alto para a centralidade de proximidade. Além disso, tais nós devem ser considerados importantes em uma rede complexa devido à sua influência, pois as informações presentes neles atingem os demais elementos da rede em um tempo menor do que os outros. Esta centralidade pode ser calculada da seguinte maneira:

$$
C_{i}=\frac{1}{l_{i}}, \text { onde } l_{i}=\frac{1}{n-1} \sum_{j(\neq i)} d_{i j}
$$

sendo que n representa o número total de nós na rede e $d_{i j}$ é o comprimento do menor caminho entre os nós $i$ e $j, \operatorname{logo} l_{i}$ representa a média do comprimento das menores distâncias entre $i$ e todos os outros nós da rede. É importante ressaltar que $C_{i}$ é definido como o inverso dessa média para que a centralidade de proximidade mantenha o mesmo padrão das demais, onde os nós com valor maior para a centralidade (e por consequência a menor distância geodésica média) sejam os mais centrais. Essa medida também apresenta algumas complicações quando a rede considerada apresenta mais de uma componente, entretanto, neste trabalho consideramos somente redes com uma componente, para detalhes sobre algumas soluções para o caso de várias componentes, conferir a referência (1). 
Outro ponto importante que se destaca sobre esta medida, é que como a distância da rede complexa aumenta logaritmicamente com o tamanho da rede, a diferença no ranking das posições dos nós é muito pequena e as vezes aparece apenas nos últimos dígitos. Portanto, qualquer pequena mudança na topologia da rede pode alterar a ordem do ranking dos vértices, quando se utiliza a medida de proximidade.

\subsection{Centralidade de interposição usando caminhada aleatória}

Já discutido na seção 3.3, um dos problemas da centralidade de interposição é que ela leva em consideração apenas os caminhos geodésicos da rede complexa. Em muitos casos, ressaltado nas referências $(58,59)$, pode ocorrer que os menores caminhos entre os dois nós que querem trocar informações sejam desconhecidos, ou ainda que não seja ideal que estes menores caminhos sejam sempre utilizados evitando assim uma sobrecarga quando os demais caminhos ficam livres. Na internet por exemplo, raramente o menor caminho é utilizado para a navegação devido a inviabilidade e sobrecarga das conexões físicas.

Nesta seção realizaremos a descrição de uma medida de centralidade de interposição que é baseada em caminhadas aleatórias pela rede complexa $(60,61)$. No artigo de Newman, também é demonstrado que esta medida é equivalente a uma medida de centralidade de fluxo de corrente na rede complexa. Devido à este motivo a centralidade de interposição baseada em caminhada aleatória também é conhecida na literatura como Random Walk Betweenness ou Current-Flow Betweenness. A seguir descreveremos como a medida pode ser calculada e a equivalência dos dois formalismos (o de caminhada aleatória e o de fluxo de corrente) como desenvolvido nas referências anteriores.

\subsubsection{O Modelo do Fluxo de corrente}

O modelo aqui desenvolvido leva em consideração que a rede complexa esteja representando uma rede elétrica (62). Imaginemos uma rede complexa onde cada ligação seja substituída por um resistor e, por questão de simplicidade, que todos os resistores sejam iguais e unitários. Essa última suposição não é, de fato, necessária. Em (61) apresenta-se uma dedução semelhante para o caso geral. Além disso estão presentes nessa rede dois nós especiais, os nós 
$s$ e $t(s \neq t)$, sendo que uma unidade de corrente é injetada no nó $s$ e uma unidade é retirada nó no $t$ (na prática é como se tivéssemos ligado os polos negativo e positivo de uma bateria nos nós $s$ e $t$ ). Assim utilizando-se essa configuração, pode-se definir uma medida chamada de centralidade de interposição de fluxo de corrente (ou também current-flow betweenness) como sendo a quantidade média de corrente que flui pelo vértice $i$ sobre todos os possíveis $s$ e $t$ da rede complexa.

Nessa rede elétrica, cada vértice $i$ possuirá um potencial $V_{i}$ relativo a algum ponto conveniente, podemos então utilizar a lei de Kirchhoff da conservação das correntes que diz que o fluxo total das correntes que chegam e que saem de um nó é zero e implica que as voltagens tenham que satisfazer as seguintes equações para todos os nós $i$ :

$$
\sum_{j} A_{i j}\left(V_{i}-V_{j}\right)=\delta_{i s}-\delta_{i t}
$$

onde $A_{i j}$ representa o elemento $i, j$ da matriz de adjacências, e os $\delta_{i j}$ são deltas de Kronecker, definidos como:

$$
\delta_{i j}= \begin{cases}1, & \text { se } i=j \\ 0, & \text { se } i \neq j\end{cases}
$$

Podemos ainda reescrever a expressão (3.5.1) da seguinte maneira:

$$
\begin{array}{r}
\sum_{j} A_{i j}\left(V_{i}-V_{j}\right)= \\
V_{i} \sum_{j} A_{i j}-\sum_{j} A_{i j} V_{j}= \\
k_{i} V_{i}-\sum_{j} A_{i j} V_{j}=\delta_{i s}-\delta_{i t}
\end{array}
$$

sendo que na equação (3.5.2) utilizamos o fato de que $\sum_{j} A_{i j}=k_{i}$, onde $k_{i}$ é o grau do nó $i$. Definindo-se ainda a matriz diagonal $\mathbf{D}$ onde:

$$
D_{i j}= \begin{cases}k_{i}, & \text { se } i=j \\ 0, & \text { se } i \neq j\end{cases}
$$

e utilizando-se essa definição e ainda definindo o vetor $\mathbf{V}$ que contem os potenciais $V_{i}$ de todos os nós da rede, assim, podemos reescrever a eq. (3.5.2) na forma matricial:

$$
\begin{array}{r}
k_{i} V_{i}-\sum_{j} A_{i j} V_{j}=\delta_{i s}-\delta_{i t} \\
(\mathbf{D})_{(i)} \mathbf{V}-(\mathbf{A})_{(i)} \mathbf{V}=s_{i} \\
(\mathbf{D}-\mathbf{A}) \mathbf{V}=\mathbf{s}
\end{array}
$$


sendo que $\mathbf{s}$ é o vetor composto pelos elementos $s_{i}$ definidos por:

$$
s_{i}= \begin{cases}+1, & \text { se } i=s \\ -1, & \text { se } i=t \\ 0, & \text { caso contrário. }\end{cases}
$$

A expressão (3.5.4) pode ser reescrita em termos da matriz laplaciana $\mathbf{L}=\mathbf{D}-\mathbf{A}$, ficando:

$$
\mathbf{L V}=\mathbf{s}
$$

Para encontrarmos o valor de $\mathbf{V}$, não podemos calcular a inversa de $\mathbf{L}$ na (3.5.6) pois trata-se de uma matriz singular: o vetor $\mathbf{V}=(1,1,1, \ldots)$, é sempre um autovetor desta matriz com autovalor nulo e como o determinante é o produto dos autovalores, o determinante da matriz L também é nulo (60).

Matematicamente isto nos diz que uma das equações do nosso sistema é redundante, e fisicamente nos indica que a corrente é conservada. Uma maneira simples de contornarmos este problema é escolher uma das equações e removê-la do sistema, ou de maneira prática, se escolhermos um vértice $v$ e medirmos os potenciais em relação à ele. Logo, se fizermos esta escolha, podemos remover da matriz $\mathbf{L}$ a $v$-ésima linha e a $v$-ésima coluna, o que torna a matriz, que agora possui dimensão $(n-1) \times(n-1)$, invertível. Denotaremos esta matriz de $\mathbf{L}_{v}=\left(\mathbf{D}_{v}-\mathbf{A}_{v}\right)$. Assim, da equação (3.5.6) temos:

$$
\mathbf{V}=\mathbf{L}_{v}^{-1} \mathbf{s}
$$

Como estamos medindo a voltagem com relação ao vértice $v, V_{v}$ é nulo. Para representarmos isso, utilizaremos a matriz $\mathbf{T}$ que é definida como sendo a matriz $\mathbf{L}_{v}$ acrescida de uma $v$-ésima linha e uma $v$-ésima coluna, ambas com todos os elementos nulos. Utilizando a equação (3.5.5), e a matriz $\mathbf{T}$ no lugar de $\mathbf{L}$ na equação (3.5.6), a voltagem do vértice $i$ quando a bateria está ligada aos vértices $s$ e $t$ é dada por:

$$
V_{i}^{(s t)}=T_{i s}-T_{i t}
$$

Desta maneira, a corrente fluindo através do $i$-ésimo vértice é dada pela metade da soma 
do valor absoluto das correntes fluindo através das ligações incidentes naquele vértice:

$$
\begin{array}{r}
I_{i}^{(s t)}=\frac{1}{2} \sum_{j} A_{i j}\left|V_{i}^{(s t)}-V_{j}^{(s t)}\right|= \\
\frac{1}{2} \sum_{j} A_{i j}\left|T_{i s}-T_{i t}-T_{j s}+T_{j t}\right|, \text { se } i \neq s, t .
\end{array}
$$

e para o caso dos vértices $s$ e $t$, que possuem valor fluxo de corrente unitário, o valor absoluto das correntes é definido como:

$$
I_{s}^{(s t)}=1, I_{t}^{(s t)}=1
$$

Logo, a centralidade de interposição baseada em fluxo de corrente ou current flow betweenness centrality de um nó $i$ da rede considerada é definida como a média do fluxo de corrente sobre todos os pares $s$ e $t$ da rede complexa:

$$
b_{i}=\frac{\sum_{s<t} I_{i}^{(s t)}}{\left(\frac{1}{2}\right) n(n-1)}
$$

Uma característica interessante desta medida é que ela leva em consideração todos os caminhos existentes entre os nós $s$ e $t$, entretanto, como os caminhos mais curtos possuem menor resistência, estes são privilegiados por esta medida e por isso os nós que encontram-se nesses caminhos possuem um valor maior para esta centralidade. Na seção seguinte demonstraremos que a medida de interposição baseada em caminhadas aleatórias é numericamente igual à centralidade de interposição baseada em fluxo de corrente.

\subsubsection{O modelo da caminhada aleatória}

No modelo da caminhada aleatória, podemos pensar em uma mensagem originada no nó $s$, que tem como destino o nó $t$. Esta mensagem e os nós por onde passará não possuem nenhuma informação sobre como chegar a $t$, logo, a cada passo no tempo, a mensagem é transmitida do nó atual para um dos seus primeiros vizinhos, até que encontre o nó $t$. Como a escolha do próximo nó para o qual a mensagem irá no instante de tempo seguinte é eventual, dependendo unicamente de probabilidades, este modelo representa uma caminhada aleatória da mensagem entre os nós da rede.

Definimos assim, a centralidade de interposição baseada em caminhada aleatória, como sendo o número líquido médio de vezes que a mensagem passa pelo nó $i$ em sua jornada até $t$. Nesse caso, líquido significa que se a caminhada passar de um vértice $a$ para o vértice $b \mathrm{e}$ 
posteriormente passar de $b$ para $a$, essas duas passagens cancelam-se, evitando que alguns nós recebam valores altos para esta centralidade caso aconteça de a mensagem percorrer um mesmo caminho diversas vezes em sentidos diferentes. Como realizar este cancelamento ficará claro mais adiante nesta seção. Além disso, precisamos realizar um número suficientemente grande de repetições de uma mesma configuração de caminhada para obter o valor da centralidade.

Consideremos então a caminhada de uma partícula que parte do nó $s$ e segue aleatoriamente entre os nós da rede até que ela esteja no nó $t$, onde é absorvida. Se a partícula em um instante de tempo estiver no nó $j$, a probabilidade que no próximo passo ela esteja no nó $i$ é dada por:

$$
M_{i j}=\frac{A_{i j}}{k_{j}}, \text { para } j \neq t
$$

onde $A_{i j}$ é o elemento $(i, j)$ da matriz de adjacência que representa a rede e $k_{j}$ é o grau do nó $j$. Podemos também escrever a equação 3.5 .12 na forma matricial:

$$
\mathrm{M}=\mathrm{AD}^{-1}
$$

onde $\mathbf{M}$ é a matriz de probabilidade de transição entre os nós e $\mathbf{D}^{-1}$ é a inversa da matriz definida na equação 3.5.3.

Como a partícula nunca deixará o nó $t, M_{i t}=0$ para todos os nós $i$ possíveis, portanto, podemos remover a linha referente ao nó $t$ sem afetar a caminhada da mesma entre os demais nós da rede. Podemos, então, reescrever a equação (3.5.13) da matriz de probabilidade de transição da partícula em um instante de tempo, como $\mathbf{M}_{\mathbf{t}}=\mathbf{A}_{\mathbf{t}} \mathbf{D}_{\mathbf{t}}^{-1}$, onde o subscrito $\mathbf{t}$ indica que as linhas referentes ao nó $t$ foram removidas das matrizes.

Se a caminhada começa no nó $s$, a probabilidade de que se esteja no nó $j$ depois de $r$ passos será dada por:

$$
\left[\mathbf{M}_{\mathbf{t}}^{\mathbf{r}}\right]_{j s}
$$

e a probabilidade de que após esses $r$ passos a partícula passe para um nó $i$ adjacente à $j$ será dada por $k_{j}^{-1}\left[\mathbf{M}_{\mathbf{t}}^{\mathbf{r}}\right]_{j s}$. Assim, a soma do número médio total de vezes que a partícula pode ir do nó $j$ para o nó $i$, sobre todas as caminhadas possíveis é dada por:

$$
\sum_{r=0}^{\infty} k_{j}^{-1}\left[\mathbf{M}_{\mathbf{t}}^{\mathbf{r}}\right]_{j s}=k_{j}^{-1} \sum_{r=0}^{\infty}\left[\mathbf{M}_{\mathbf{t}}^{\mathbf{r}}\right]_{j s}
$$

utilizando a série de Neumann, que diz que $\sum_{k=0}^{\infty} \mathbf{T}^{\mathbf{k}}=(\mathbf{I}-\mathbf{T})^{-1}$ na equação (3.5.15) obtemos:

$$
k_{j}^{-1} \sum_{r=0}^{\infty}\left[\mathbf{M}_{\mathbf{t}}^{\mathbf{r}}\right]_{j s}=k_{j}^{-1}\left[\left(\mathbf{I}-\mathbf{M}_{\mathbf{t}}\right)\right]_{j s}
$$


que em notação matricial pode ser escrita como um elemento do vetor:

$$
\mathbf{V}=\mathbf{D}_{\mathbf{t}}^{-\mathbf{1}}\left(\mathbf{I}-\mathbf{M}_{\mathbf{t}}\right)^{-1} \mathbf{s}=\left(\mathbf{D}_{\mathbf{t}}-\mathbf{A}_{\mathbf{t}}\right)^{-1} \mathbf{s}
$$

onde s é definido da mesma maneira que na equação (3.5.5). Comparando a equação (3.5.17) com a (3.5.7), notamos que trata-se a mesma equação para o caso em que $v=t$. Novamente o fluxo líquido da caminhada aleatória pela ligação que conecta o nó $j$ ao nó $i$ é dado por $\left|V_{i}-V_{j}\right|$ e o fluxo líquido da caminhada que passa pelo nó $i$ é igual à metade da soma dos fluxos das ligações que incidem em $i$. O valor da centralidade de interposição baseada em fluxo de corrente atribuído aos nós da rede, segue a mesma dedução realizada a partir da equação (3.5.9), chegando na expressão da equação (3.5.11), que fornece o valor da centralidade de interposição de caminhada aleatória para cada vértice da rede complexa.

\subsubsection{Centralidade de interposição de caminhada aleatória para ligações}

Como observamos, a centralidade de interposição baseada em caminhada aleatória para os nós da rede, é calculada utilizando-se os valores atribuídos as ligações conectadas a cada nó. Logo, pode-se generalizar facilmente esta medida para as ligações da rede complexa, como sendo a soma de todos os valores de corrente que cada ligação recebe para todos os pares possíveis de $s$ e $t$. Assim, para obtermos o valor da centralidade para a ligação $e$ da rede complexa que liga os nós $i$ e $j$, podemos fazer:

$$
b_{e}=\frac{\sum_{s<t}\left|V_{i}^{(s t)}-V_{j}^{s t}\right|}{(1 / 2) n(n-1)}
$$

onde, de maneira análoga à equação 3.5.9, cada potencial $V_{i}$ pode ser escrito em termos da matriz $\mathbf{T}$ como $V_{i}^{(s t)}=T_{i s}-T_{i t}$.

\subsection{Centralidade de proximidade utilizando o modelo do fluxo de corrente}

A ideia da medida de centralidade de proximidade utilizando o modelo do fluxo de corrente, também conhecida por current flow closeness centrality, foi proposta no artigo de Brandes e Fleischer (61). Neste mesmo artigo, os autores demonstram que esta medida é equivalente 
a chamada information centrality, que é pouco difundida por tratar-se de uma medida que não é muito intuitiva (58). Segundo os autores, utilizar a ideia de fluxo de corrente torna o entendimento da medida mais evidente.

A ideia desta centralidade é a mesma da de proximidade explicada na seção 3.4 , com a diferença de que ao invés de utilizar-se a menor distância (medida pelo menor caminho) entre um vértice e todos os outros da rede para realizar-se a média, utiliza-se a distância resistiva entre os pares de nós da rede complexa. A distância resistiva entre dois nós $i$ e $j$ da rede complexa é dada em termos da diferença de tensões entre estes nós quando, uma unidade de corrente é injetada na rede pelo nó $i$ e removida da rede pelo nó $j$. Assim, em termos da equação 3.5.8, a distância resistiva entre os nós $i$ e $j$ é dada por $R_{i j}=V_{i}^{(i j)}-V_{j}^{(i j)}$. Portanto, a centralidade de proximidade utilizando o modelo de fluxo de corrente para um dado nó $i$ é definida como:

$$
C_{i}=\frac{(n-1)}{\sum_{j} R_{i j}}
$$

onde $n$ é o número total de nós da rede e $R_{i j}$ é a distância resistiva.

\subsection{Centralidade de subgrafo}

Esta medida, também conhecida por subgraph centrality ou communicability centrality, foi proposta no artigo de Estrada (63). Sua ideia utiliza a participação dos nós da rede complexa em subgrafos para diferenciar os nós importantes dos demais. A medida dá um peso maior para os subgrafos menores e utiliza caminhadas fechadas de um dado tamanho para determinar a participação destes nós em subgrafos com este mesmo tamanho. Caminhadas são travessias feitas passando-se de um nó para outro da rede através da ligações; caminhadas fechadas são aquelas que o primeiro e último nó da caminhada são o mesmo. Uma caminhada de tamanho $k$, é uma caminhada que passa por $k$ arestas da rede. Dessa forma, o número de caminhadas fechadas de tamanho 2 de um nó da rede é equivalente ao grau daquele nó, o número de caminhadas fechadas de tamanho 3 que um nó participa representa o número de triângulos que ele faz parte e assim sucessivamente. A ideia de utilizar a participação em subgrafos da rede, vem do conceito de motifs, que são pequenos subgrafos associados à funções específica desempenhadas pela rede, que ocorrem em redes reais mas não em redes aleatórias geradas com a mesma sequência de grau da rede real (39).

O número de caminhadas fechadas de tamanho $k$, que começam e terminam no vértice $i$ é dado pelos momentos espectrais locais $\mu_{k}(i)=\left(\mathbf{A}^{k}\right)_{i i}(64,65)$, que são os elementos da 
diagonal da matriz $\mathbf{A}^{k}$. Podería-se tentar definir a centralidade de subgrafo de um vértice $i$ como a soma do número de caminhadas fechadas de todos os tamanhos daquele vértice, ou seja, $\sum_{k=0}^{\infty} \mu_{k}(i)$. Sabe-se, porém, que os motifs presentes em redes reais são subgrafos com tamanhos relativamente pequenos dessa forma é razoável que as caminhadas fechadas de tamanho menor recebam um peso maior para esta medida. Além disso, a soma anterior diverge, assim para obtermos o valor da participação de um nó em caminhos fechados e ao mesmo tempo dar uma importância maior aos caminhos menores, a sugestão feita no artigo em que a medida é proposta (63) é a de reescalar as contribuições das caminhadas fechadas pelo fatorial de seu tamanho. Dessa forma, a soma anterior pode ser escrita como:

$$
c_{i}=\sum_{k=0}^{\infty} \frac{\mu_{k}(i)}{k !}
$$

onde $c_{i}$, é o valor da centralidade de subgrafo para o nó $i$ e $\mu_{k}(i)$ são os momentos espectrais do grafo. No artigo onde a centralidade é proposta o autor também mostra que a equação (3.7.1) pode ser escrita na forma:

$$
c_{i}=\sum_{j=1}^{N}\left(v_{j}^{i}\right)^{2} e^{\lambda_{j}}
$$

novamente, $c_{i}$ é o valor da centralidade de subgrafo para o nó $i, v_{j}^{i}$ é a componente $i$ do autovetor $v_{j}$ da matriz de adjacências representando a rede estudada e $\lambda_{j}$ é o autovalor associado ao autovetor $v_{j}$.

\subsection{Considerações Finais}

Até aqui, apresentamos a literatura e os conceitos necessários para o entendimento de nosso trabalho. Nos capítulos seguintes descrevemos o trabalho que realizamos, no capítulo 4 apresentamos a metodologia empregada, os sistemas utilizados em nossas análises e discutimos os resultados de nossos estudos; no capítlo 5, encontram-se as discussões finais sobre os resultados mais relevantes e sugestões de trabalhos futuros. 


\section{Metodologia e resultados}

As medidas de centralidade são necessárias para identificar nós e ligações vitais da rede complexa. Como vimos no capítulo 3, existem diversas formas de avaliar esta importância. Isso pode fazer com que os elementos mais centrais da rede sejam evidenciados por mais de uma medida. Dessa forma, neste capítulo estudamos como medidas distintas comportam-se na seleção dos nós e ligações das redes, qual seu impacto nos sistemas considerados e se podemos utilizá-las para caracterizar as redes complexas.

Na seção 4.1 apresentamos as redes utilizadas em nossos experimentos. As comparações sobre a similaridade das classificações fornecidas pelas diferentes medidas estão na seção 4.2, e os resultados sobre como os elementos selecionados por elas influenciam as diferentes redes estão na 4.3. Finalmente, a diferenciação das redes através das centralidades é a apresentada na seção 4.4 .

\subsection{Redes utilizadas}

Neste trabalho, utilizamos dois tipos de redes: reais e baseadas em modelos; todas sem direção e sem peso. Quando elas possuíam mais de uma componente, utilizamos a maior deles para calcular as centralidades, evitando problemas com as definições das medidas. No caso das redes reais, com exceção da Yeast usada apenas nos estudos da seção 4.4.3, sempre utilizamos o mesmo conjunto em todos os nossos estudos.

\subsubsection{Redes baseadas em modelos}

Utilizamos redes baseadas nos modelos de Erdős-Rényi e Barabási-Albert. Para cada um deles consideramos 50 amostras com 1000 nós e grau médio 6 . 


\subsubsection{Redes reais}

Os diversos sistemas que foram modelados como redes reais e utilizados em nossos estudos foram: uma comunidade de golfinhos e suas interações (66), um clube de caratê formado por estudantes de uma universidade (41), colaborações entre cientistas de redes complexas em pesquisas científicas (67), livros de política que foram comprados em conjunto no website Amazon.com (68), o sistema de distribuição de energia da costa oeste dos Estados Unidos (31) e as colaborações entre autores em pesquisas na área de física de altas energias (69-71). Todas as redes mencionadas estão disponíveis para download no website do professor Mark Newman (72). Para o experimento da seção 4.4.3 utilizamos a rede de interação de proteínas da levedura Yeast (73), obtida no banco de dados do software Pajek (74). Devido ao tamanho das redes utilizadas, não foi possível caracterizar sua distribuição de grau, contudo na tabela 4.1 apresentamos algumas medidas sobre as redes utilizadas.

Tabela 4.1 - Tabela com informações estruturais das redes reais utilizadas no trabalho. $\mathrm{N}$ indica 0 número de nós da rede, $\langle k\rangle$ o grau médio, $\langle C\rangle$ representa o coeficiente de clusterização médio e $\langle L\rangle$ indica o comprimento médio do menor caminho entre todos os pares de nós da rede. Redes que possuem o símbolo * ao lado do nome, indicam que os dados são referentes à maior componente da rede.

\begin{tabular}{l|cccc}
\hline Redes & $\mathrm{N}$ & $\langle k\rangle$ & $\langle C\rangle$ & $\langle L\rangle$ \\
\hline Golfinhos & 62 & 5.13 & 0.26 & 3.36 \\
Colaboração em física de altas energias* & 5835 & 4.74 & 0.51 & 7.03 \\
Caratê & 34 & 4.59 & 0.57 & 2.41 \\
Colaboração em redes* & 379 & 4.82 & 0.74 & 6.04 \\
Livros de política & 105 & 8.4 & 0.49 & 3.08 \\
Distribuição de energia & 4941 & 2.67 & 0.80 & 18.99 \\
Yeast & 2361 & 6.08 & 0.13 & 4.2 \\
\hline
\end{tabular}

Fonte: Elaborada pelo autor.

\subsection{Correlações entre as medidas de centralidade}

Para avaliar o comportamento entre pares de centralidades e mensurar o quão distintos são os resultados fornecidos por medidas diferentes, calculamos o coeficiente de correlação de Pearson dos valores atribuídos para os elementos das redes pelas diferentes centralidades. Outros trabalhos sobre correlações já foram desenvolvidos, um dos pioneiros foi desenvolvido por Holme et al. (75),onde os autores analisam as medidas de grau e interposição. Seus 
resultados mostraram que a estrutura da rede muda quando seus nós mais importantes são removidos e que as centralidades consideradas estão correlacionadas. Pesquisas similares também foram feitas por Lee (76) e Valente et al. (77). Os dois últimos artigos, mostraram que as medidas de centralidade estão correlacionadas, entretanto, em ambas as análises os autores consideram apenas as centralidades de grau, proximidade, autovetor e interposição; além disso, não encontramos nenhum estudo com respeito às centralidades de ligação. $\mathrm{O}$ trabalho descrito nessa seção difere dos demais pois incluímos medidas que não estão presentes neles e as centralidades de ligação.

O coeficiente de Pearson assume que a relação entre os elementos analisados é linear. Por esta razão, como observamos um comportamento lei de potência entre as centralidades, utilizamos o logaritmo das medidas no cálculo da correlação, portanto sempre que utilizarmos o termo correlação entre as medidas de centralidade, estaremos nos referindo ao coeficiente de correlação entre o logaritmo dos rankings atribuídos aos nós e arestas da rede pelas medidas de centralidade. Entretanto, alguns cuidados tiveram de ser tomados com os valores dos rankings. Algumas das centralidades podem atribuir o valor nulo para um nó ou ligação. Quando isto acontece, o dado é removido das duas medidas pertencentes ao par de centralidades analisado. Como a fração de nós removidos é pequena se comparada com o tamanho total de elementos da rede, acreditamos que esta remoção não representa um problema. A centralidade de autovetor forneceu valores negativos para os elementos de algumas das redes, nesses casos utilizamos o valor absoluto da centralidade para classificar os nós e ligações da rede. Dessa forma, todos os nós que participaram da análise das correlações possuíam valor de centralidades $c_{i}$, tal que $c_{i}>0$.

\subsubsection{Correlações das centralidades dos nós}

Primeiro estudamos o comportamento das medidas dos nós. Os resultados das correlações entre todos os pares de medidas considerados estão na tabela 4.2. Analisando-os, o primeiro fato que nos chama a atenção é que a maioria dos pares de medidas estão correlacionados (poucos valores apresentaram coeficientes menores que 0.3); implicando que os elementos que recebem um valor elevado de significância por uma medida frequentemente são classificados de maneira semelhante pelas demais. Também observamos que dentre todas as redes reais,

o clube de caratê foi a que apresentou os maiores valores de correlação. Acreditamos que esse fato pode estar relacionado com o número pequeno de nós da rede associado com dois nós que são mais centrais para ela, assim, os nós mais importantes são considerados impor- 
tantes por todas as medidas enquanto que os demais são evidenciados apenas por algumas delas. Mesmo para a rede de distribuição de energia, que apresentou os menores valores de correlação entre os pares de centralidades, uma parte significativa de seus coeficientes indicou correlação (moderada ou elevada) entre os pares de medidas. Ao observarmos as correlações das redes geradas com os modelos, notamos que as do tipo Erdős-Rényi todos os pares de medidas de centralidade apresentaram correlações fortes, exceto os que envolvem a medida de interposição baseada em caminhada aleatória, enquanto que nas redes Barabási-Albert, embora as medidas estejam correlacionadas, seus valores são ligeiramente menores do que as do modelo Erdős-Rényi. Para analisarmos melhor o comportamento dos pares de medidas dos nós, selecionamos e geramos os gráficos dos quatro pares de centralidades com os maiores (seção 4.2.1.1) e menores (seção 4.2.1.2) valores de correlação para cada uma das redes. Na tabela 4.3, apresentamos os valores obtidos para os expoentes das leis de potência para todos os pares de medidas de centralidade de nós considerados; esses valores foram obtidos através do método dos mínimos quadrados do gráfico dilogaritmo de cada um dos pares de medidas. Precisamos ressaltar que apesar de apresentarmos expoentes de todas as medidas na tabela, eles possuem significado apenas quando par de centralidades estão correlacionadas. Por exemplo, para a rede de distribuição de energia o par de medidas proximidade e autovetor apresenta expoente de 2,27 mas esse valor não faz sentido pois o coeficiente de correlação entre elas é de $-0,04$. Podemos observar que os valores dos expoentes de um mesmo par de medida sofrem variações entre as diferentes redes e modelos considerados. 
Tabela 4.2 - Correlação de Pearson para as redes: golfinhos (GF), clube de caratê (CT), colaboração em artigos de física de altas energias (CF), colaboração em redes complexas (CR), livros de política (LP), rede de distribuição de energia (DE), modelo de Erdős-Rényi (ER), e modelo Barabási-Albert (BA). As centralidades Proximidade $F C$ e Interposição $C A$ significam proximidade utilizando o modelo de fluxo de corrente e interposição baseada em caminhada aleatória, respectivamente.

\begin{tabular}{l|cccccccc}
\hline Medidas & GF & CT & CF & CR & LP & DE & ER & BA \\
\hline Grau/Proximidade & 0.75 & 0.80 & 0.54 & 0.26 & 0.61 & 0.22 & 0.92 & 0.67 \\
Grau/Interposição & 0.73 & 0.84 & 0.52 & 0.58 & 0.65 & 0.47 & 0.98 & 0.92 \\
Grau/Autovetor & 0.63 & 0.82 & 0.49 & 0.21 & 0.69 & 0.16 & 0.91 & 0.62 \\
Grau/Subgrafo & 0.94 & 0.91 & 0.79 & 0.79 & 0.83 & 0.89 & 0.97 & 0.62 \\
Grau/Interposição CA & 0.70 & 0.95 & 0.59 & 0.51 & 0.79 & 0.46 & 0.51 & 0.94 \\
Grau/Proximidade FC & 0.96 & 0.95 & 0.77 & 0.59 & 0.95 & 0.35 & 0.98 & 0.97 \\
Proximidade/Interposição & 0.71 & 0.78 & 0.35 & 0.40 & 0.75 & 0.40 & 0.90 & 0.77 \\
Proximidade/Autovetor & 0.83 & 0.92 & 0.91 & 0.58 & 0.45 & -0.04 & 0.99 & 0.98 \\
Proximidade/Subgrafo & 0.72 & 0.89 & 0.71 & 0.34 & 0.47 & 0.16 & 0.96 & 0.97 \\
Proximidade/Interposição CA & 0.55 & 0.82 & 0.48 & 0.14 & 0.84 & 0.50 & 0.43 & 0.54 \\
Proximidade/Proximidade FC & 0.87 & 0.89 & 0.85 & 0.76 & 0.69 & 0.75 & 0.93 & 0.70 \\
Interposição/Autovetor & 0.39 & 0.78 & 0.24 & 0.34 & 0.35 & 0.05 & 0.89 & 0.72 \\
Interposição/Subgrafo & 0.60 & 0.82 & 0.30 & 0.33 & 0.31 & 0.35 & 0.95 & 0.70 \\
Interposição/Interposição CA & 0.93 & 0.90 & 0.69 & 0.71 & 0.93 & 0.55 & 0.98 & 0.91 \\
Interposição/Proximidade FC & 0.71 & 0.85 & 0.29 & 0.39 & 0.62 & 0.34 & 0.96 & 0.93 \\
Autovetor/Subgrafo & 0.70 & 0.97 & 0.71 & 0.46 & 0.82 & 0.32 & 0.95 & 0.96 \\
Autovetor/Interposição CA & 0.61 & 0.74 & 0.40 & 0.15 & 0.45 & 0.10 & 0.44 & 0.49 \\
Autovetor/Proximidade FC & 0.76 & 0.92 & 0.78 & 0.65 & 0.72 & 0.06 & 0.92 & 0.66 \\
Subgrafo/Interposição CA & 0.55 & 0.82 & 0.41 & 0.34 & 0.46 & 0.37 & 0.40 & 0.49 \\
Subgrafo/Proximidade FC & 0.90 & 0.96 & 0.77 & 0.71 & 0.87 & 0.29 & 0.94 & 0.65 \\
Interposição CA/Proximidade FC & 0.76 & 0.91 & 0.57 & 0.39 & 0.77 & 0.70 & 0.58 & 0.93 \\
\hline
\end{tabular}

Fonte: Elaborada pelo autor. 
Tabela 4.3 - Tabela com os expoentes das leis de potência encontradas encontrados entre as medidas de centralidade de nós das redes: golfinhos (GF), clube de caratê (CT), colaboração em artigos de física de altas energias (CF), colaboração em redes complexas (CR), livros de política (LP), rede de distribuição de energia (DE), modelo de Erdős-Rényi (ER), e modelo Barabási-Albert (BA).

\begin{tabular}{l|cccccccc}
\hline Medidas & GF & CT & CF & CR & LP & DE & ER & BA \\
\hline Grau/Proximidade & 0.18 & 0.20 & 0.11 & 0.07 & 0.13 & 0.05 & 0.14 & 0.11 \\
Grau/Interposição & 2.26 & 2.86 & 2.07 & 3.33 & 2.51 & 2.64 & 2.16 & 2.18 \\
Grau/Autovetor & 1.25 & 0.76 & 2.38 & 1.16 & 1.12 & 3.00 & 1.16 & 0.95 \\
Grau/Subgrafo & 1.53 & 1.29 & 2.08 & 1.86 & 2.25 & 0.91 & 1.18 & 1.83 \\
Grau/Interposição CA & 10.59 & 1.64 & 1.97 & 4.26 & 1.05 & 9.60 & 3.87 & 1.19 \\
Grau/Proximidade FC & 0.42 & 0.36 & 0.34 & 0.21 & 0.38 & 0.19 & 0.52 & 0.35 \\
Proximidade/Interposição & 7.22 & 10.38 & 5.62 & 7.00 & 13.67 & 6.99 & 13.04 & 11.21 \\
Proximidade/Autovetor & 6.90 & 3.39 & 22.37 & 13.08 & 3.36 & -2.27 & 8.46 & 9.18 \\
Proximidade/Subgrafo & 4.96 & 5.01 & 9.44 & 3.21 & 5.93 & 0.90 & 7.79 & 17.71 \\
Proximidade/Interposição CA & 30.51 & 5.43 & 6.58 & 4.45 & 5.19 & 0.21 & 22.07 & 4.17 \\
Proximidade/Proximidade FC & 1.63 & 1.37 & 1.90 & 1.07 & 1.29 & 1.07 & 3.33 & 1.54 \\
Interposição/Autovetor & 0.31 & 0.23 & 0.37 & 0.43 & 0.14 & 0.18 & 0.52 & 0.46 \\
Interposição/Subgrafo & 0.40 & 0.39 & 0.26 & 0.16 & 0.22 & 0.09 & 0.55 & 0.87 \\
Interposição/Interposição CA & 0.42 & 0.34 & 0.28 & 0.27 & 0.31 & 0.31 & 0.53 & 0.46 \\
Interposição/Proximidade FC & 0.09 & 0.09 & 0.04 & 0.03 & 0.06 & 0.03 & 0.22 & 0.14 \\
Autovetor/Subgrafo & 0.58 & 1.48 & 0.38 & 0.19 & 1.38 & 0.02 & 0.90 & 1.85 \\
Autovetor/Interposição CA & 3.86 & 1.34 & 0.23 & 0.21 & 0.37 & 0.03 & 2.62 & 0.40 \\
Autovetor/Proximidade FC & 0.17 & 0.38 & 0.07 & 0.04 & 0.18 & 0.00 & 0.38 & 0.15 \\
Subgrafo/Interposição CA & 4.65 & 0.99 & 0.43 & 1.16 & 0.23 & 4.65 & 2.51 & 0.21 \\
Subgrafo/Proximidade FC & 0.24 & 0.26 & 0.13 & 0.11 & 0.13 & 0.16 & 0.41 & 0.08 \\
Interposição CA/Proximidade FC & 0.02 & 0.20 & 0.08 & 0.02 & 0.23 & 0.01 & 0.04 & 0.26 \\
\hline
\end{tabular}

Fonte: Elaborada pelo autor.

\subsubsection{Centralidades de nós mais correlacionadas}

Os gráficos das figuras de 4.1 a 4.8 apresentam o comportamento dos quatro pares de medidas de nós com os maiores valores de correlação para cada uma das redes. Neles, observamos que o comportamento lei de potência entre os pares de medidas melhora com o aumento da importância dos nós, e verificamos que mesmo analisando apenas os pares mais correlacionadas para cada rede, aquelas que são baseadas em modelos apresentam coeficientes maiores que nas demais. Dessas figuras, também observamos que alguns dos pares de centralidades aparecem com frequência nas redes reais ou modelos. Os pares (grau e subgrafo) e (subgrafo e proximidade de fluxo de corrente), por exemplo, encontram-se apenas nos gráficos dos sistemas reais; já o par (proximidade e autovetor), em contrapartida, aparece fortemente 
correlacionado nos modelos e em duas das redes reais. No caso particular da dupla (grau e subgrafo), acreditamos que essa relação entre as duas centralidades deve estar associada ao fato que nós com um número maior de conexões provavelmente participam de um número maior de subgrafos e, geralmente estão ligados entre si. Há alguns pares de medidas que estão entre as maiores correlações em apenas algumas das redes (independendo se elas são reais ou baseadas em modelos). Um exemplo é o da dupla (grau e proximidade de fluxo de corrente), presente em metade das redes reais e em ambos modelos, ou ainda, a dupla (interposição e sua variante baseada em caminhada aleatória) que aparece nos sistemas reais e naqueles gerados pelo modelo de Erdôs-Rényi.
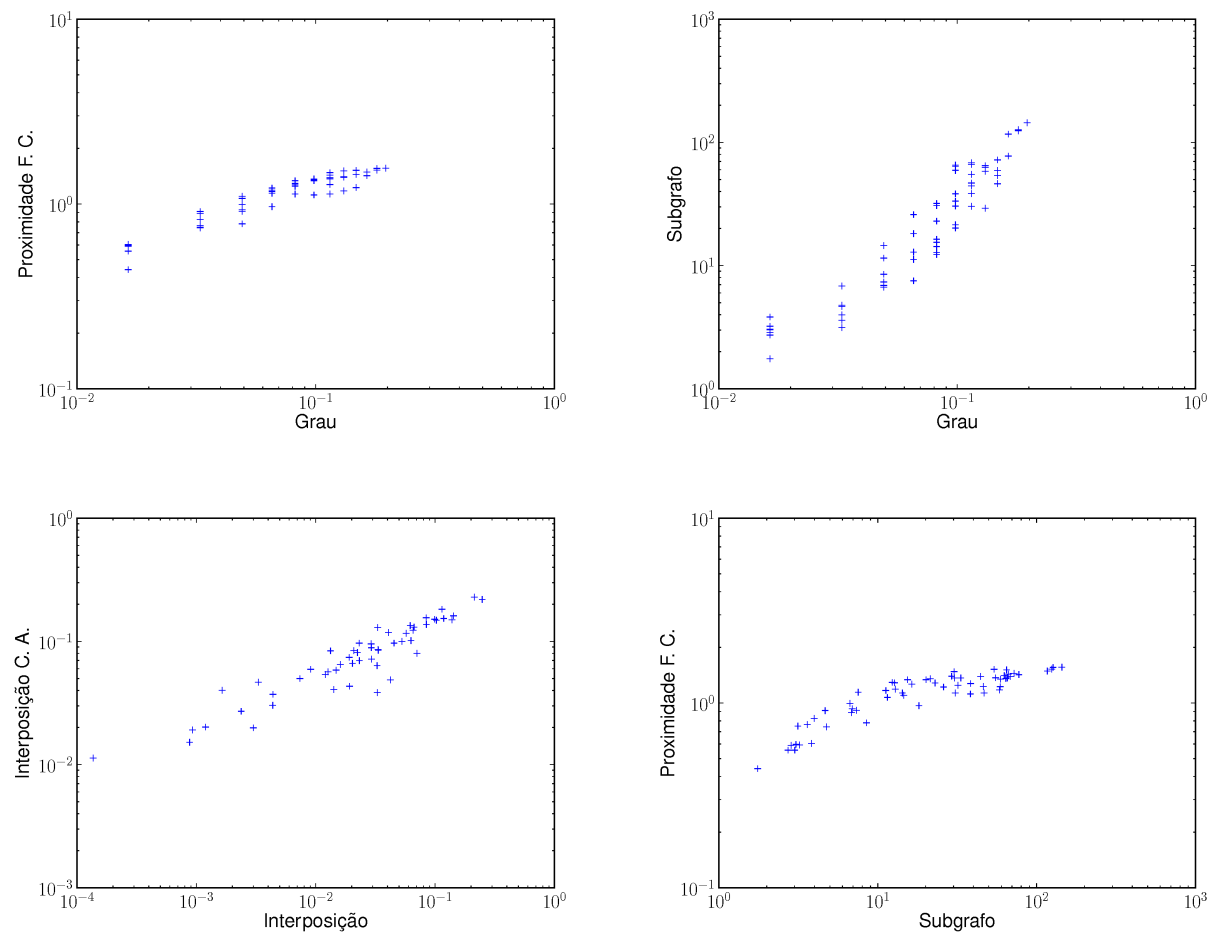

Figura 4.1 - Pares de medidas centralidade com os maiores valores de correlação para a rede dos golfinhos. Fonte: Elaborada pelo autor. 

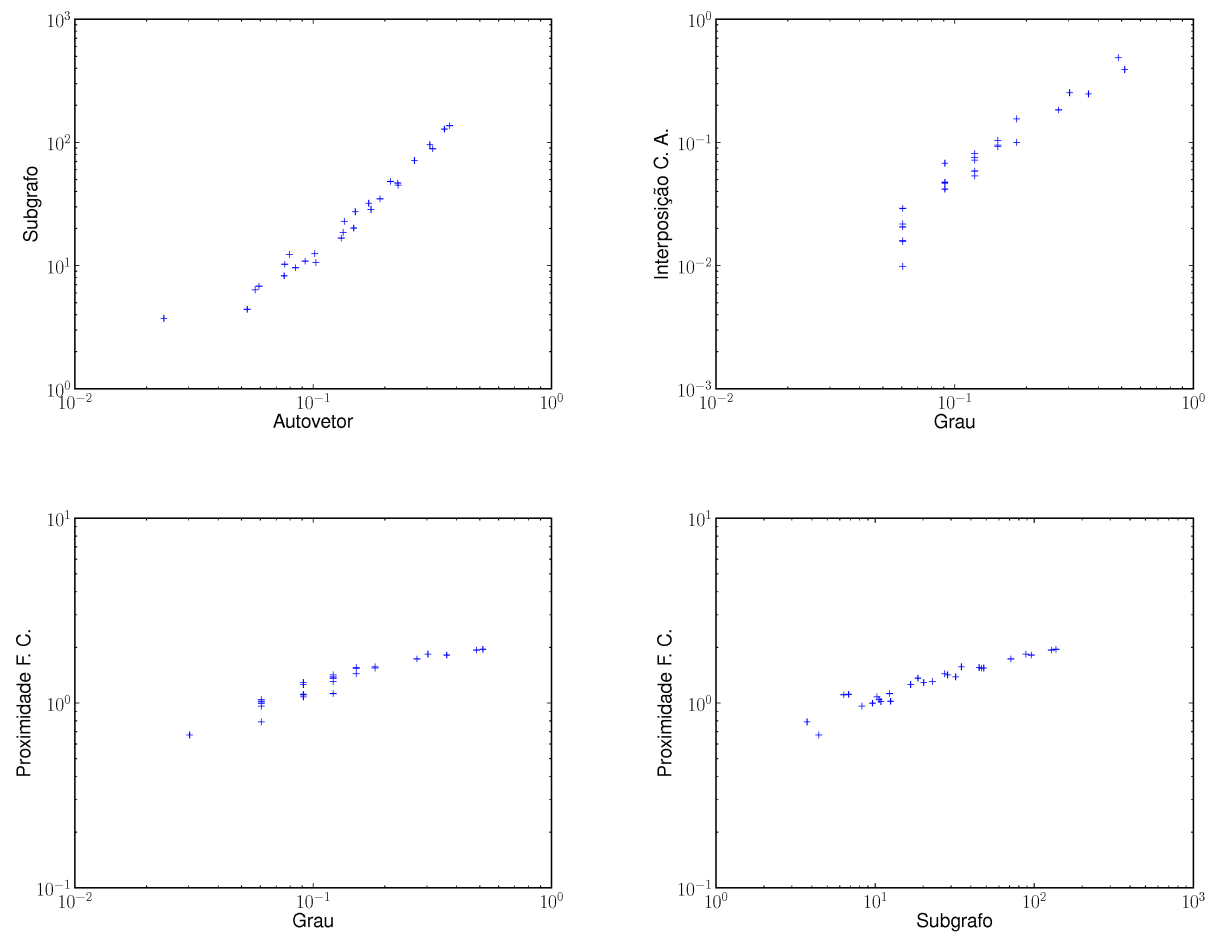

Figura 4.2 - Pares de medidas centralidade com os maiores valores de correlação para a rede dos membros do clube de caratê. Fonte: Elaborada pelo autor.
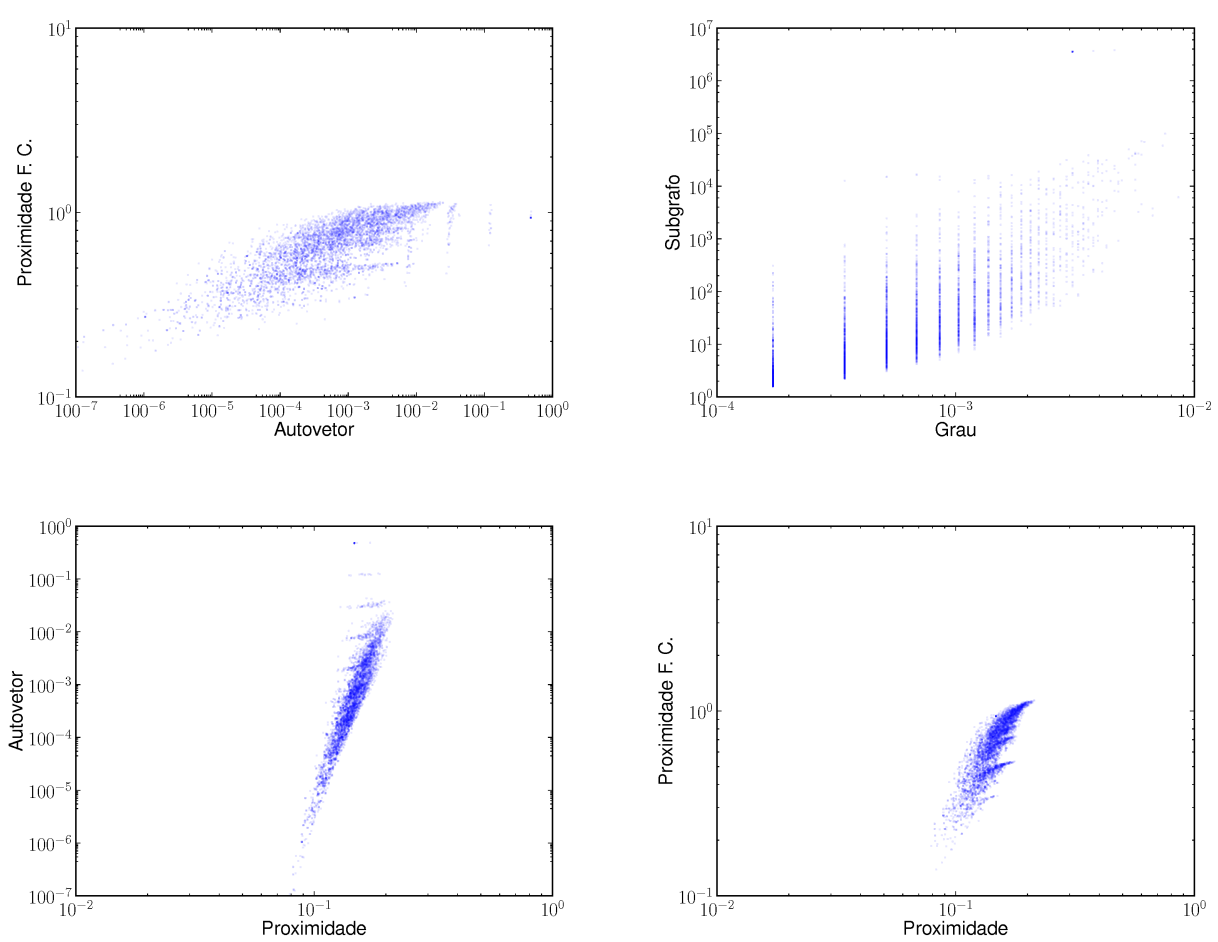

Figura 4.3 - Pares de medidas centralidade com os maiores valores de correlação para a rede colaboração entre autores em artigos de física de altas energias. Fonte: Elaborada pelo autor. 

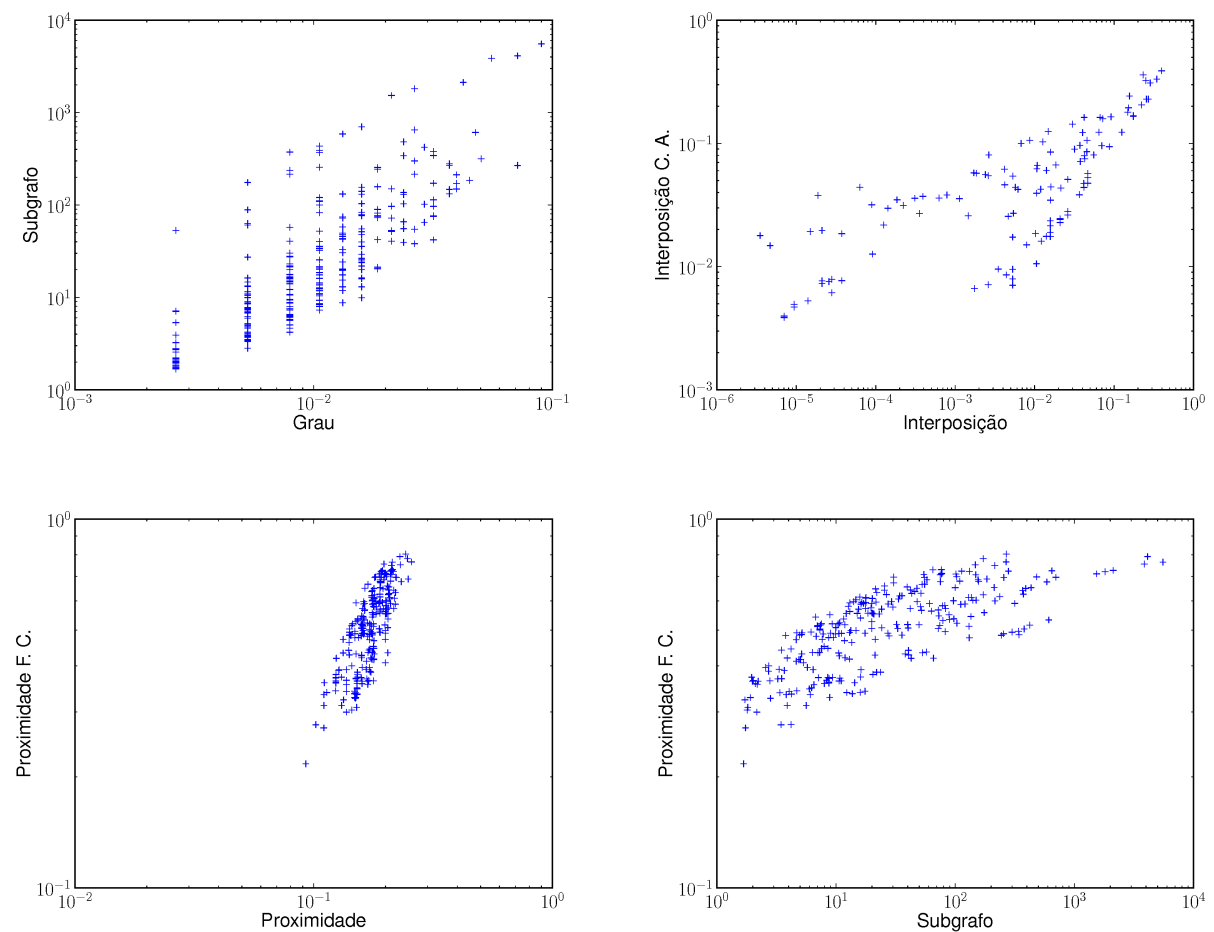

Figura 4.4 - Pares de medidas centralidade com os maiores valores de correlação para a rede colaboração entre autores em artigos de redes complexas. Fonte: Elaborada pelo autor.
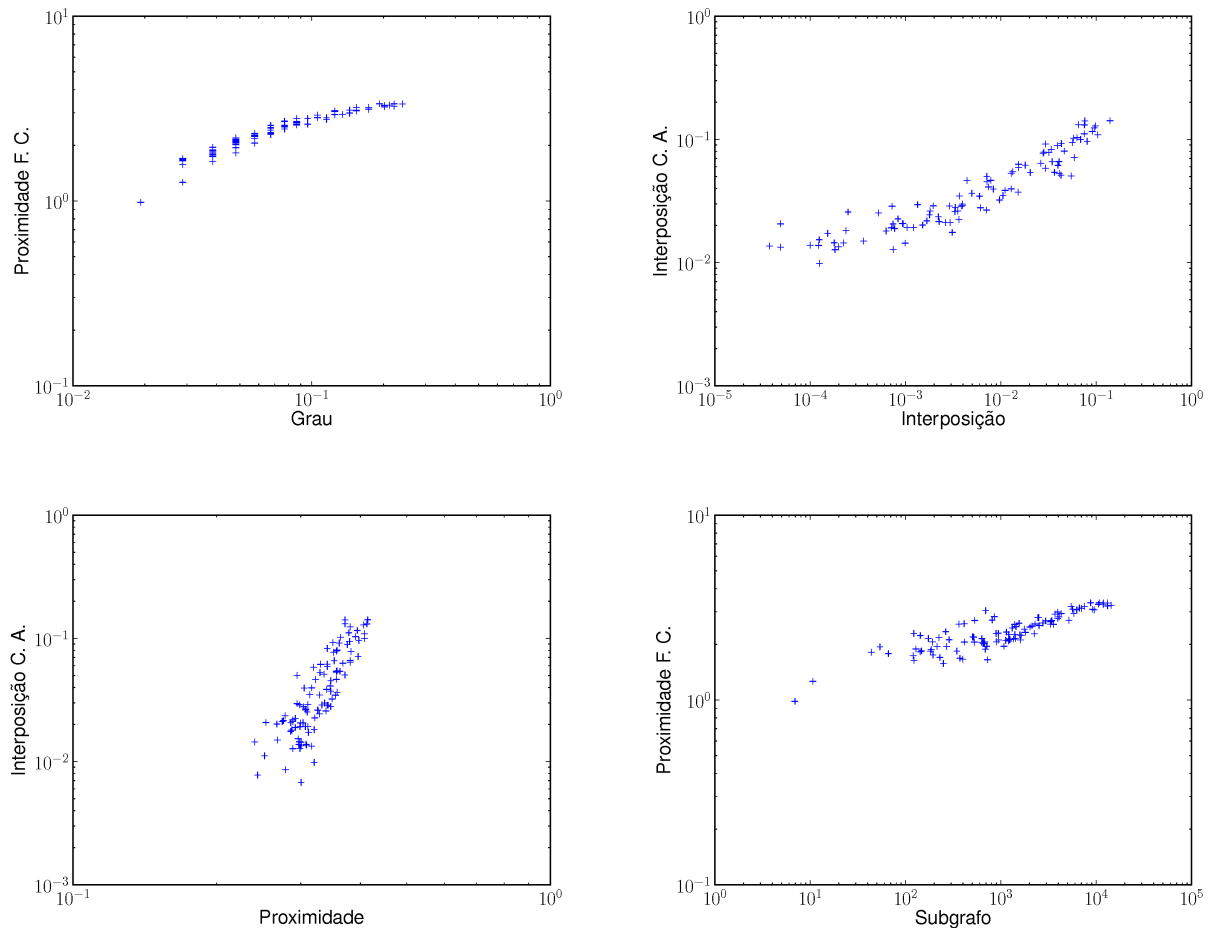

Figura 4.5 - Pares de medidas centralidade com os maiores valores de correlação para a rede de livros de politica. Fonte: Elaborada pelo autor. 

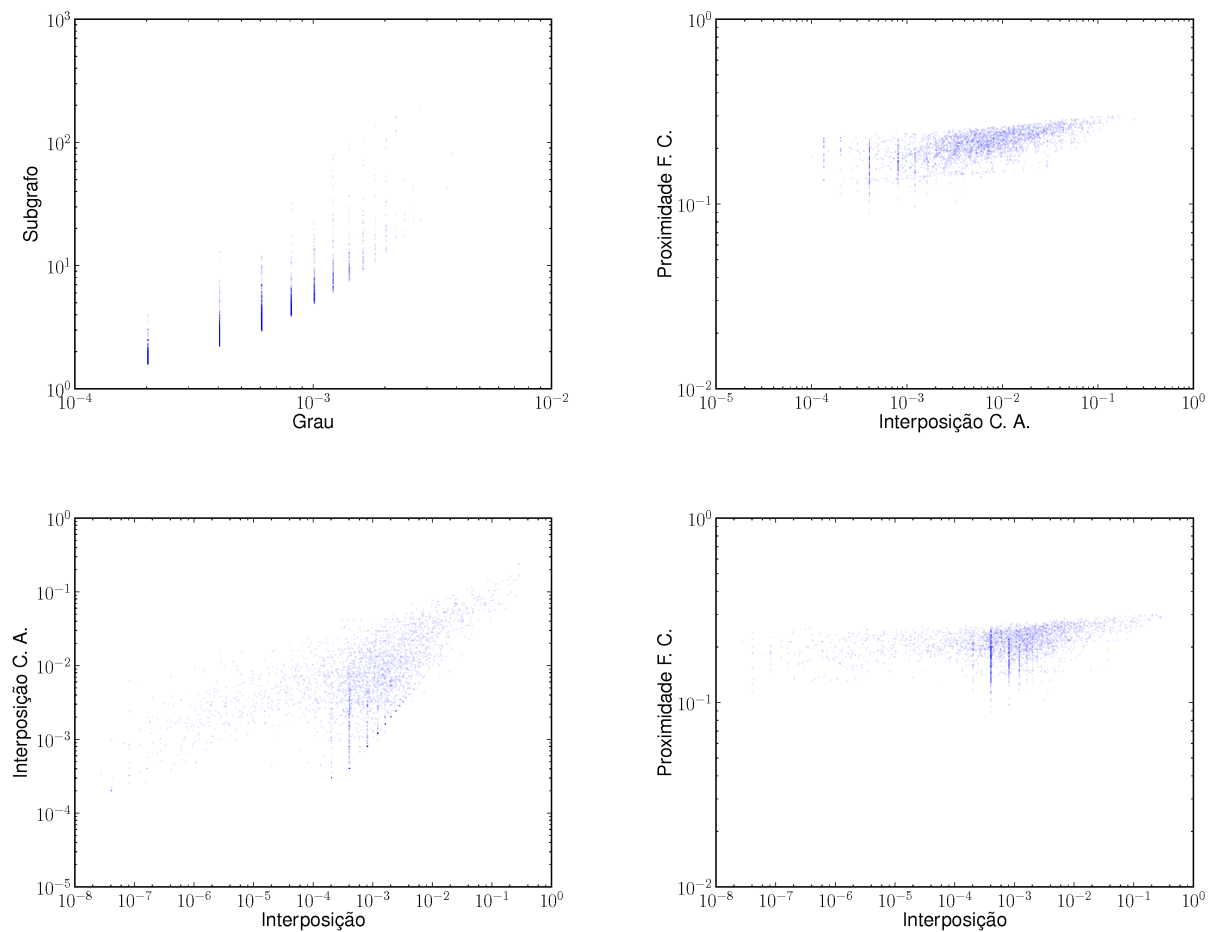

Figura 4.6 - Pares de medidas centralidade com os maiores valores de correlação para a rede de distribuição de energia. Fonte: Elaborada pelo autor.
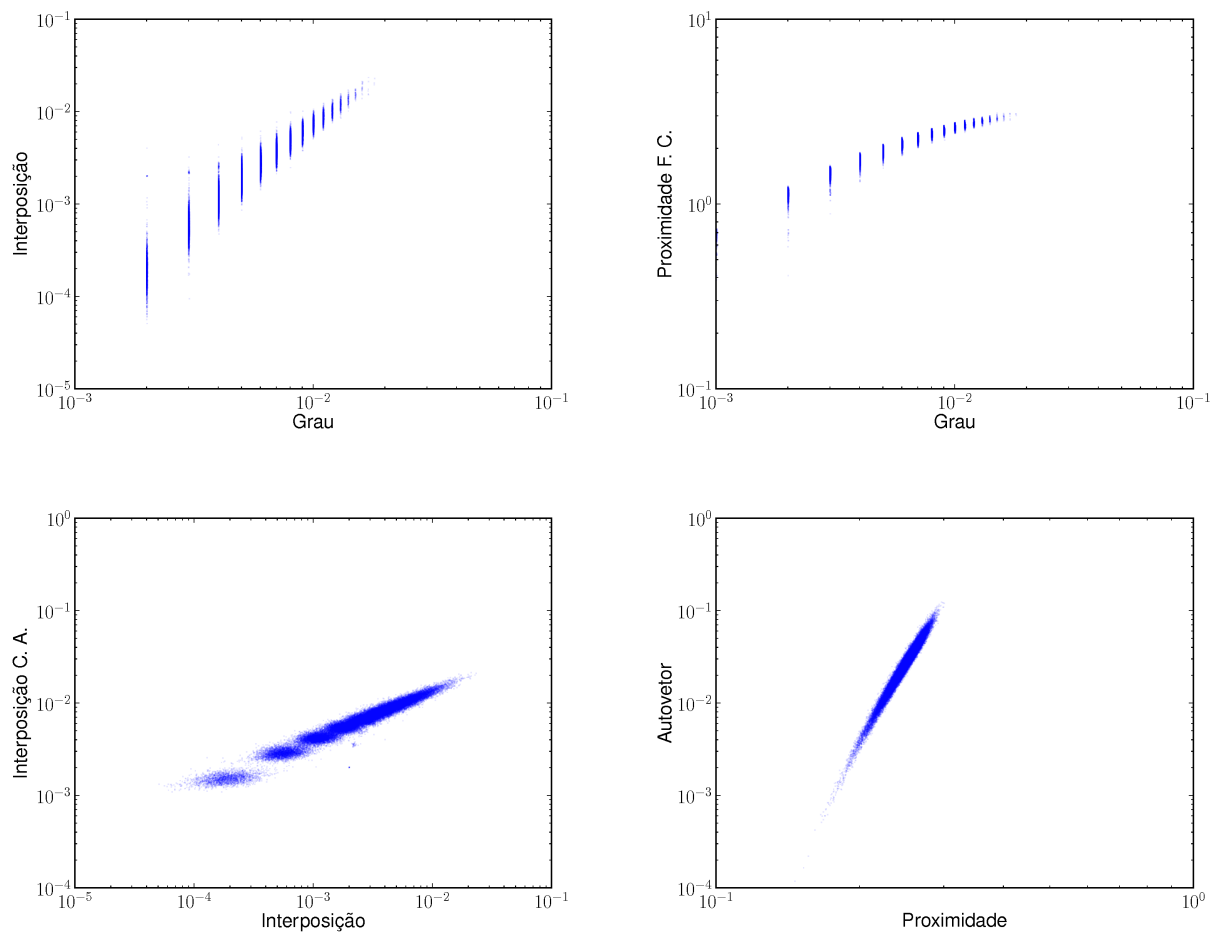

Figura 4.7 - Pares de medidas centralidade com os maiores valores de correlação para as redes geradas utilizando-se o modelo de Erdôs-Rényi. Fonte: Elaborada pelo autor. 

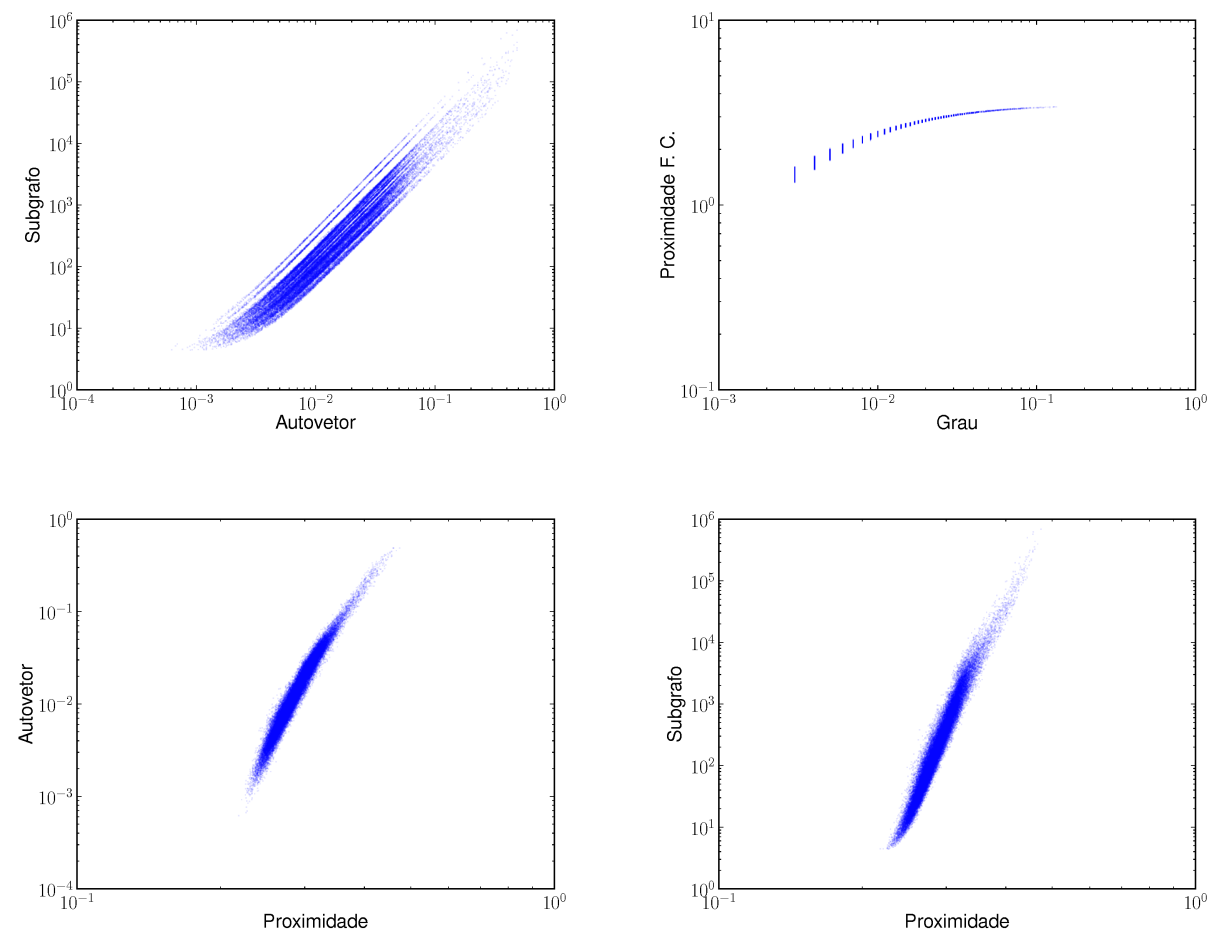

Figura 4.8 - Pares de medidas centralidade com os maiores valores de correlação para as redes geradas utilizando-se o modelo de Barabási-Albert. Fonte: Elaborada pelo autor. 


\subsubsection{Centralidades de nós menos correlacionadas}

Nas figuras de 4.9 a 4.16, apresentamos o comportamento das quatro duplas de centralidades de que possuem os menores valores de correlação para cada uma das redes. Nesse conjunto de gráficos, observamos que existem pares de medidas que estão correlacionadas mesmo estando entre as menores correlações, principalmente para os modelos de rede. Também ressaltamos a existência de duplas medidas que apareceram na maioria das redes, como no caso do par (autovetor e interposição baseada em caminhada aleatória). O par (interposição e autovetor) aparece apenas nos sistemas reais e as duplas (proximidade e interposição baseada em caminhada aleatória) e (subgrafo e interposição baseada em caminhada aleatória) estão presentes nos modelos e em poucas das redes reais.
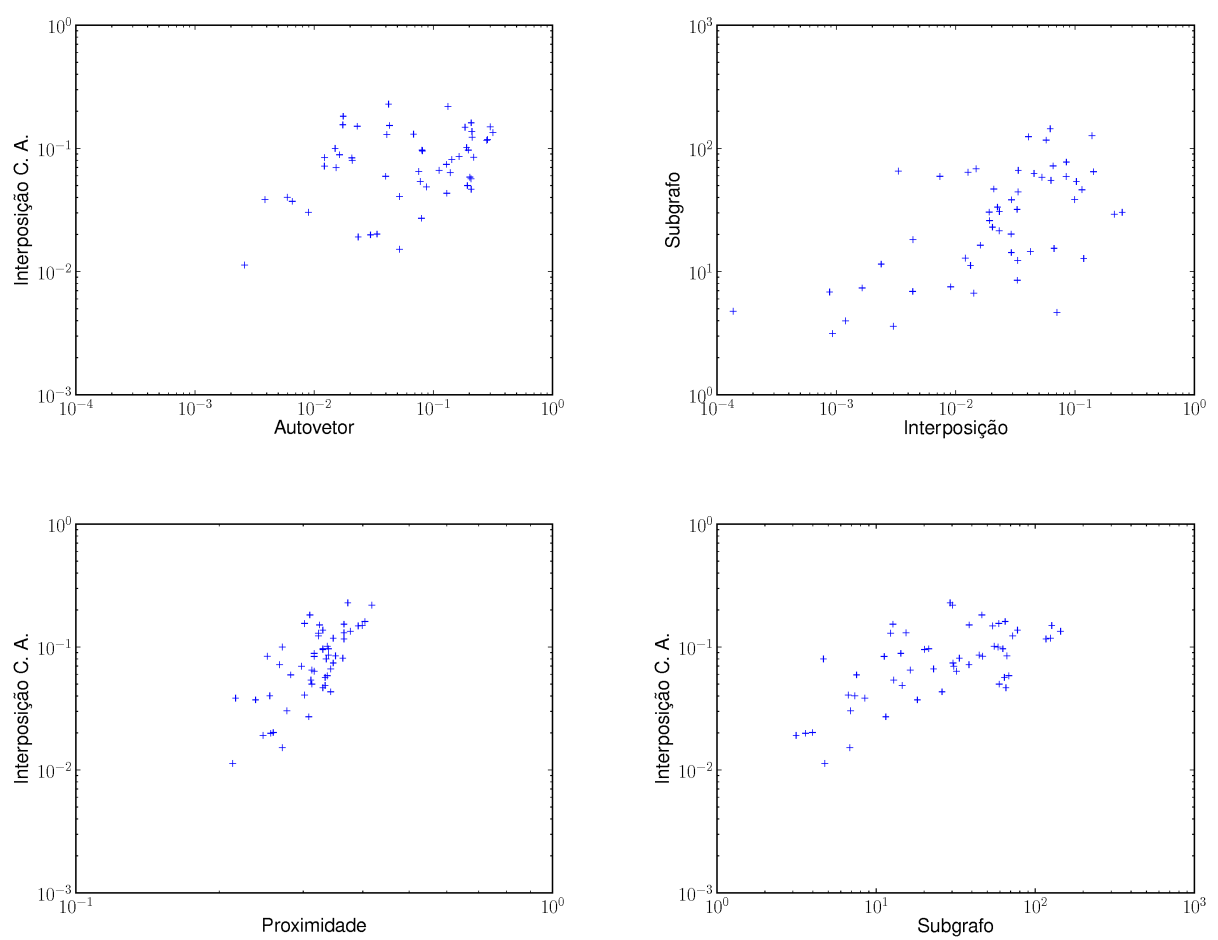

Figura 4.9 - Pares de medidas centralidade com os menores valores de correlação para a rede dos golfinhos. Fonte: Elaborada pelo autor. 

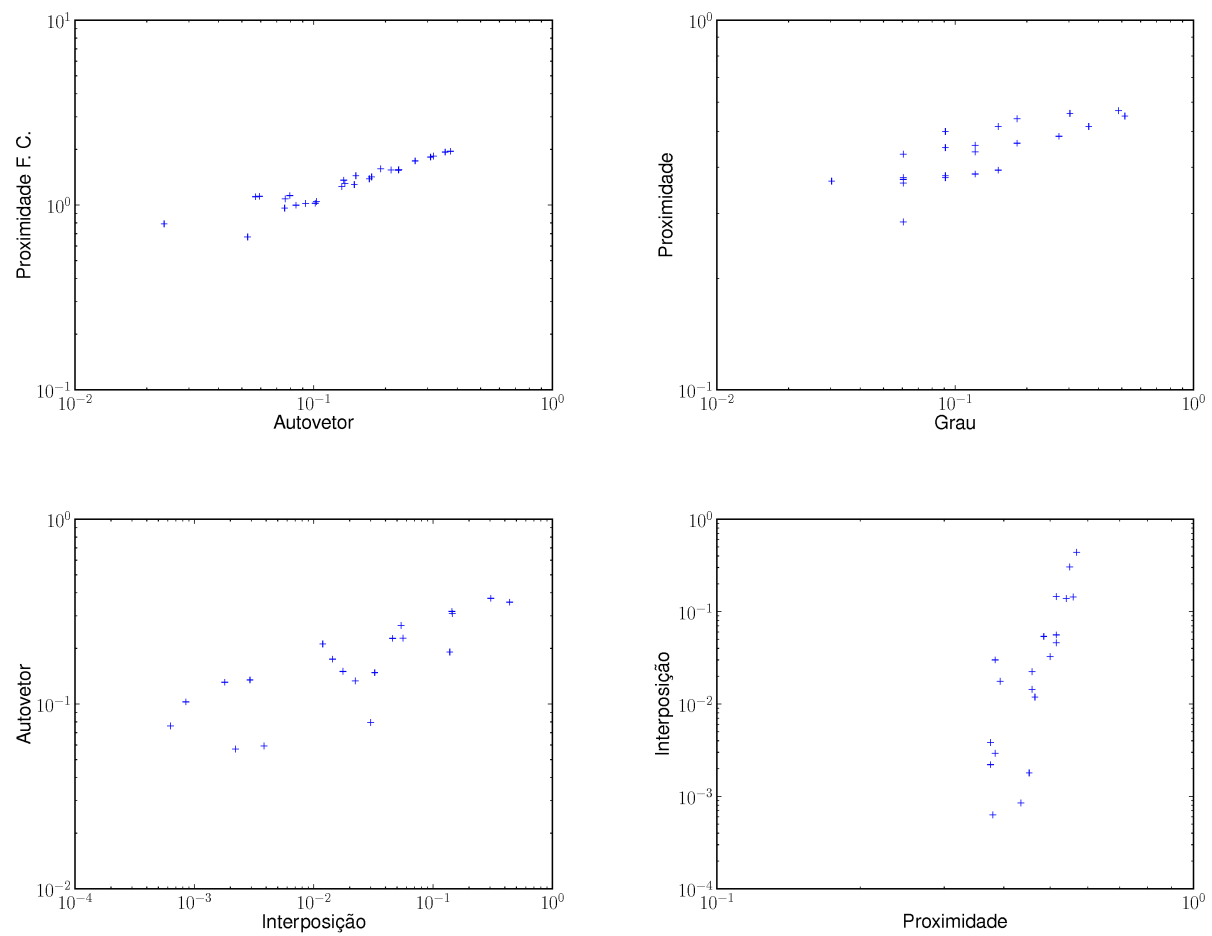

Figura 4.10 - Pares de medidas centralidade com os menores valores de correlação para a rede dos membros do clube de caratê. Fonte: Elaborada pelo autor.
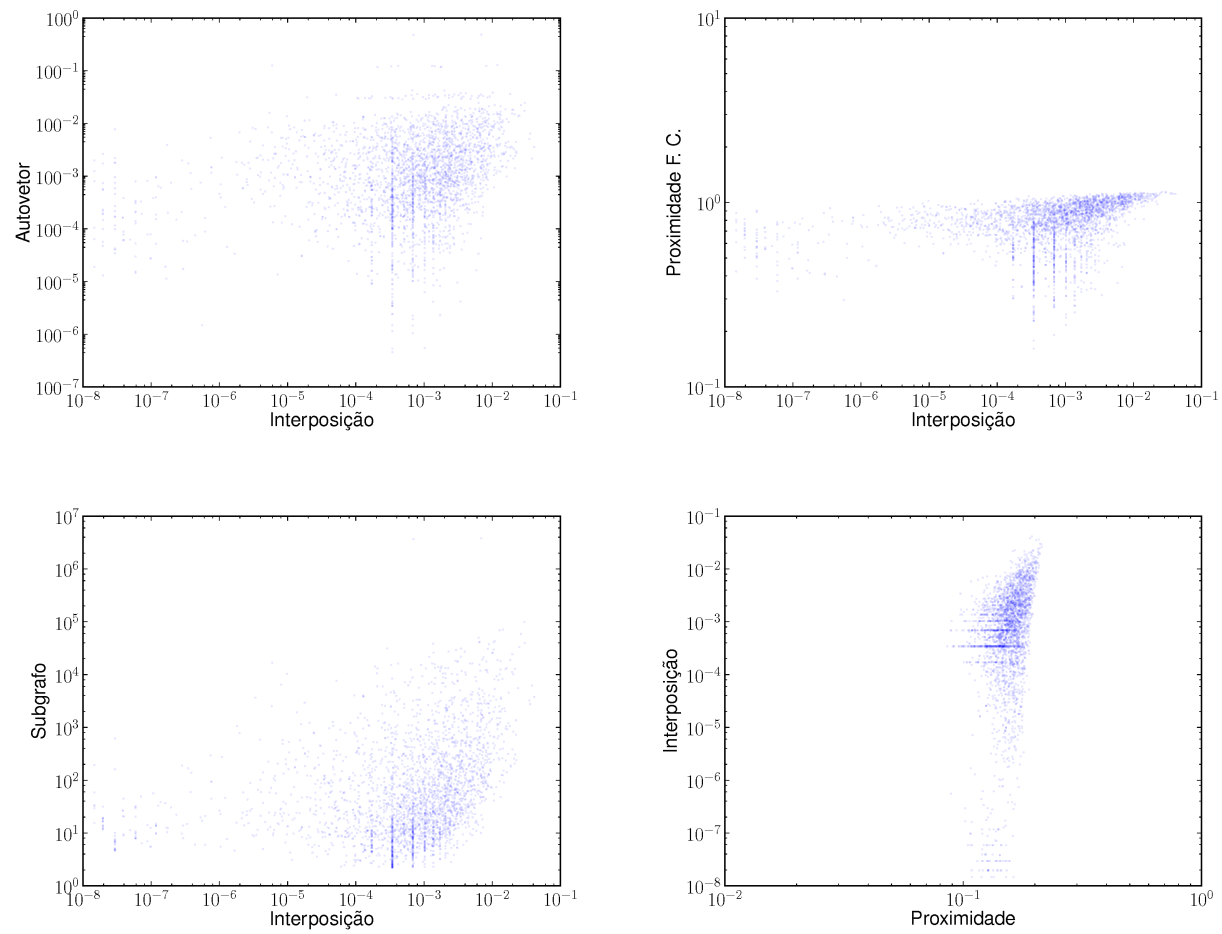

Figura 4.11 - Pares de medidas centralidade com os menores valores de correlação para a rede colaboração entre autores em artigos de física de altas energias. Fonte: Elaborada pelo autor. 

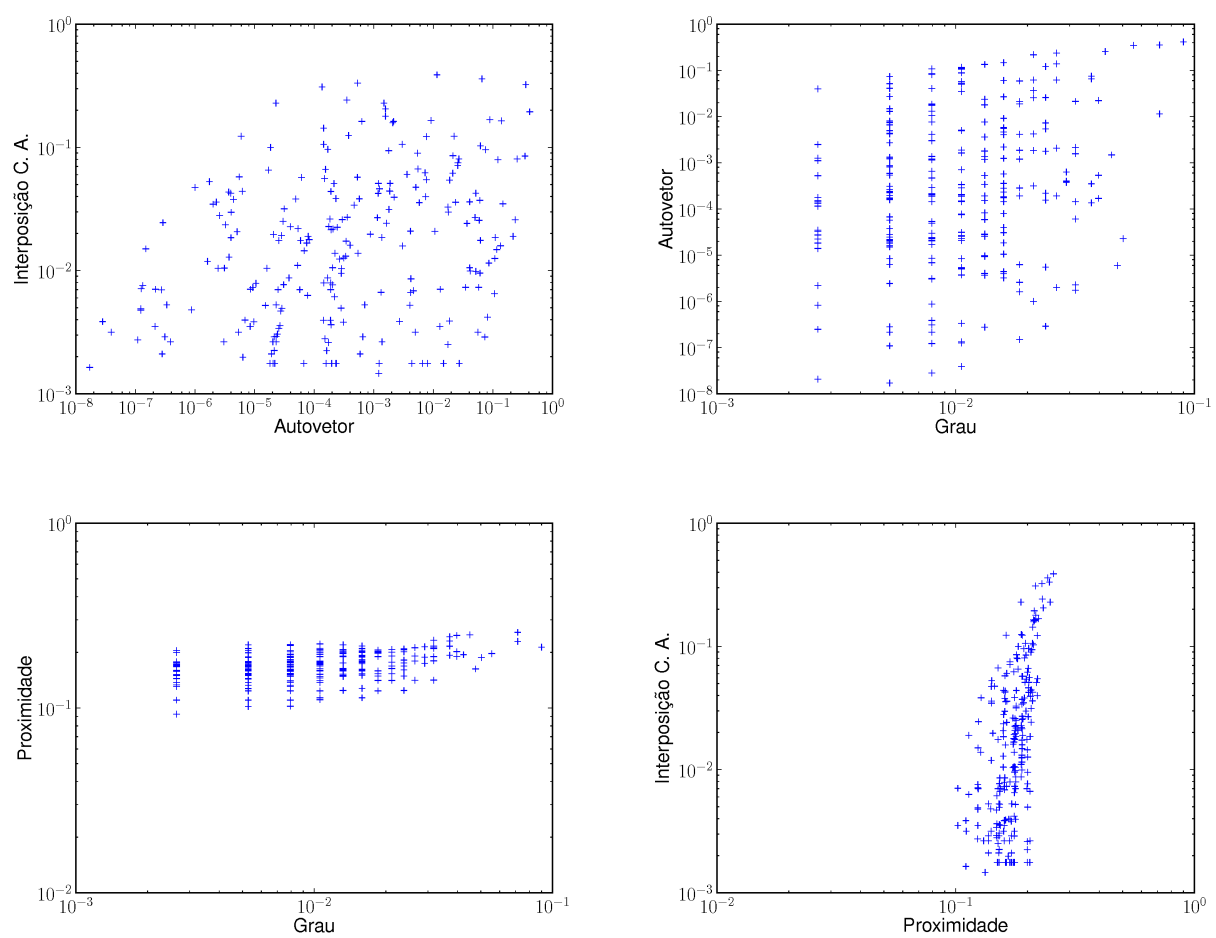

Figura 4.12 - Pares de medidas centralidade com os menores valores de correlação para a rede colaboração entre autores em artigos de redes complexas. Fonte: Elaborada pelo autor.
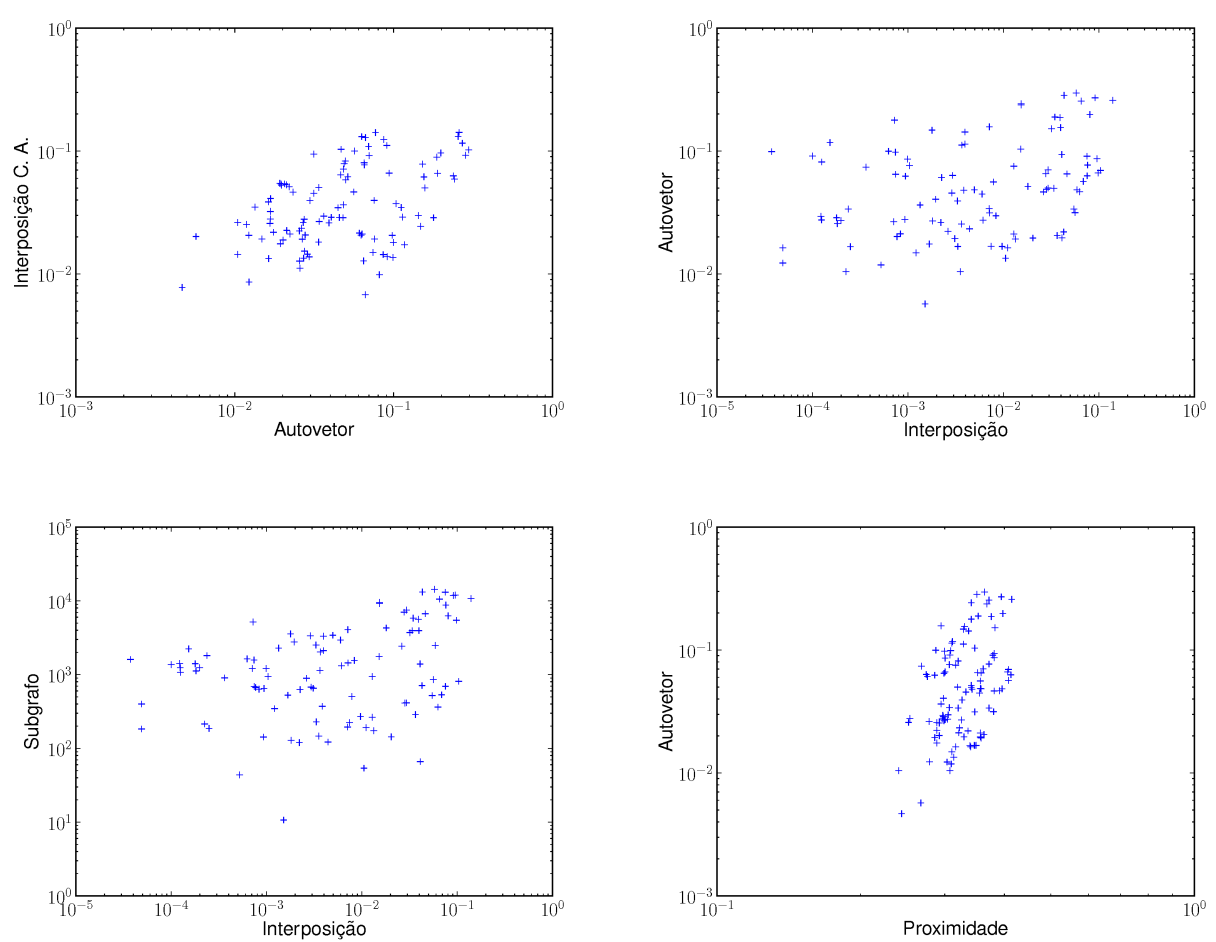

Figura 4.13 - Pares de medidas centralidade com os menores valores de correlação para a rede de livros de politica. Fonte: Elaborada pelo autor. 

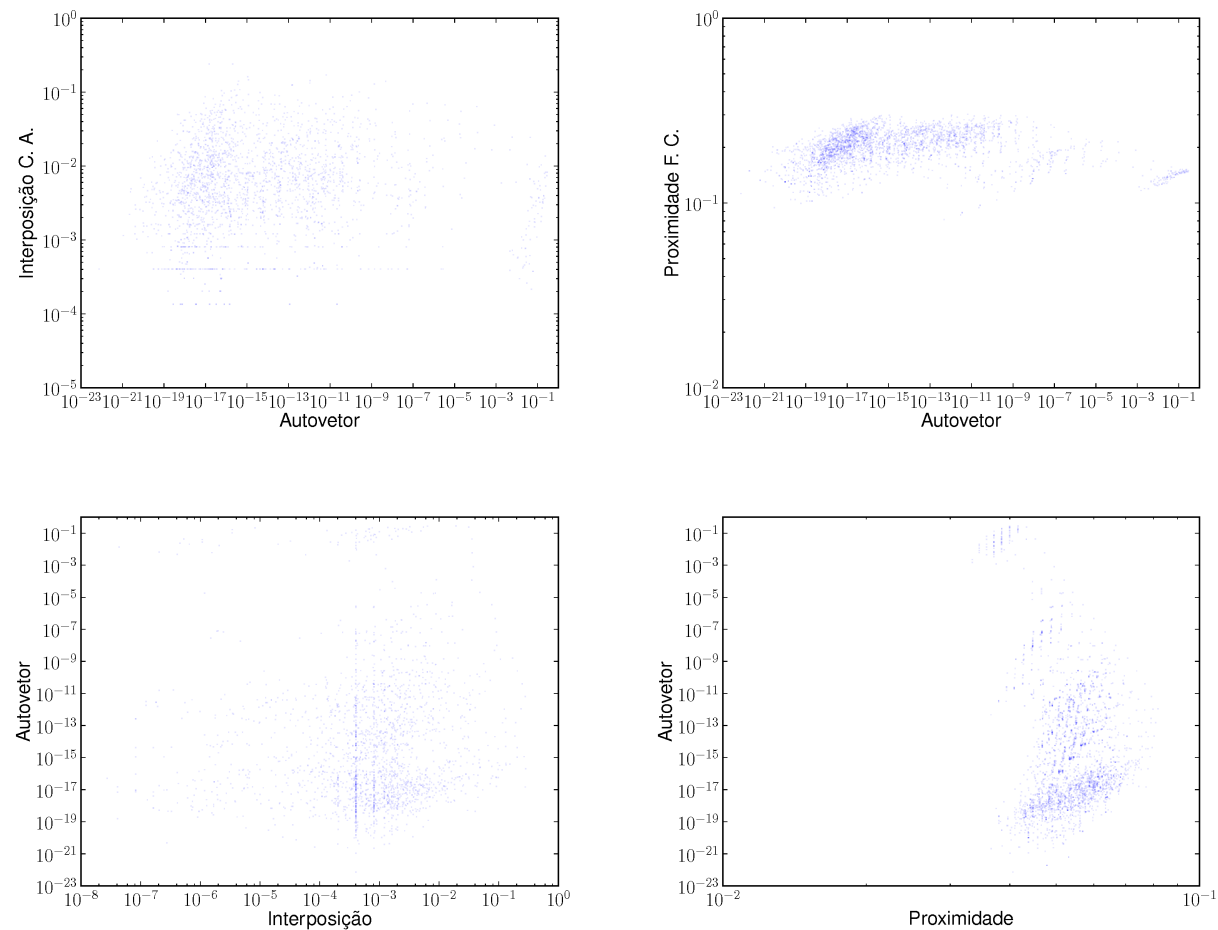

Figura 4.14 - Pares de medidas centralidade com os menores valores de correlação para a rede de distribuição de energia. Fonte: Elaborada pelo autor.
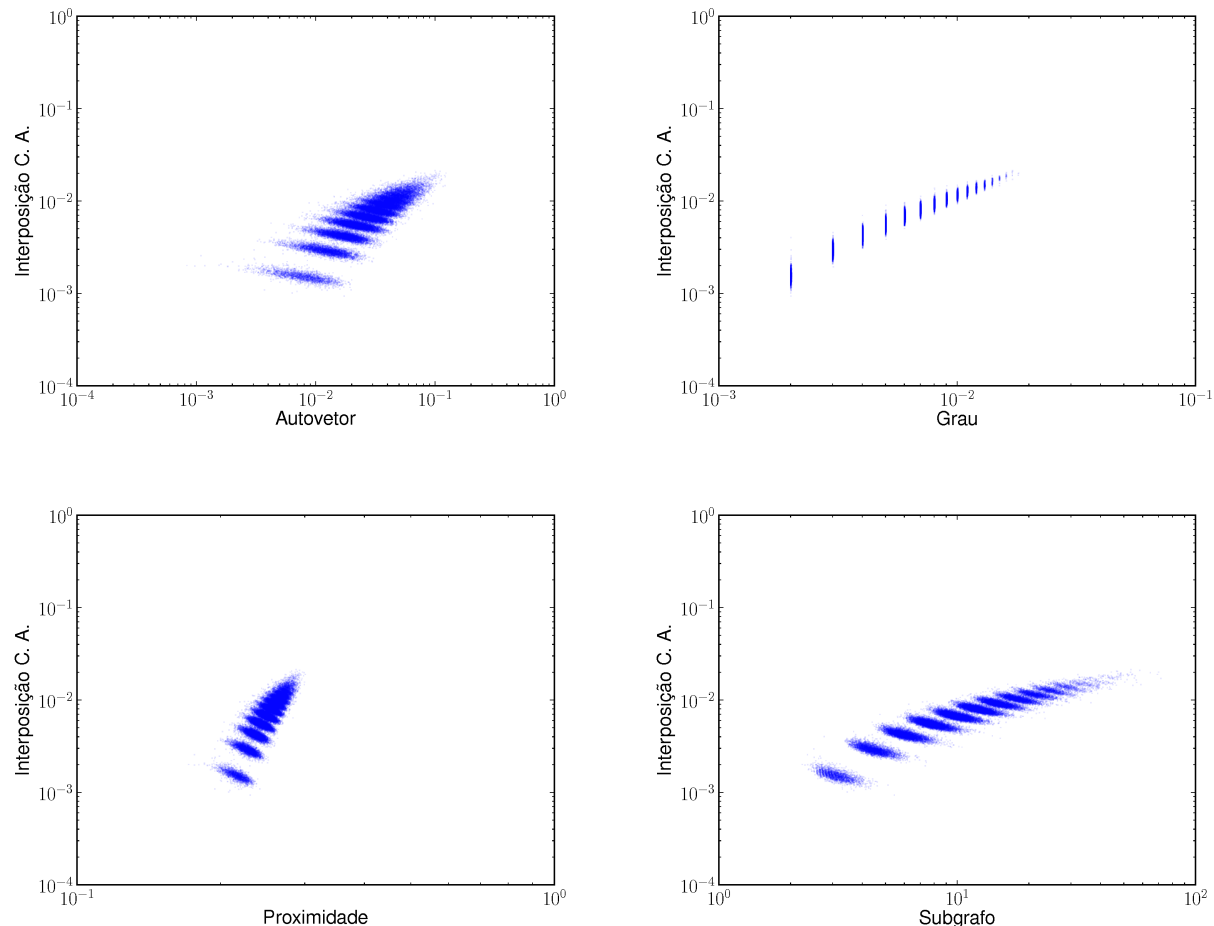

Figura 4.15 - Pares de medidas centralidade com os menores valores de correlação para as redes geradas utilizando-se o modelo de Erdős-Rényi. Fonte: Elaborada pelo autor. 

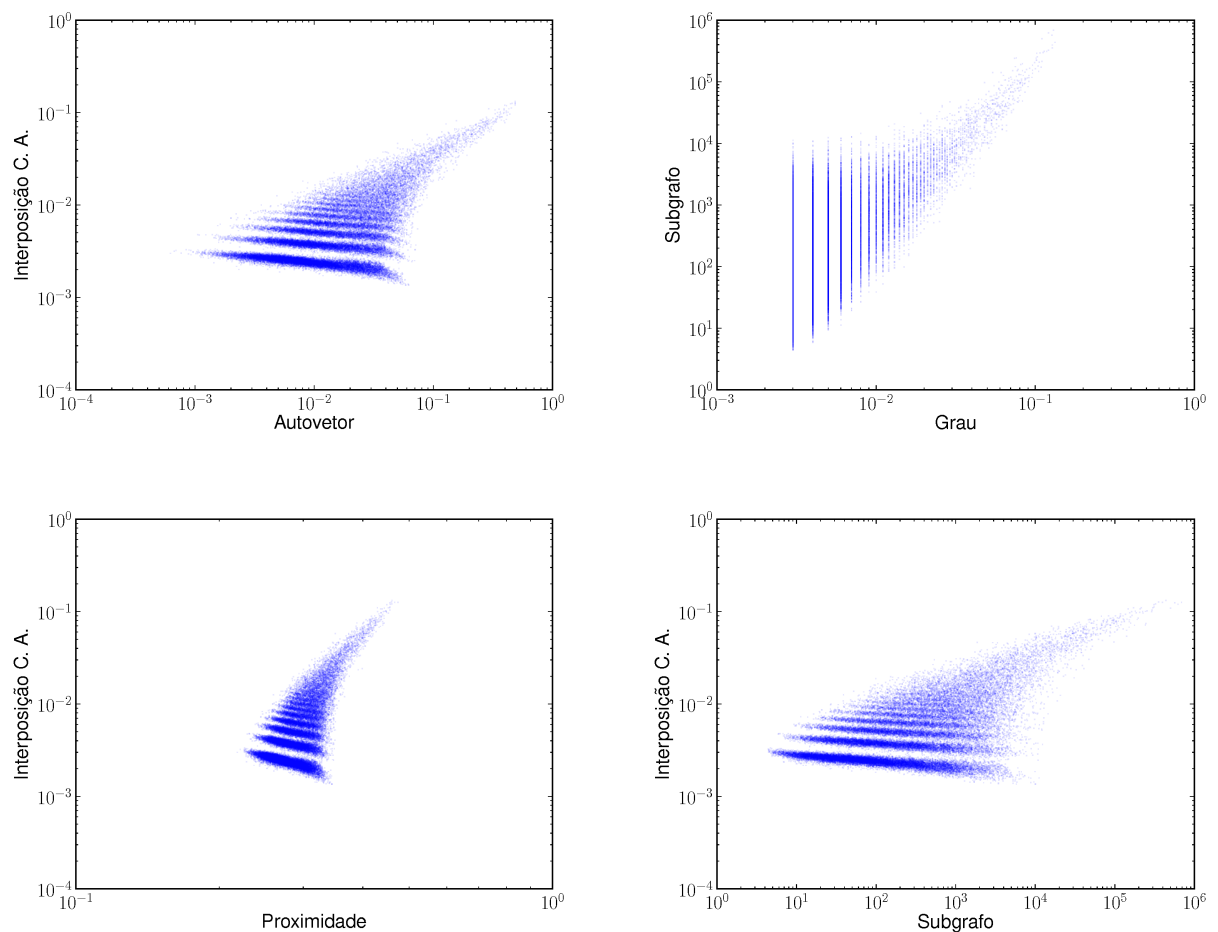

Figura 4.16 - Pares de medidas centralidade com os menores valores de correlação para as redes geradas utilizando-se o modelo de Barabási-Albert. Fonte: Elaborada pelo autor. 


\subsubsection{Correlações das centralidades das ligações}

Além das medidas de centralidade utilizadas para identificar os nós importantes, existem também medidas desenvolvidas para classificar as ligações da rede. Assim, realizamos o mesmo tipo de análise feita na seção 4.2.1 para as centralidades de ligação.

Um problema com o qual nos deparamos é que existe um número menor de medidas de centralidade amplamente utilizadas para ligações. Para contornar esta dificuldade, utilizamos o produto das centralidades dos nós para classificar as conexões, ou seja, se a ligação $e$ conecta os nós $i$ e $j$ ela recebe um valor de importância igual ao produto das centralidades desses nós. Acreditamos que esta é uma maneira razoável de se classificar as ligações de redes complexas, pois ela baseia-se na ideia de que se uma conexão relaciona dois nós importantes, ela também deve ser essencial para a rede. Como essas novas centralidades de ligações provém das medidas definidas para os nós, as chamamos de centralidades derivadas para diferenciá-las das demais. Assim, as mesmas centralidades utilizadas para classificar os nós também foram utilizadas para atribuir rankings para as ligações da rede.

Como nesse caso as medidas também apresentaram comportamento lei de potência, procedemos da mesma forma que no caso dos nós. Os valores das correlações de Pearson do logaritmo das medidas de centralidade é apresentado na tabela 4.4. Nela, as medidas que não são classicamente definidas para as ligações, como a centralidade de grau, por exemplo, representam uma centralidade derivada, ou seja, o valor atribuído para a ligação é igual ao produto das centralidades dos nós conectados por ela. As centralidades que são classicamente definidas paras as ligações da rede possuem a palavra ligação no nome, como no caso da interposição para ligação (abreviada como Interp L na tabela). Analisando os valores das correlações apresentadas na tabela, notamos que os pares de medidas das centralidades derivadas estão correlacionados em todas as redes consideradas, entretanto, ela é mais forte nos modelos do que nas redes reais. Além disso, também notamos que as medidas de interposição para ligações e sua variante baseada em caminhada aleatória, estão correlacionadas apenas nos sistemas reais. Na tabela 4.5, apresentamos os valores dos expoentes para todos os pares de medidas de centralidade de ligações utilizados neste trabalho. Esse valores foram obtidos através do método dos mínimos quadrados aplicados aos gráficos dilogaritmos dos pares de centralidades das redes utilizadas. Da mesma forma que no caso dos expoentes para as centralidades dos nós, é preciso ter em mente que os valores de expoentes apresentados nesta tabela só fazem sentido quando as medidas de centralidade das ligações estão correlacionadas entre si. 
Tabela 4.4 - Correlação de Pearson para as redes: golfinhos (GF), clube de caratê (CT), colaboração em artigos de física de altas energias (CF), colaboração em redes complexas (CR), livros de política (LP), rede de distribuição de energia (DE), modelo de Erdős-Rényi (ER), e modelo Barabási-Albert (BA). Nas medidas de centralidade as abreviações Interp $L$ significam Interposição para ligação, Interp $L C A$ interposição para ligação baseada em caminhada aleatória, Interp interposição, Interp $C A$ interposição baseada em caminhada aleatória e Proximidade $F C$ proximidade utilizando o modelo do fluxo de corrente.

\begin{tabular}{|c|c|c|c|c|c|c|c|c|}
\hline Medidas & GF & CT & CF & $\mathrm{CR}$ & LP & $\mathrm{DE}$ & ER & $\mathrm{BA}$ \\
\hline Interp L/Interp L CA & 0.84 & 0.75 & 0.73 & 0.72 & 0.74 & 0.54 & 0.15 & -0.19 \\
\hline Interp L/Grau & -0.04 & 0.59 & 0.32 & 0.39 & 0.10 & 0.15 & 0.77 & 0.84 \\
\hline Interp L/Proximidade & 0.32 & 0.62 & 0.26 & 0.33 & 0.49 & 0.40 & 0.67 & 0.72 \\
\hline Interp L/Interp & 0.50 & 0.63 & 0.66 & 0.66 & 0.56 & 0.74 & 0.83 & 0.82 \\
\hline Interp L/Autovetor & -0.02 & 0.52 & 0.16 & 0.11 & 0.02 & -0.09 & 0.66 & 0.67 \\
\hline Interp L/Subgrafo & -0.17 & 0.53 & 0.11 & 0.08 & -0.08 & -0.03 & 0.75 & 0.65 \\
\hline Interp L/Interp CA & 0.41 & 0.65 & 0.58 & 0.59 & 0.53 & 0.52 & 0.80 & 0.83 \\
\hline Interp L/Proximidade FC & 0.06 & 0.56 & 0.21 & 0.21 & 0.12 & 0.33 & 0.66 & 0.75 \\
\hline Interp L CA/Grau & -0.28 & 0.15 & 0.08 & 0.23 & -0.39 & 0.12 & -0.25 & -0.39 \\
\hline Interp L CA/Proximidade & 0.13 & 0.25 & 0.07 & 0.50 & 0.30 & 0.53 & -0.50 & -0.63 \\
\hline Interp L CA/Interp & 0.36 & 0.23 & 0.55 & 0.58 & 0.30 & 0.55 & -0.15 & -0.34 \\
\hline Interp L CA/Autovetor & -0.27 & 0.12 & -0.03 & 0.16 & -0.30 & -0.08 & -0.49 & -0.64 \\
\hline Interp L CA/Subgrafo & -0.46 & 0.12 & -0.17 & 0.03 & -0.54 & -0.04 & -0.39 & -0.62 \\
\hline Interp L CA/Interp CA & 0.34 & 0.24 & 0.57 & 0.79 & 0.23 & 0.90 & -0.05 & -0.27 \\
\hline Interp L CA/Proximidade FC & -0.16 & 0.13 & 0.14 & 0.47 & -0.32 & 0.60 & -0.34 & -0.28 \\
\hline Grau/Proximidade & 0.53 & 0.80 & 0.72 & 0.41 & 0.52 & 0.21 & 0.92 & 0.89 \\
\hline Grau/Interp & 0.65 & 0.88 & 0.62 & 0.59 & 0.60 & 0.49 & 0.98 & 0.98 \\
\hline Autovetor & 0.52 & 0.90 & 0.61 & 0.33 & 0.63 & 0.28 & 0.91 & 0.86 \\
\hline /Subgrafo & 0.93 & 0.94 & 0.84 & 0.79 & 0.88 & 0.90 & 0.97 & 0.84 \\
\hline & 0.70 & 0.98 & 0.80 & 0.59 & 0.71 & 0.43 & 0.97 & 0.99 \\
\hline Grau/Proximidade FC & 0.83 & 0.93 & 0.75 & 0.50 & 0.96 & 0.32 & 0.97 & 0.96 \\
\hline & 0.61 & 0.84 & 0.49 & 0.49 & 0.78 & 0.47 & 0.89 & 0.89 \\
\hline tovetor & 0.78 & 0.91 & 0.89 & 0.55 & 0.33 & -0.19 & 0.97 & 0.98 \\
\hline Proximidade/Subgrafo & 0.45 & 0.88 & 0.81 & 0.26 & 0.32 & 0.02 & 0.96 & 0.98 \\
\hline Proximidade/Interp CA & 0.61 & 0.85 & 0.63 & 0.71 & 0.86 & 0.60 & 0.82 & 0.83 \\
\hline Proximidade/Proximidade FC & 0.86 & 0.90 & 0.88 & 0.82 & 0.63 & 0.81 & 0.93 & 0.83 \\
\hline & 0.23 & 0.83 & 0.35 & 0.32 & 0.32 & 0.05 & 0.89 & 0.87 \\
\hline ic chofo & 0.45 & 0.85 & 0.39 & 0.29 & 0.31 & 0.30 & 0.94 & 0.84 \\
\hline Interp/Interp CA & 0.94 & 0.92 & 0.81 & 0.75 & 0.93 & 0.68 & 0.98 & 0.97 \\
\hline Interp/Proximidade FC & 0.60 & 0.87 & 0.43 & 0.46 & 0.62 & 0.42 & 0.93 & 0.96 \\
\hline Autovetor/Subgrafo & 0.60 & 0.99 & 0.77 & 0.49 & 0.74 & 0.48 & 0.96 & 0.96 \\
\hline Autovetor/Interp CA & 0.19 & 0.89 & 0.47 & 0.33 & 0.38 & 0.03 & 0.82 & 0.80 \\
\hline Autovetor/Proximidade FC & 0.82 & 0.98 & 0.79 & 0.70 & 0.64 & -0.11 & 0.90 & 0.81 \\
\hline Subgrafo/Interp CA & 0.45 & 0.93 & 0.54 & 0.36 & 0.40 & 0.25 & 0.91 & 0.78 \\
\hline Subgrafo/Proximidade FC & 0.76 & 0.98 & 0.74 & 0.50 & 0.87 & 0.11 & 0.94 & 0.78 \\
\hline Interp CA/Proximidade FC & 0.64 & 0.92 & 0.72 & 0.73 & 0.73 & 0.71 & 0.92 & 0.97 \\
\hline
\end{tabular}


Tabela 4.5 - Tabela com os expoentes das leis de potência encontradas entre as medidas de centralidade de ligação das redes: golfinhos (GF), clube de caratê (CT), colaboração em artigos de física de altas energias (CF), colaboração em redes complexas (CR), livros de política (LP), rede de distribuição de energia (DE), modelo de Erdôs-Rényi (ER), e modelo Barabási-Albert (BA).

\begin{tabular}{|c|c|c|c|c|c|c|c|c|}
\hline Medidas & GF & $\mathrm{CT}$ & CF & CR & LP & DE & ER & BA \\
\hline Interp A/Interp A CA & 0.39 & 0.21 & 0.21 & 0.27 & 0.34 & 0.32 & 0.04 & -0.03 \\
\hline Interp A/Grau & -0.13 & 0.43 & 0.15 & 0.16 & 0.10 & 0.07 & 1.41 & 1.50 \\
\hline Interp A/Proximidade & 0.06 & 0.13 & 0.04 & 0.05 & 0.10 & 0.04 & 0.22 & 0.22 \\
\hline Interp A/Interp & 1.11 & 1.77 & 1.17 & 1.17 & 1.57 & 1.55 & 3.45 & 3.06 \\
\hline Interp A/Autovetor & -0.22 & 0.40 & 0.55 & 0.60 & 0.06 & -0.30 & 1.85 & 1.78 \\
\hline Interp A/Subgrafo & -0.42 & 0.65 & 0.20 & 0.21 & -0.12 & -0.01 & 2.05 & 3.42 \\
\hline Interp A/Interp CA & -0.72 & 0.63 & 0.54 & 0.53 & 0.55 & 0.69 & 1.00 & 1.57 \\
\hline Interp A/Proximidade FC & -0.04 & 0.13 & 0.07 & 0.05 & 0.04 & 0.05 & 0.58 & 0.38 \\
\hline Interp A CA/Grau & -0.43 & 0.59 & 0.56 & 0.39 & -0.68 & 0.26 & -1.27 & -4.62 \\
\hline Interp A CA/Proximidade & 0.07 & 0.26 & 0.15 & 0.17 & 0.12 & 0.08 & -0.51 & -1.28 \\
\hline Interp A CA/Interp & 1.61 & 2.05 & 2.87 & 2.37 & 1.75 & 2.03 & -2.06 & -8.51 \\
\hline Interp A CA/Autovetor & -1.52 & 0.40 & 1.52 & 1.62 & -1.07 & 0.72 & -4.20 & -11.27 \\
\hline Interp A CA/Subgrafo & -1.66 & 0.60 & 0.23 & 0.48 & -2.81 & 0.16 & -3.24 & -22.01 \\
\hline Interp A CA/Interp CA & 0.58 & 1.62 & 2.10 & 2.16 & 0.50 & 3.62 & 3.41 & -3.39 \\
\hline Interp A CA/Proximidade FC & -0.11 & 0.19 & 0.31 & 0.21 & -0.20 & 0.16 & -0.84 & -0.97 \\
\hline Grau/Proximidade & 0.22 & 0.27 & 0.17 & 0.14 & 0.13 & 0.08 & 0.16 & 0.15 \\
\hline Grau/Interp & 1.96 & 2.92 & 1.95 & 3.01 & 2.01 & 2.64 & 2.14 & 2.02 \\
\hline Grau/Autovetor & 1.85 & 1.04 & 4.05 & 2.80 & 1.27 & 6.28 & 1.39 & 1.27 \\
\hline Grau/Subgrafo & 1.98 & 1.63 & 3.40 & 2.66 & 2.64 & 1.41 & 1.41 & 2.48 \\
\hline Grau/Interp CA & 4.36 & 1.46 & 1.49 & 2.29 & 0.91 & 3.45 & 1.79 & 1.04 \\
\hline Grau/Proximidade FC & 0.41 & 0.38 & 0.37 & 0.28 & 0.36 & 0.21 & 0.49 & 0.27 \\
\hline Proximidade/Interp & 4.79 & 9.40 & 5.97 & 6.47 & 11.46 & 6.66 & 10.82 & 10.92 \\
\hline Proximidade/Autovetor & 7.49 & 3.45 & 21.11 & 13.91 & 3.10 & -10.54 & 8.26 & 8.56 \\
\hline Proximidade/Subgrafo & 3.22 & 4.98 & 11.29 & 3.09 & 5.02 & 0.41 & 7.75 & 16.95 \\
\hline Proximidade/Interp CA & 9.71 & 4.25 & 5.18 & 4.38 & 4.63 & 2.74 & 8.22 & 5.16 \\
\hline Proximidade/Proximidade FC & 1.13 & 1.20 & 1.65 & 1.05 & 1.07 & 1.04 & 2.60 & 1.38 \\
\hline Interp/Autovetor & 0.28 & 0.29 & 0.70 & 0.60 & 0.19 & 0.21 & 0.62 & 0.62 \\
\hline Interp/Subgrafo & 0.36 & 0.46 & 0.54 & 0.19 & 0.27 & 0.10 & 0.64 & 1.19 \\
\hline Interp/Interp CA & 0.42 & 0.36 & 0.35 & 0.33 & 0.34 & 0.38 & 0.50 & 0.49 \\
\hline Interp/Proximidade FC & 0.09 & 0.10 & 0.06 & 0.04 & 0.06 & 0.04 & 0.21 & 0.13 \\
\hline Autovetor/Subgrafo & 0.41 & 1.45 & 0.52 & 0.21 & 1.13 & 0.03 & 0.91 & 1.90 \\
\hline Autovetor/Interp CA & 0.96 & 1.02 & 0.15 & 0.12 & 0.25 & 0.01 & 0.98 & 0.57 \\
\hline Autovetor/Proximidade FC & 0.11 & 0.33 & 0.06 & 0.04 & 0.12 & -0.00 & 0.30 & 0.16 \\
\hline Subgrafo/Interp CA & 1.33 & 0.73 & 0.21 & 0.49 & 0.18 & 0.87 & 1.02 & 0.28 \\
\hline Subgrafo/Proximidade FC & 0.17 & 0.23 & 0.08 & 0.09 & 0.11 & 0.07 & 0.32 & 0.08 \\
\hline Interp CA/Proximidade FC & 0.03 & 0.23 & 0.16 & 0.06 & 0.23 & 0.01 & 0.07 & 0.26 \\
\hline
\end{tabular}

Fonte: elaborada pelo autor. 


\subsubsection{Centralidades de ligação mais correlacionadas}

Também selecionamos os quatro pares de centralidades mais correlacionados para cada uma das redes. Essas duplas de medidas encontram-se nas figuras de 4.17 a 4.24 que apresentam seu comportamento. Nelas, notamos que existem centralidades que estão presentes em redes de ambos os tipos, como no caso dos pares (interposição e sua variante baseada em caminhada aleatória) e (grau e subgrafo) que aparecem no modelo Erdős-Rényi e na maioria dos sistemas reais. No caso do segundo par, acreditamos que as ligações que recebem valores elevados pela medida de grau são as que conectam os nós com grande número de vizinhos, e quanto maior for este, maior é a probabilidade do nó participar de vários subgrafos da rede; de forma similar com o que foi observado para os nós. Desta forma as ligações também recebem um valor elevado pela medida de subgrafo, explicando a correlação entre este par de medidas.

Também há casos de pares de medidas que aparecem entre os mais correlacionados em apenas redes de um tipo, como as duplas (grau e interposição baseada em caminhada aleatória) e (proximidade e autovetor) que estão presentes em ambos os modelos mas não nas redes reais.
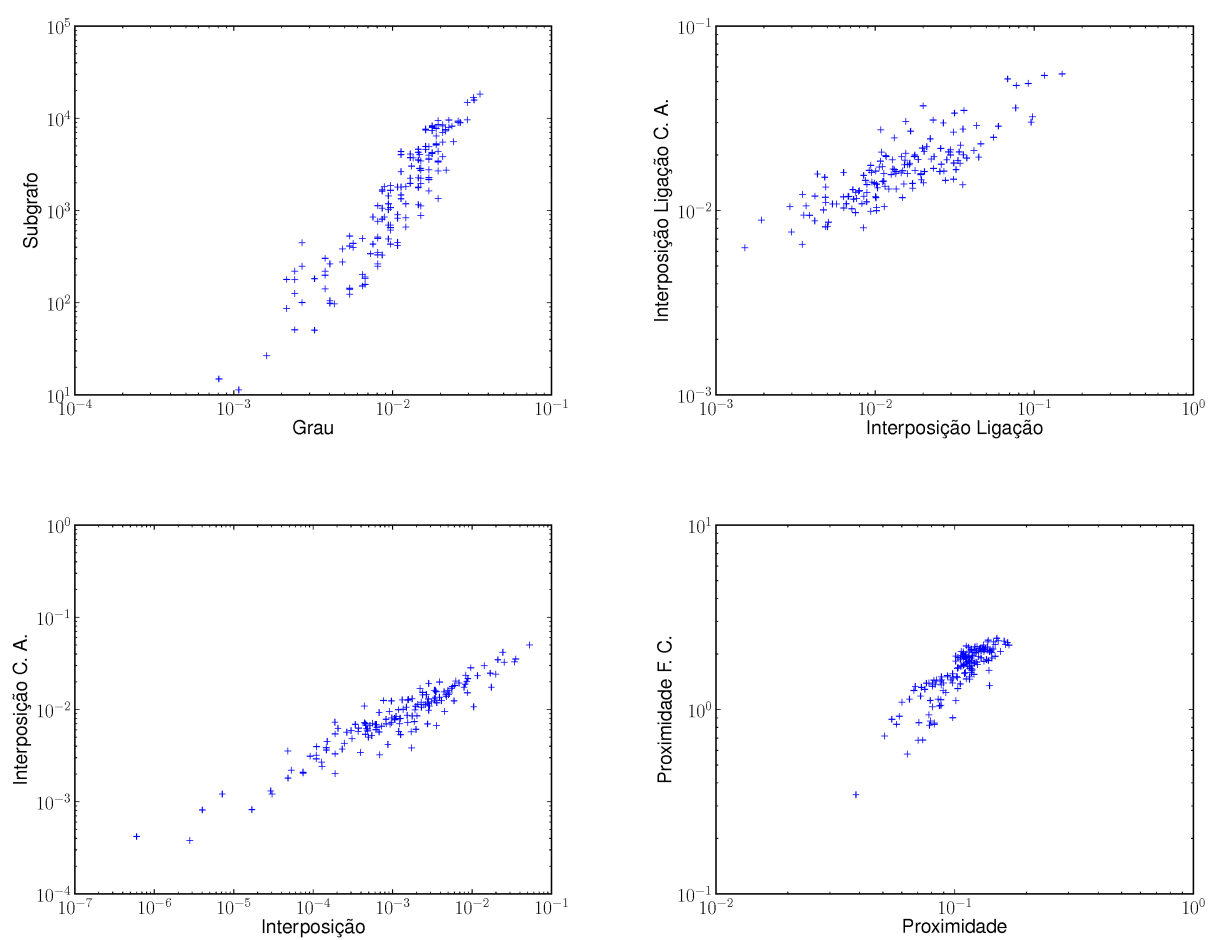

Figura 4.17 - Pares de medidas centralidade de ligações com os maiores valores de correlação para a rede dos golfinhos. Fonte: Elaborada pelo autor. 

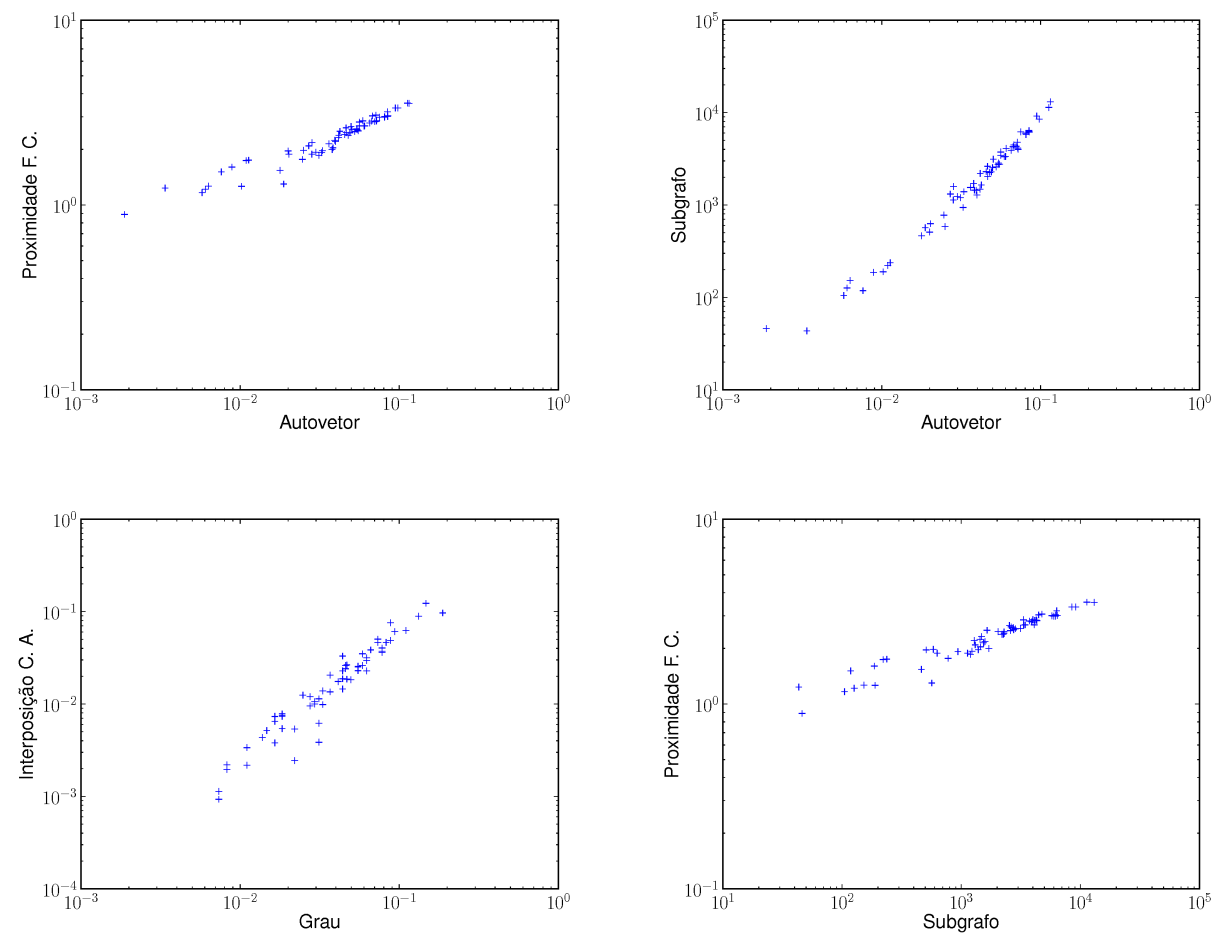

Figura 4.18 - Pares de medidas centralidade de ligações com os maiores valores de correlação para a rede do clube de caratê. Fonte: Elaborada pelo autor.
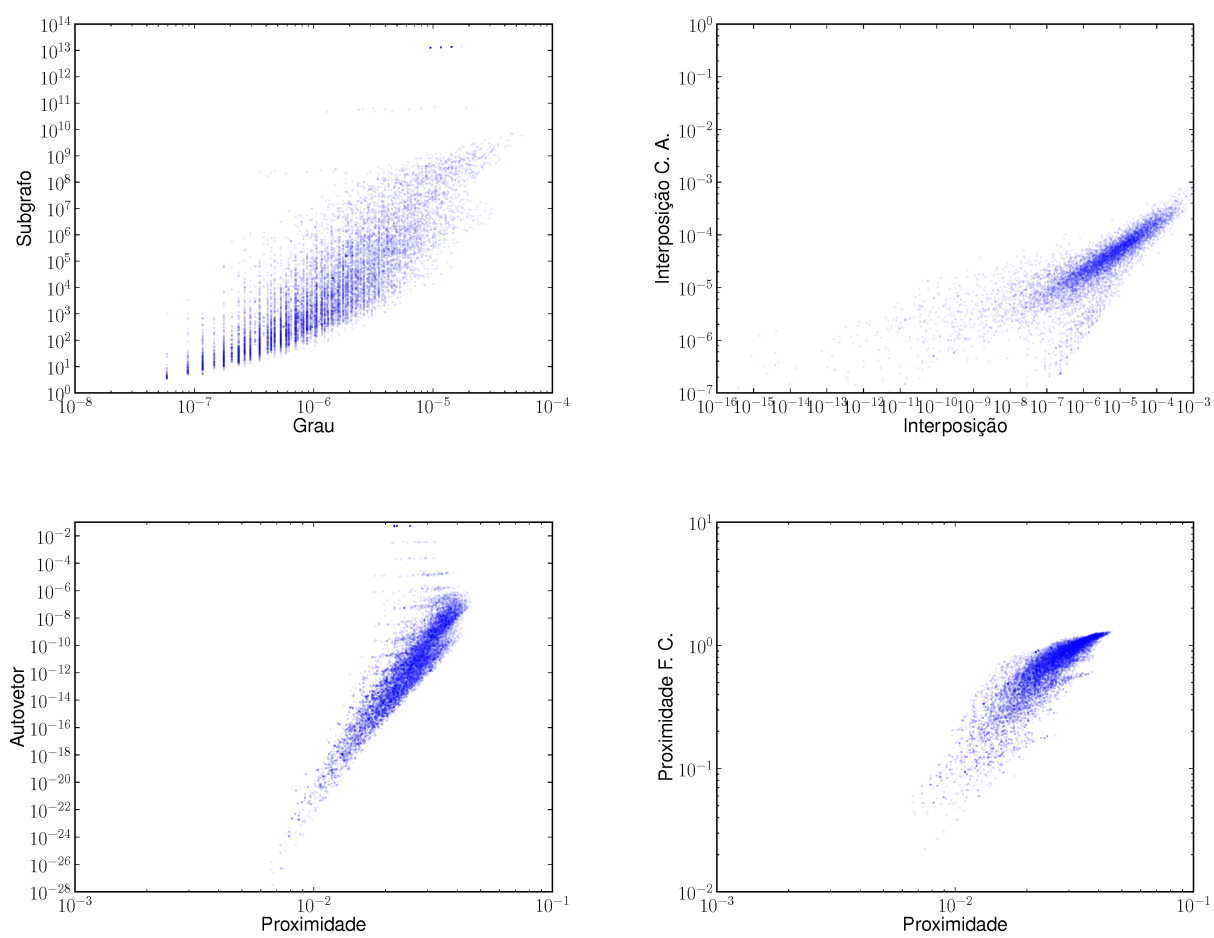

Figura 4.19 - Pares de medidas centralidade de ligações com os maiores valores de correlação para a rede de colaboração entre autores em física de altas energias. Fonte: Elaborada pelo autor. 

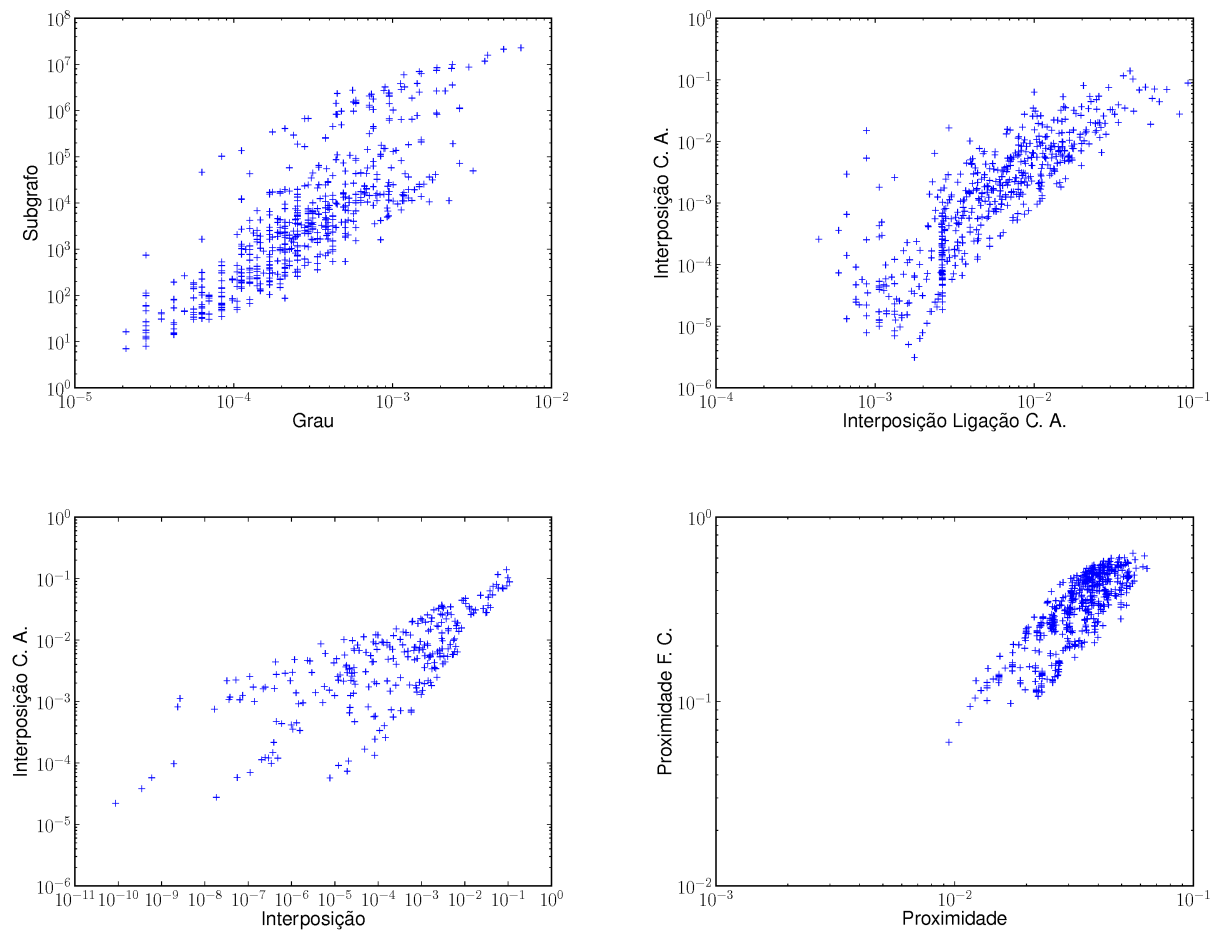

Figura 4.20 - Pares de medidas centralidade de ligações com os maiores valores de correlação para a rede de colaboração entre autores em redes complexas. Fonte: Elaborada pelo autor.
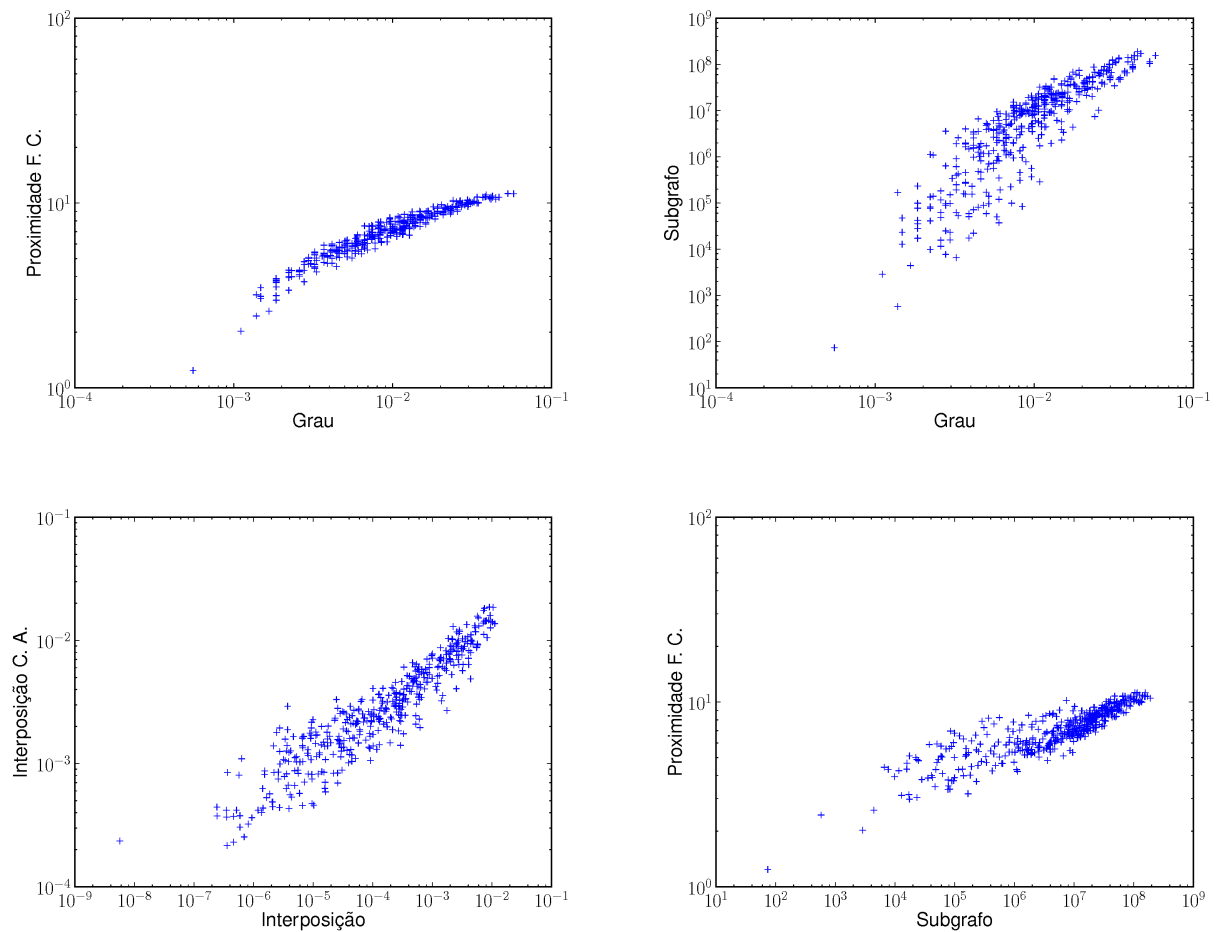

Figura 4.21 - Pares de medidas centralidade de ligações com os maiores valores de correlação para a rede de livros de política. Fonte: Elaborada pelo autor. 

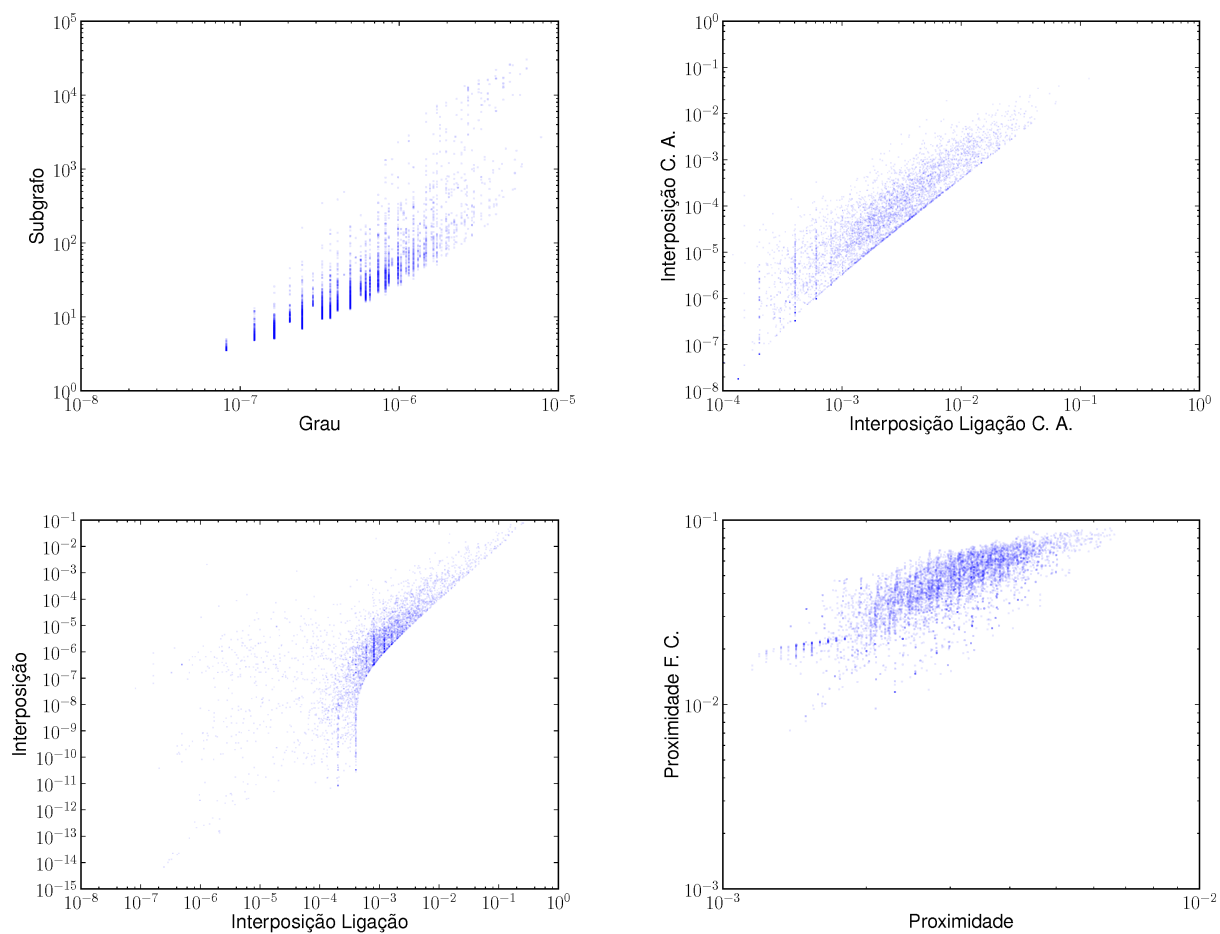

Figura 4.22 - Pares de medidas centralidade de ligações com os maiores valores de correlação para a rede de distribuição de energia. Fonte: Elaborada pelo autor.
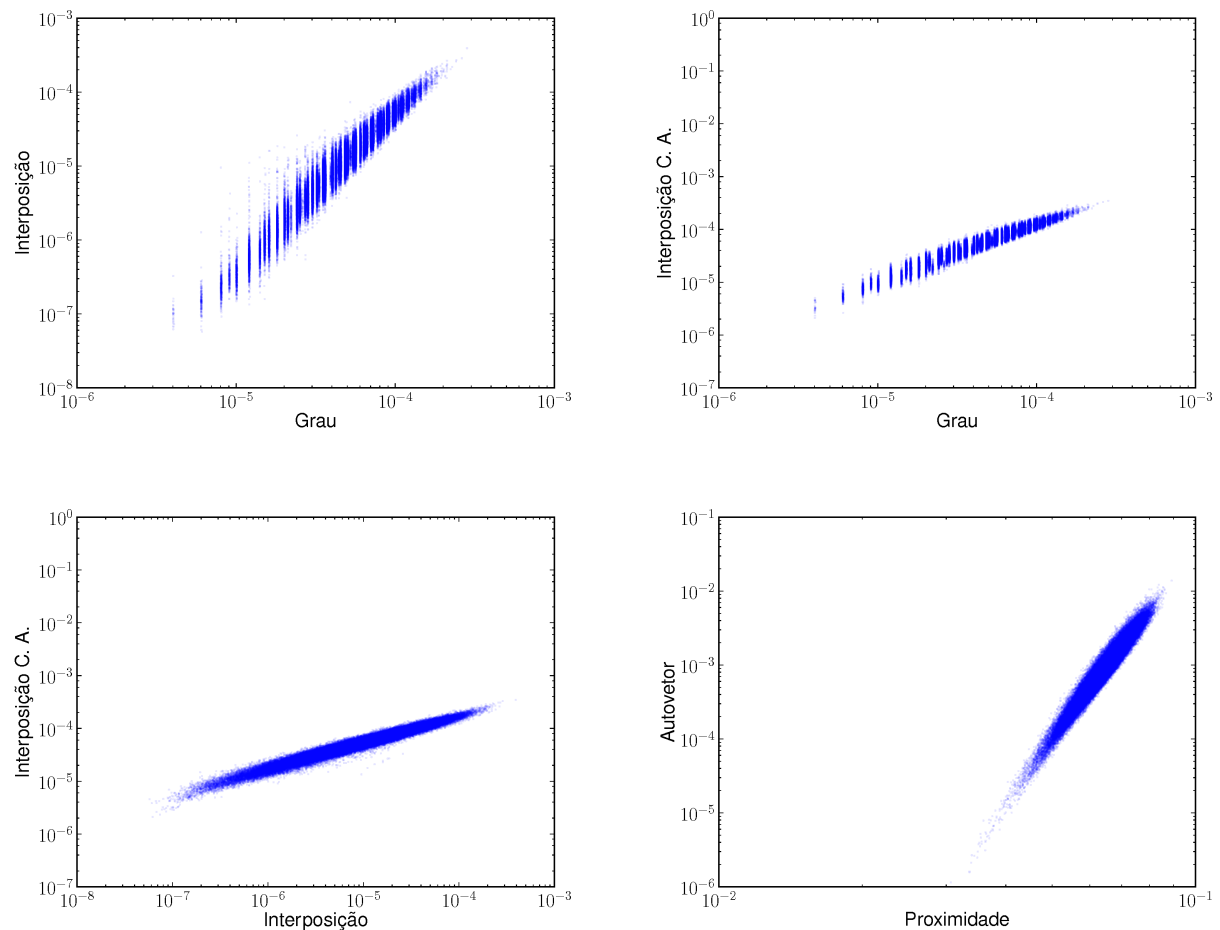

Figura 4.23 - Pares de medidas centralidade de ligações com os maiores valores de correlação para as redes geradas utilizando-se o modelo de Erdős-Rényi. Fonte: Elaborada pelo autor. 

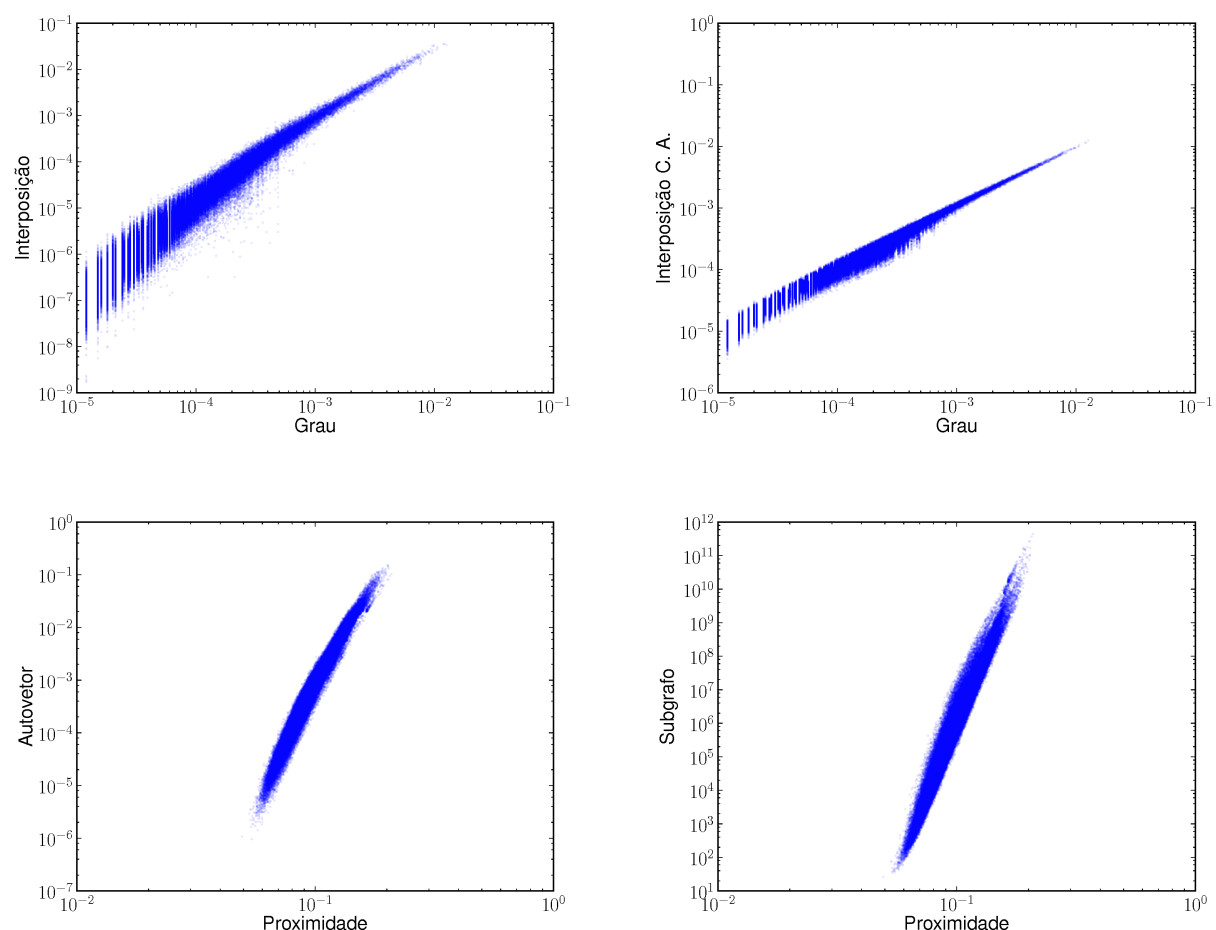

Figura 4.24 - Pares de medidas centralidade de ligações com os maiores valores de correlação para as redes geradas utilizando-se o modelo de Barabási-Albert. Fonte: Elaborada pelo autor. 


\subsubsection{Centralidades de ligação menos correlacionadas}

Também selecionamos os quatro pares de medidas de ligações com os menores valores de correlação para cada rede, que encontram-se nas figuras 4.25 a 4.32. Analisando esses gráficos, observamos que para os modelos de rede, a medida de interposição de ligação baseada em caminhada aleatória sempre está presente e os menores coeficientes de correlação, ocorrem quando ela forma par com os outros tipos de interposição. As redes reais apresentam um comportamento diferente, nelas, as centralidades de interposição de ligação e sua variante baseada em caminhada aleatória se relacionam com os menores coeficientes quando formam par com autovetor ou subgrafo. Novamente o comportamento das correlações é bastante distinto entre as redes, sejam elas sistemas reais ou modelos. Deferentemente do casos dos nós, não observamos nenhuma correlação neste grupo de pares de medidas.
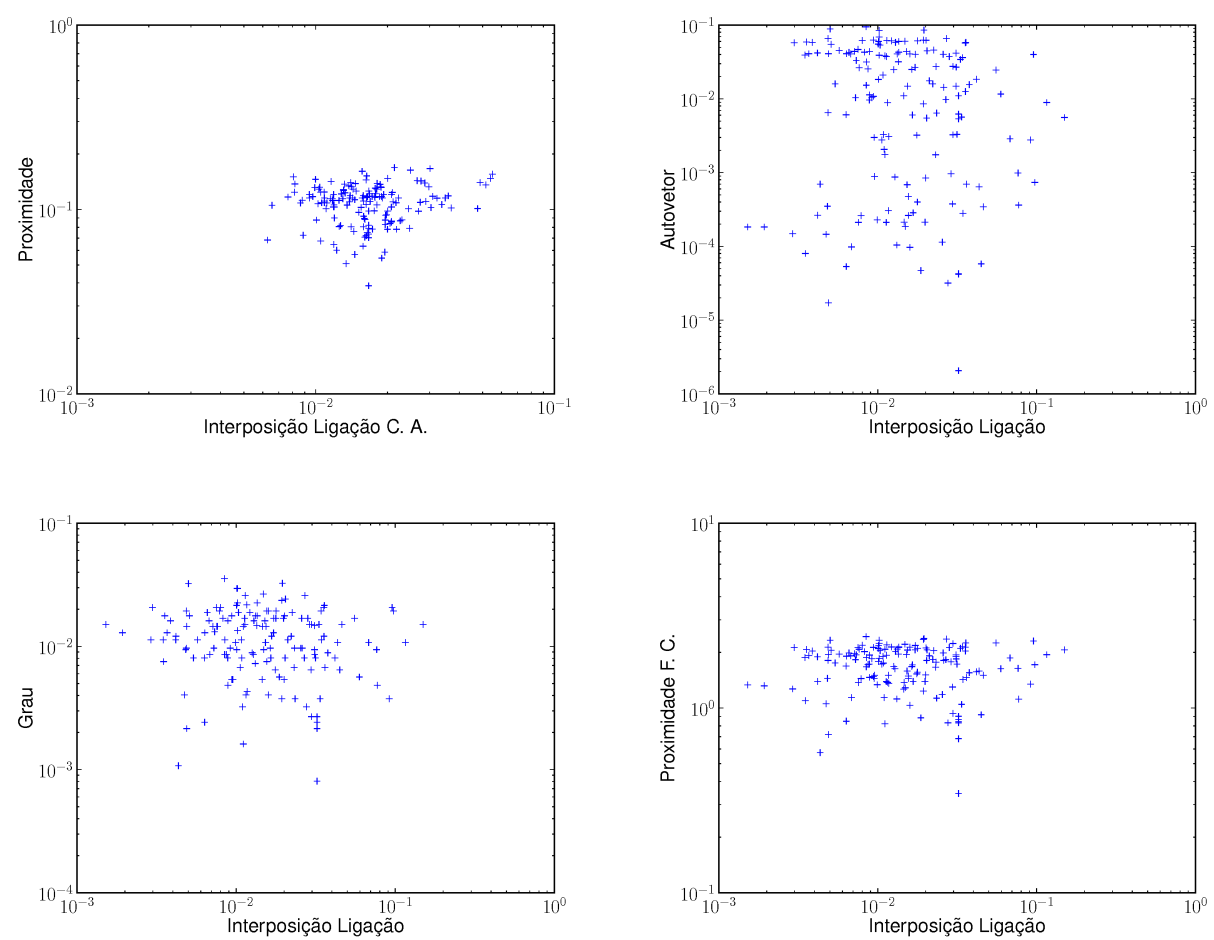

Figura 4.25 - Pares de medidas centralidade de ligações com os menores valores de correlação para a rede dos golfinhos. Fonte: Elaborada pelo autor. 

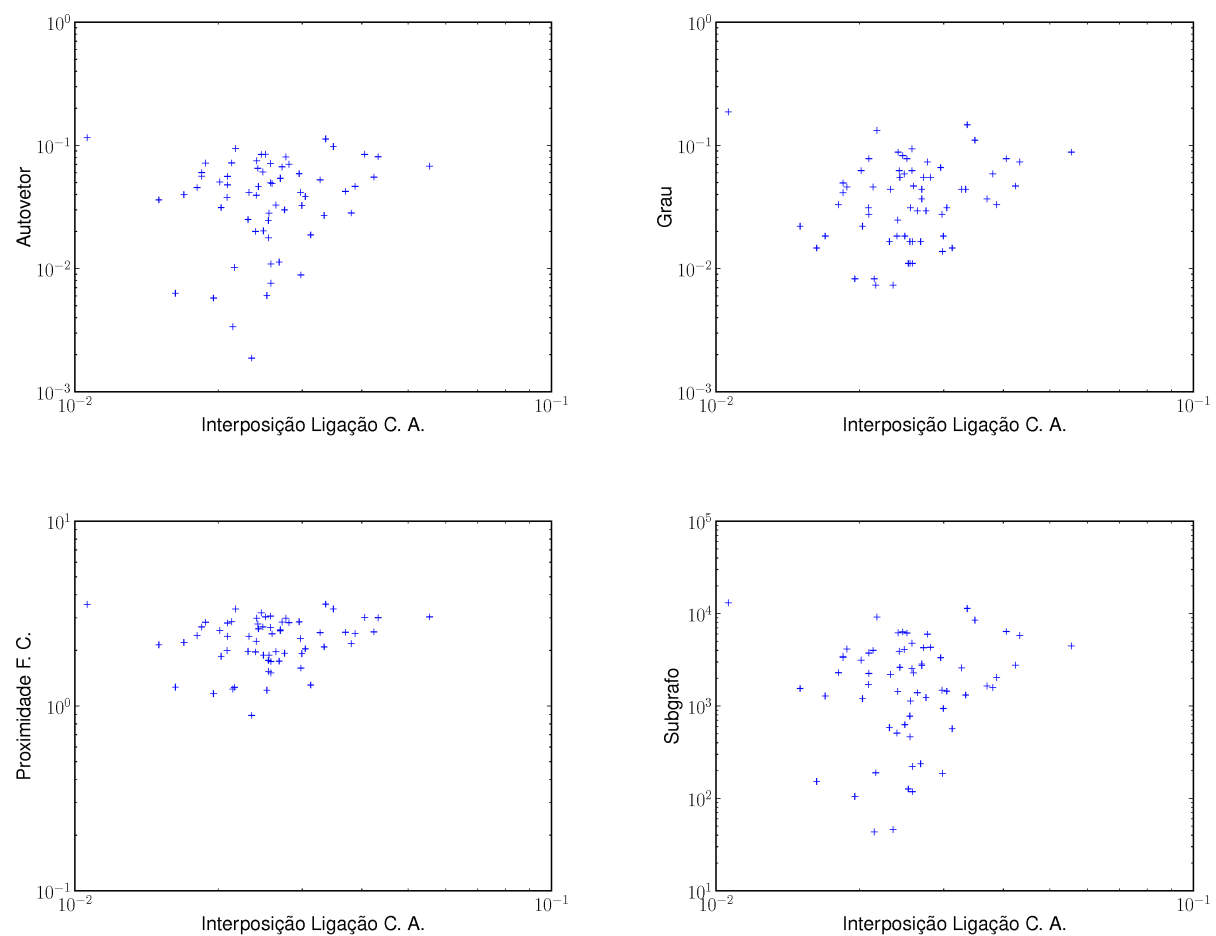

Figura 4.26 - Pares de medidas centralidade de ligações com os menores valores de correlação para a rede do clube de caratê. Fonte: Elaborada pelo autor.
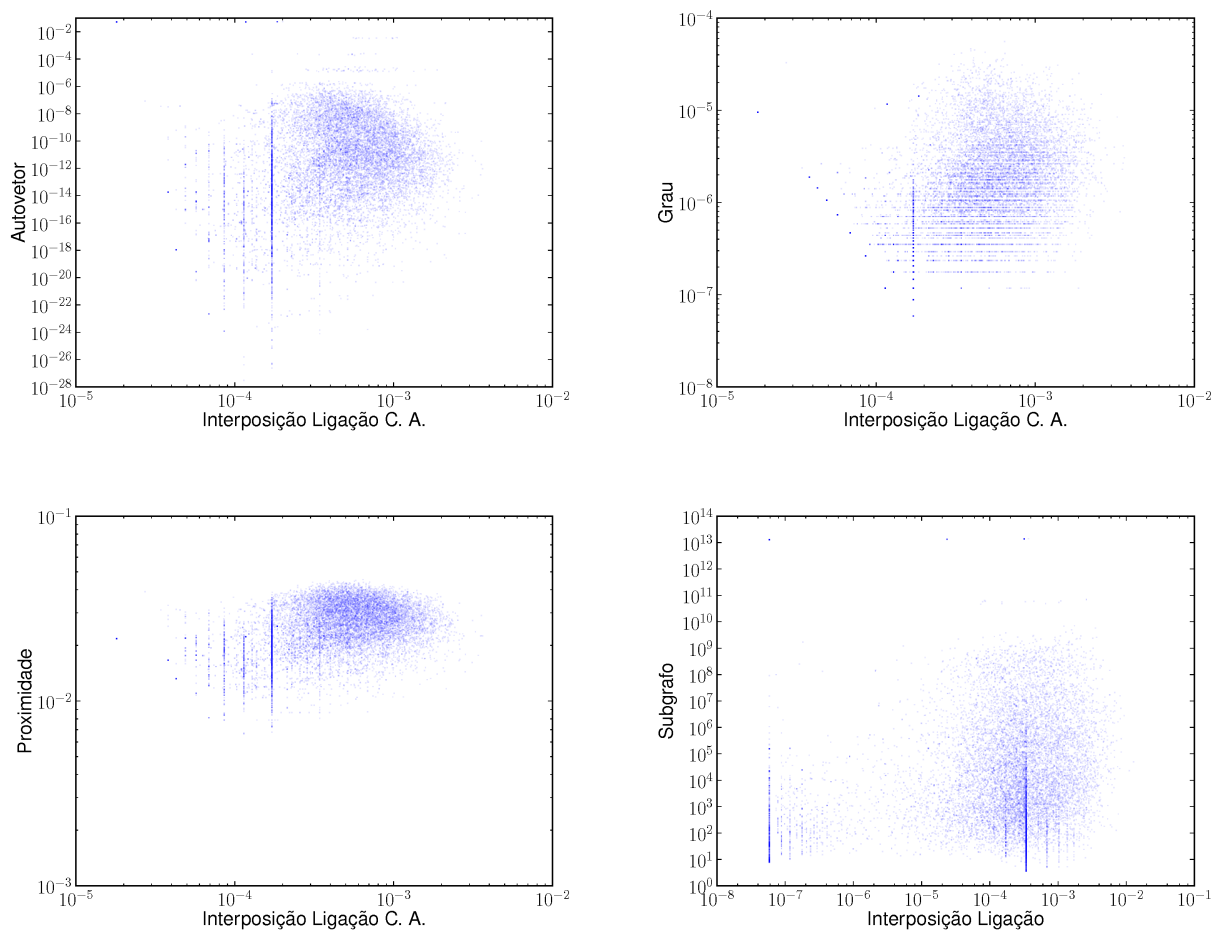

Figura 4.27 - Pares de medidas centralidade de ligações com os menores valores de correlação para a rede de colaboração entre autores em física de altas energias. Fonte: Elaborada pelo autor. 

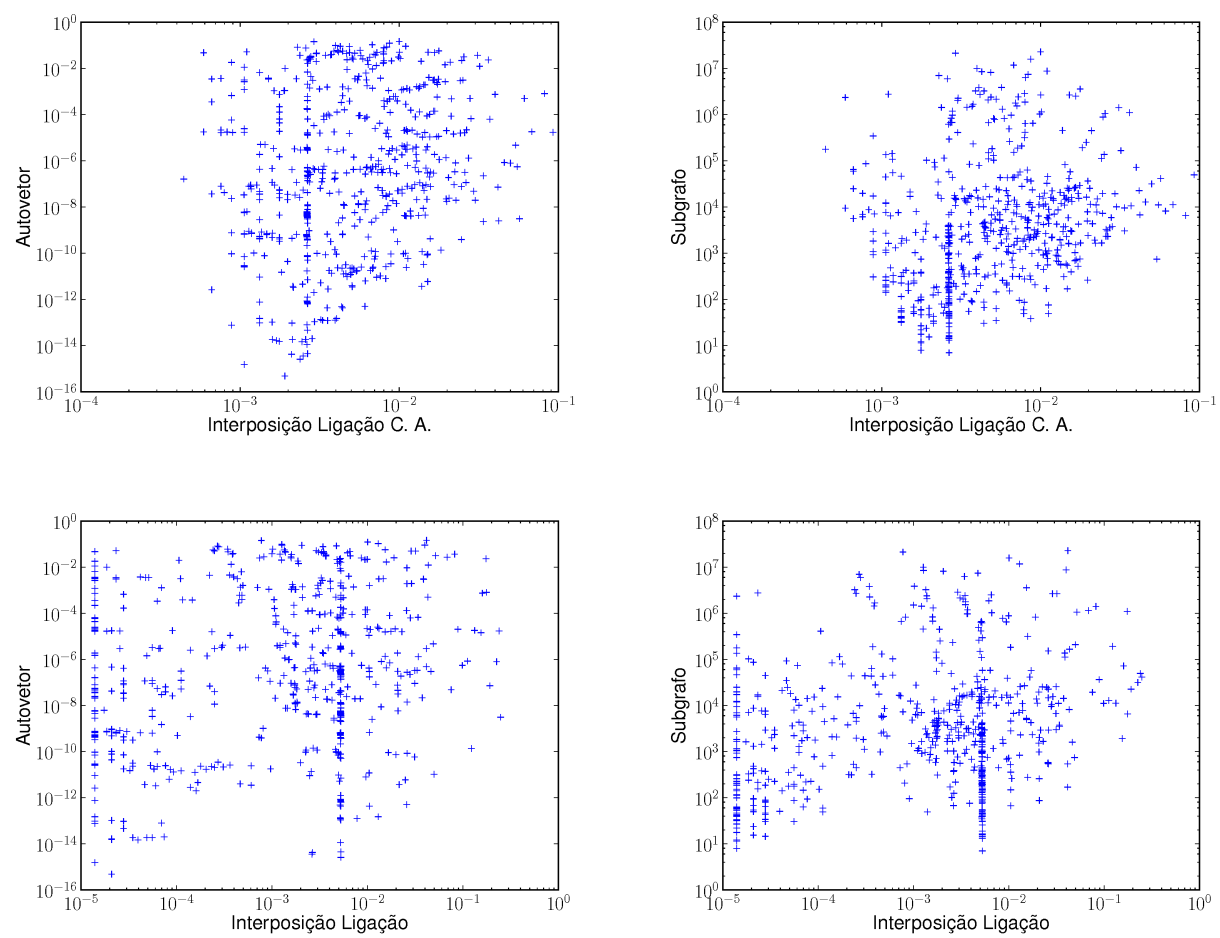

Figura 4.28 - Pares de medidas centralidade de ligações com os menores valores de correlação para a rede de colaboração entre autores em redes complexas. Fonte: Elaborada pelo autor.
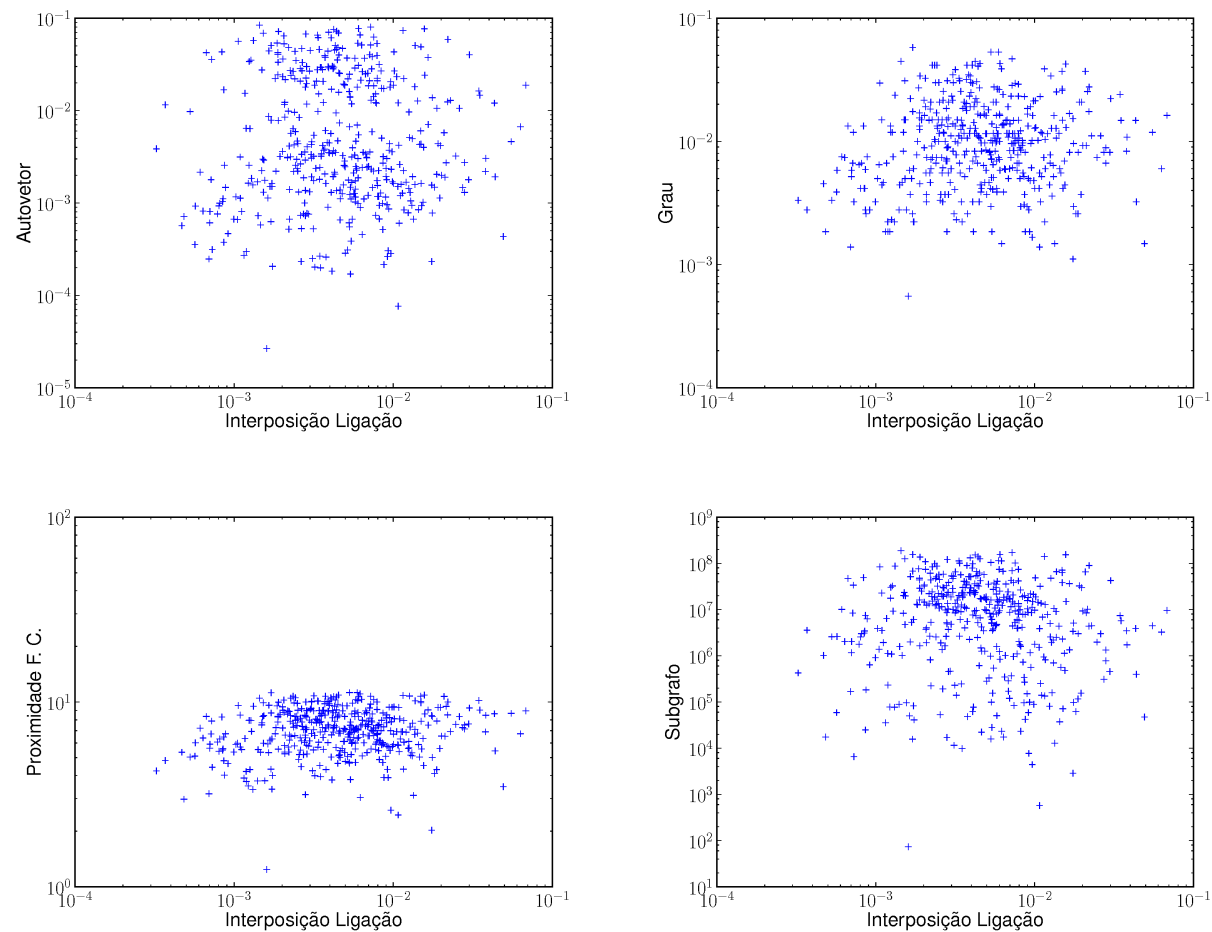

Figura 4.29 - Pares de medidas centralidade de ligações com os menores valores de correlação para a rede de livros de política. Fonte: Elaborada pelo autor. 

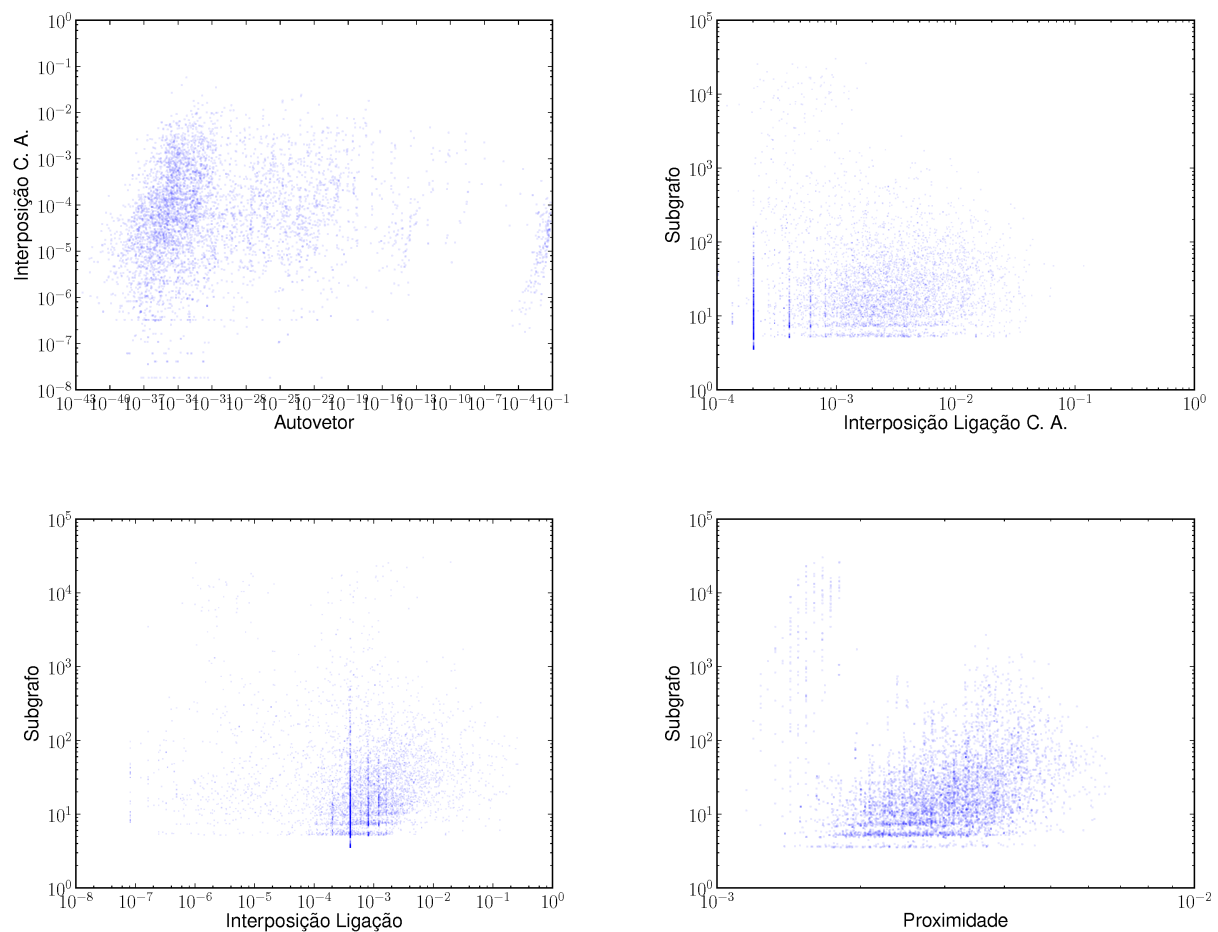

Figura 4.30 - Pares de medidas centralidade de ligações com os menores valores de correlação para a rede de distribuição de energia. Fonte: Elaborada pelo autor.
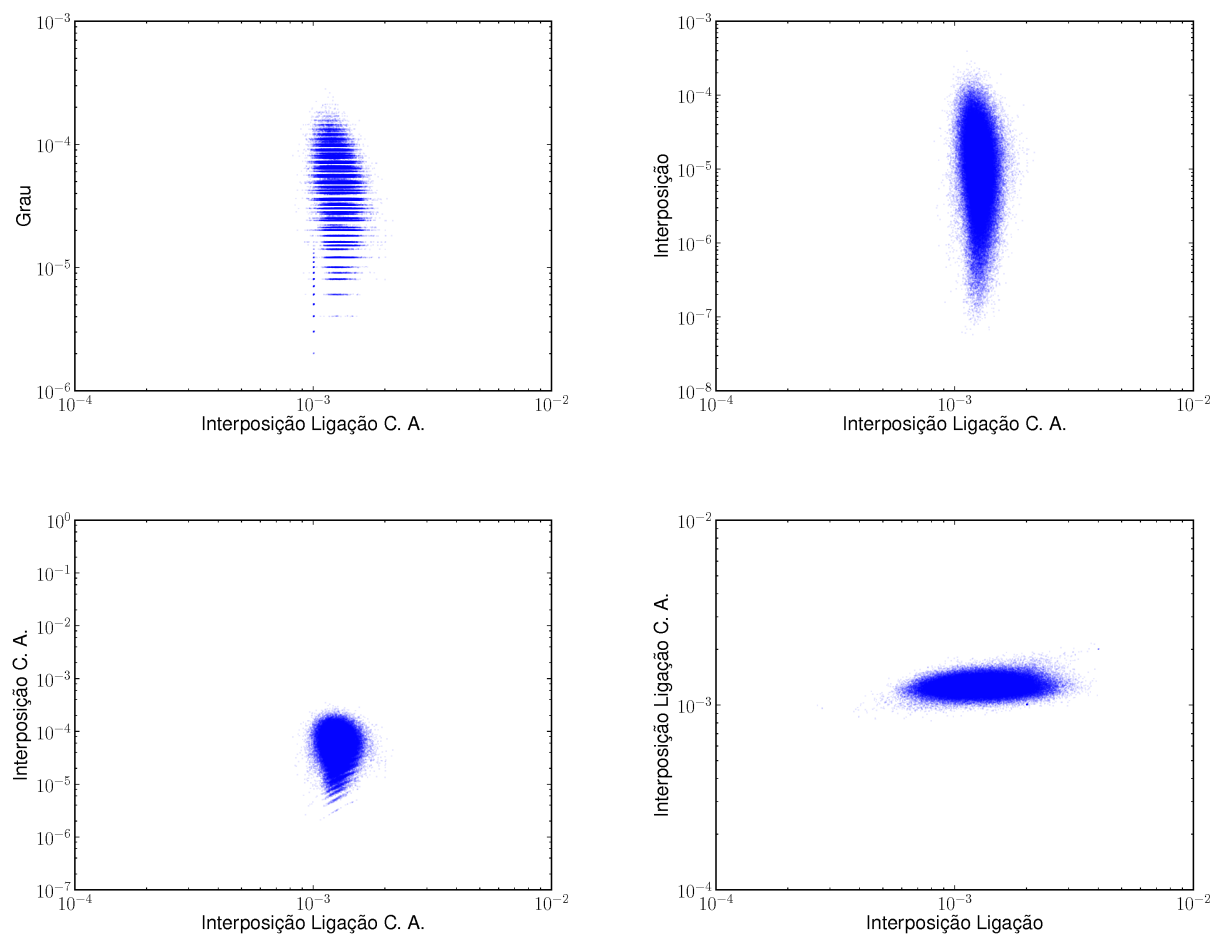

Figura 4.31 - Pares de medidas centralidade de ligações com os menores valores de correlação para as redes geradas utilizando-se o modelo de Erdős-Rényi. Fonte: Elaborada pelo autor. 

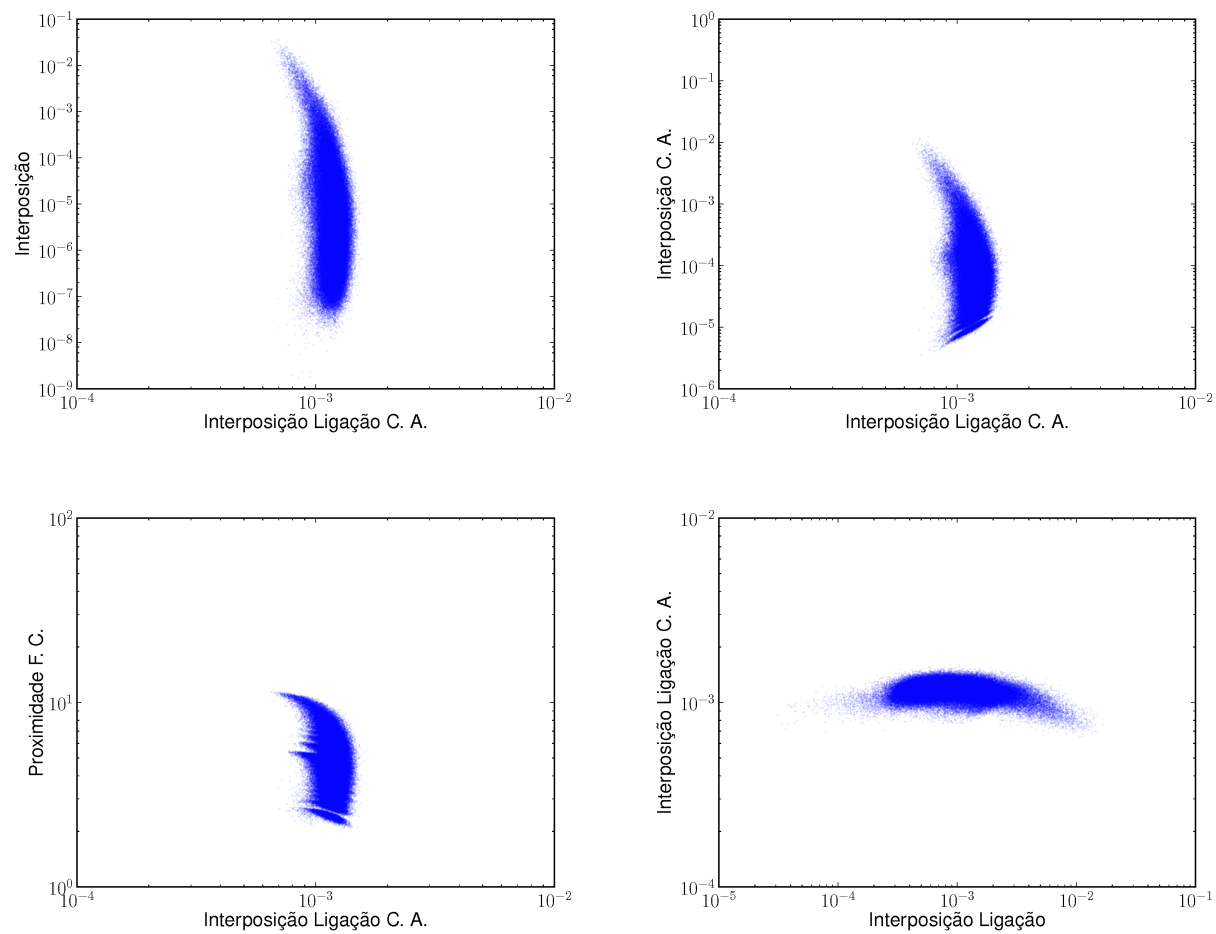

Figura 4.32 - Pares de medidas centralidade de ligações com os menores valores de correlação para as redes geradas utilizando-se o modelo de Barabási-Albert. Fonte: Elaborada pelo autor. 


\subsection{Diferenças entre medidas de centralidades}

Os resultados da seção 4.2 mostram que na maioria dos casos, os pares de centralidades de redes complexas estão correlacionados. Dessa forma, grande parte dos nós e ligações essenciais são destacados por diversas medidas. Isso nos levou a um questionamento sobre como as medidas afetam as redes: será que medidas com coeficiente de correlação elevado para uma determinada rede são similares? Ou as diferenças entre os resultados, por menores que sejam, implicam em maneiras diferentes de se avaliar os sistemas? E quando os pares de medidas não estão correlacionados, isso implica que as medidas são diferentes?

Assim, estudamos como as diferenças nos rankings dos nós e ligações afetam as redes. Para isso, realizamos ataques maliciosos às redes reais (78) utilizando as centralidades como indicadores para sua remoção. Elementos que recebiam um ranking maior eram removidos antes dos nós ou ligações com valores menores para aquela medida. E para mensurar a eficiência das centralidades em afetar as redes estudadas, medimos a fração de nós presentes na maior componente da rede e a sua eficiência global, que é uma medida proporcional a soma do inverso das menores distâncias entre todos os pares de nós da rede e mede o quão eficiente é a troca de informações nela (47), e analisamos como esses dois indicadores decaem com a porcentagem de elementos removidos. É possível então avaliar como as divergências na classificação entre as medidas de centralidade de um nó ou ligação influenciam as diferentes redes estudadas.

\subsubsection{Ataques utilizando centralidades dos nós}

Neste tipo de ataque, utilizamos os valores fornecidos pelas medidas de centralidade para classificar os nós, e em seguida removê-los na ordem decrescente de importância. É essencial ressaltar que as centralidades foram calculadas apenas uma vez antes de qualquer remoção. Dessa forma, elas sempre usaram a estrutura inicial da rede para atribuir os valores aos nós. Esse tipo de ataque é chamado de simultaneous targeted attack em (78). As remoções dos nós ocorrem em passos de $5 \%$

Nas figuras de 4.33 a 4.38 apresentamos os resultados dos ataques realizados em cada uma das redes. Nos gráficos observamos que existe diversidade em como as medidas de centralidade afetam os sistemas estudados. Isso nos mostra que as diferenças na classificação dos nós são de fato significativas para as redes, logo a escolha de qual centralidade deve ser utilizada em 
um ataque, dependerá especificamente do sistema estudado e qual ideia de centralidade é mais relevante para entendê-lo.

Comparando os gráficos dos ataques para as redes também notamos que frequentemente as centralidades de grau, interposição e interposição baseada em caminhada aleatória estão entre as mais efetivas. Em contrapartida autovetor, proximidade e subgrafo geralmente estão entre as medidas com menor desempenho. Proximidade baseada em fluxo de corrente apresenta uma eficiência mediana, porém, para algumas redes seu desempenho está entre os três melhores.

Analisando os resultados dos ataques para cada medida e comparando com os valores obtidos para as correlações, observamos que existem diversas situações possíveis quanto a sua efetividade. Em alguns sistemas as centralidades correlacionadas apresentam comportamento similar, como exemplo, o par (interposição e sua variante baseada em caminhada aleatória) no caso da colaboração entre autores em redes complexas. Também existem observações em que as medidas correlacionadas apresentam comportamentos distintos, como no da dupla (autovetor e proximidade de fluxo de corrente) na rede de colaboradores em física de altas energias. A rede de livros de política demonstra uma situação peculiar, onde a eficiência dos ataques guiados pelas medidas de interposição baseada em caminhada aleatória e proximidade (correlacionadas), são semelhantes na maior parte das remoções, porém, quando a porcentagem de nós removidos encontra-se entre 20 e $30 \%$ do total, existe diferença nos resultados obtidos pelas duas medidas.

Quando analisamos os pares de medidas com os menores valores de correlação notamos, na maioria das vezes que os resultados dos ataques são distintos, como o par (interposição baseada em caminhada aleatória e autovetor) para a rede de distribuição de energia ou a dupla (proximidade e interposição) no caso da rede de autores em física de altas energias.

Comparando os resultados, tanto para o decréscimo da maior componente quanto da eficiência da rede, notamos que nos dois casos o desempenho das medidas de centralidade são parecidas, ou seja, pares com comportamento semelhantes ou distintos em um dos tipos de ataque também o são no outro. 

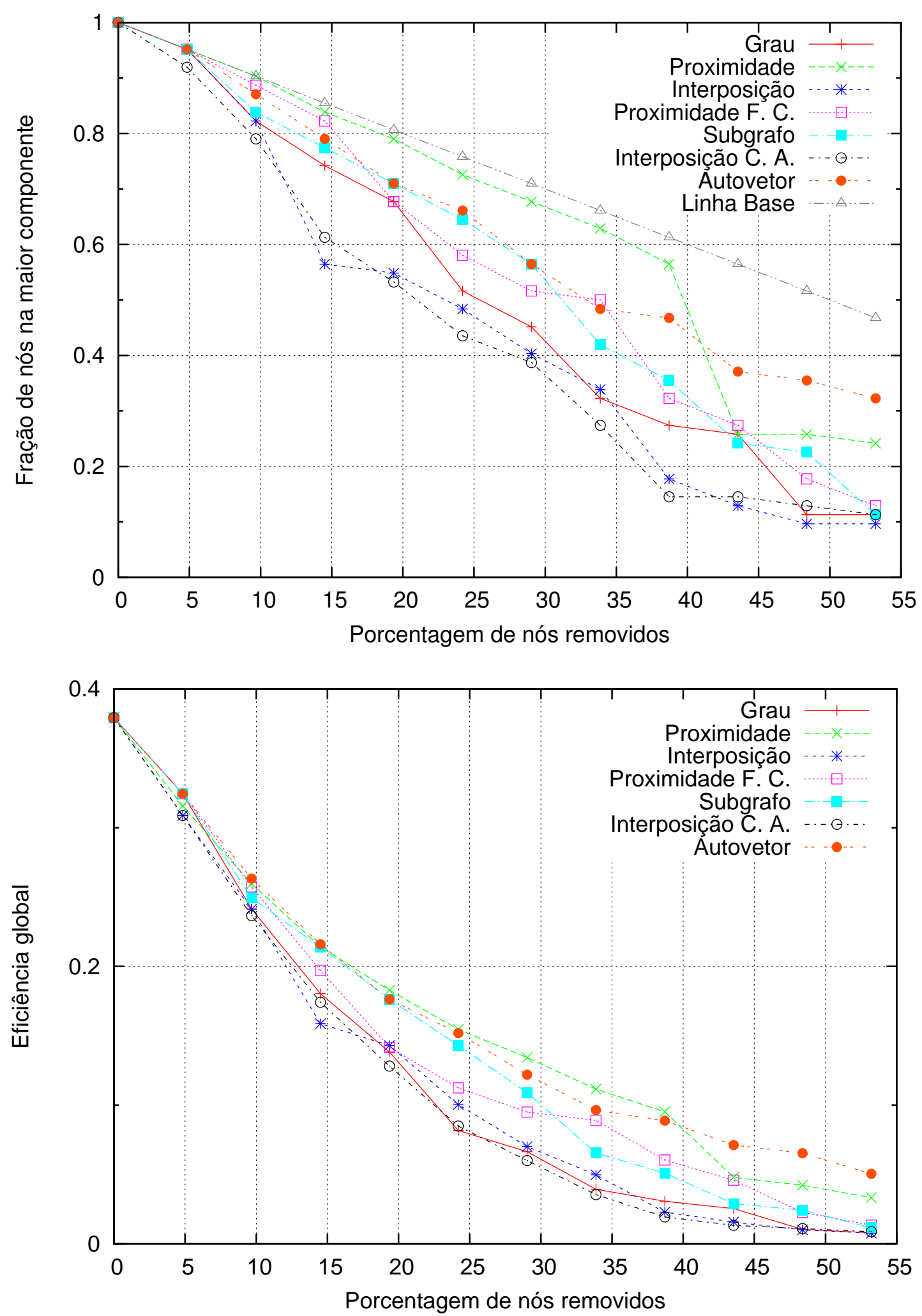

Figura 4.33 - Ataques realizados na rede golfinhos. Os gráficos mostram como o tamanho da maior componente e eficiência da rede decaem com a remoção de seus nós para as diferentes medidas de centralidade consideradas. Fonte: Elaborada pelo autor. 

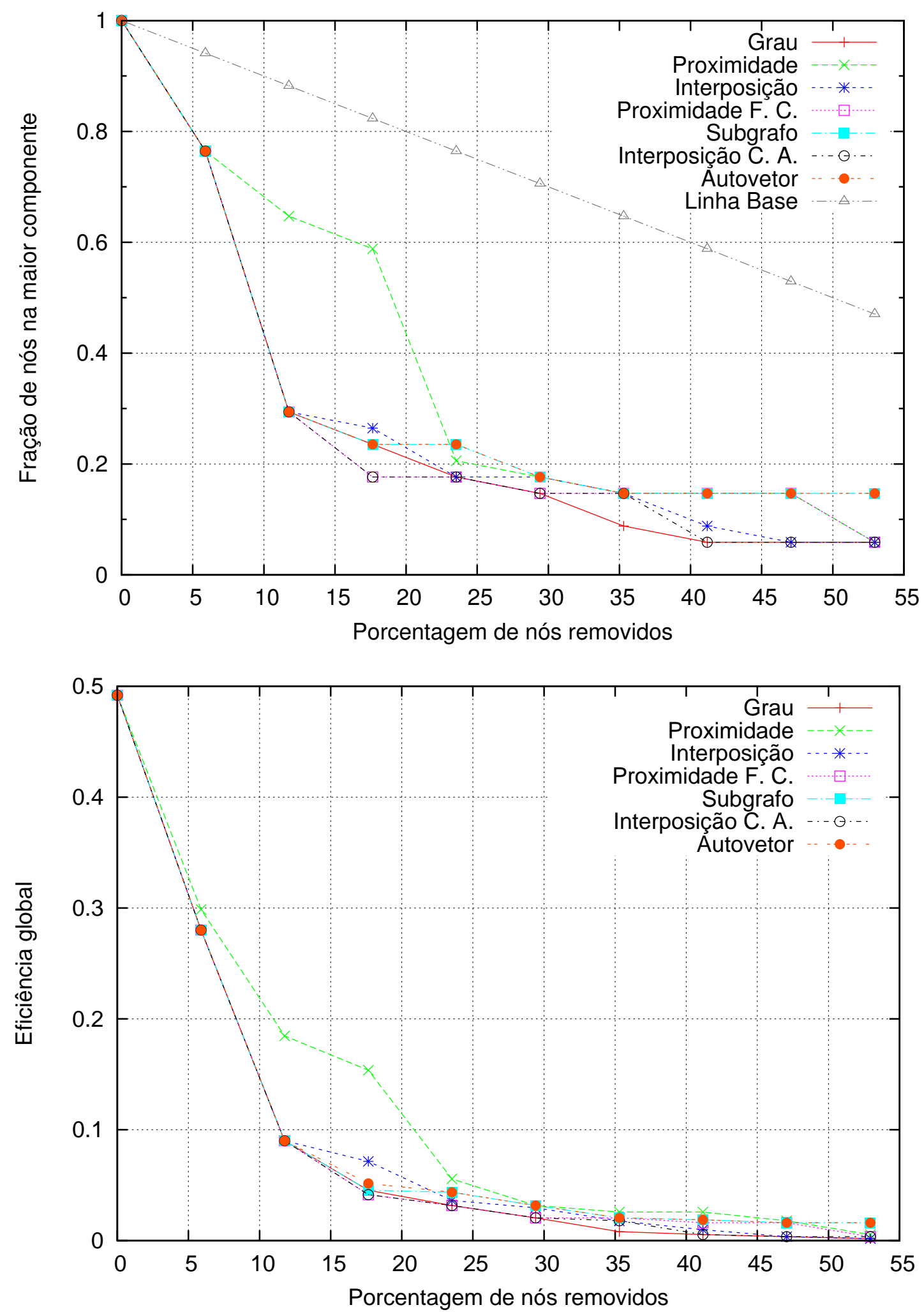

Figura 4.34 - Ataques realizados na rede do clube de caratê. Os gráficos mostram como o tamanho da maior componente e eficiência da rede decaem com a remoção de seus nós para as diferentes medidas de centralidade consideradas. Fonte: Elaborada pelo autor. 

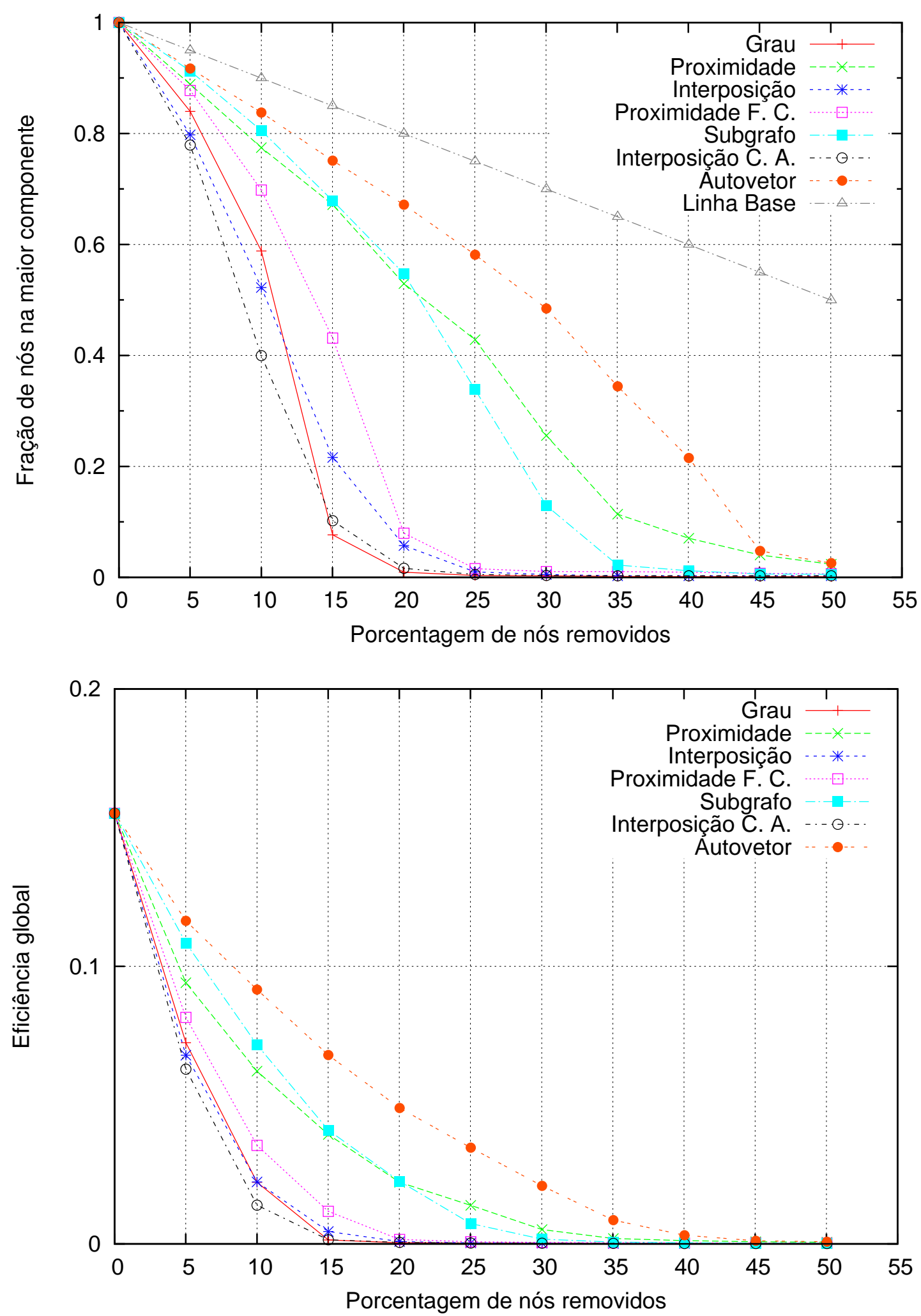

Figura 4.35 - Ataques realizados na rede de colaboradores em física de altas energias. Os gráficos mostram como o tamanho da maior componente e eficiência da rede decaem com a remoção de seus nós para as diferentes medidas de centralidade consideradas. Fonte: Elaborada pelo autor. 

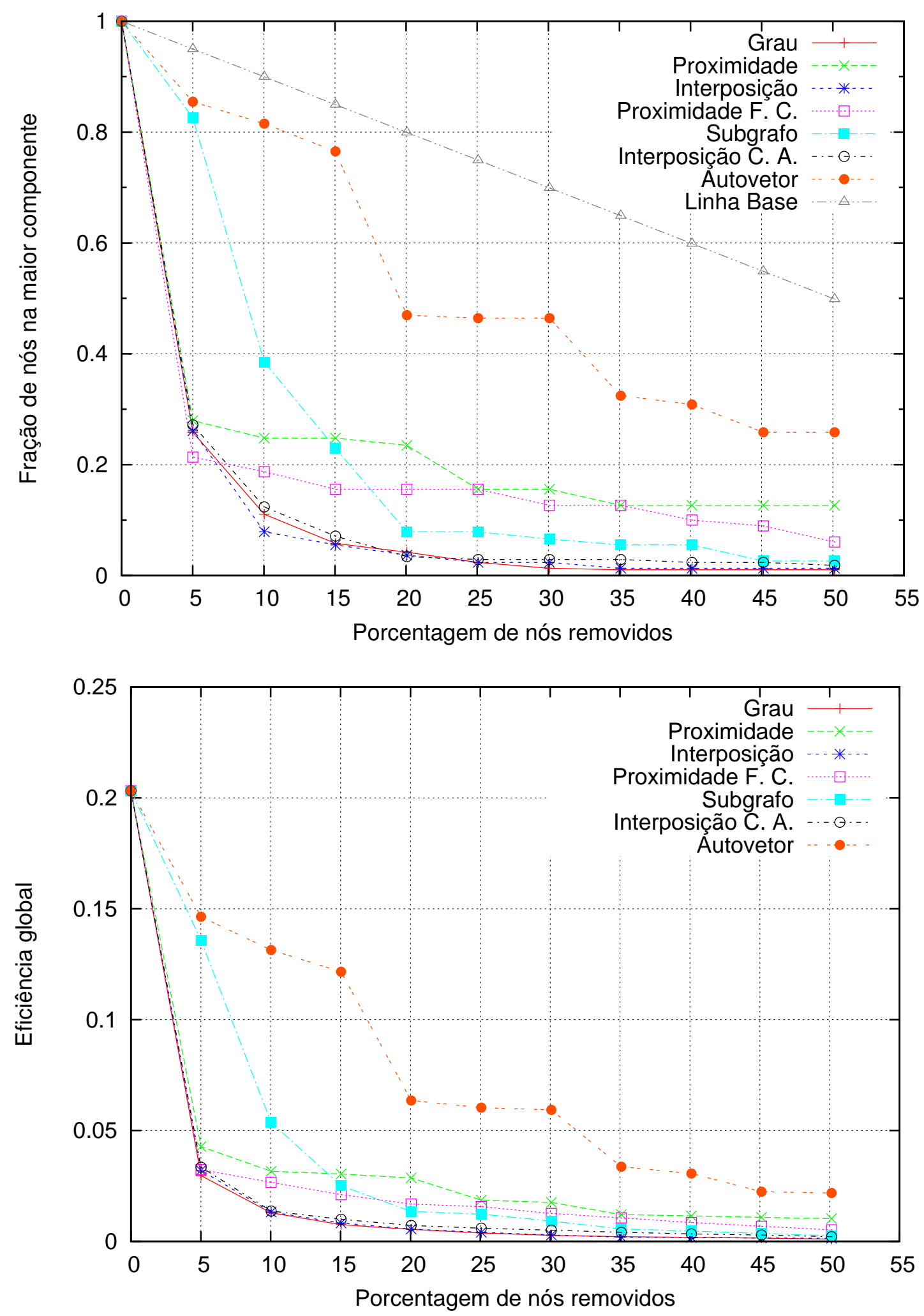

Figura 4.36 - Ataques realizados na rede de colaboradores em redes complexas. Os gráficos mostram como o tamanho da maior componente e eficiência da rede decaem com a remoção de seus nós para as diferentes medidas de centralidade consideradas. Fonte: Elaborada pelo autor. 

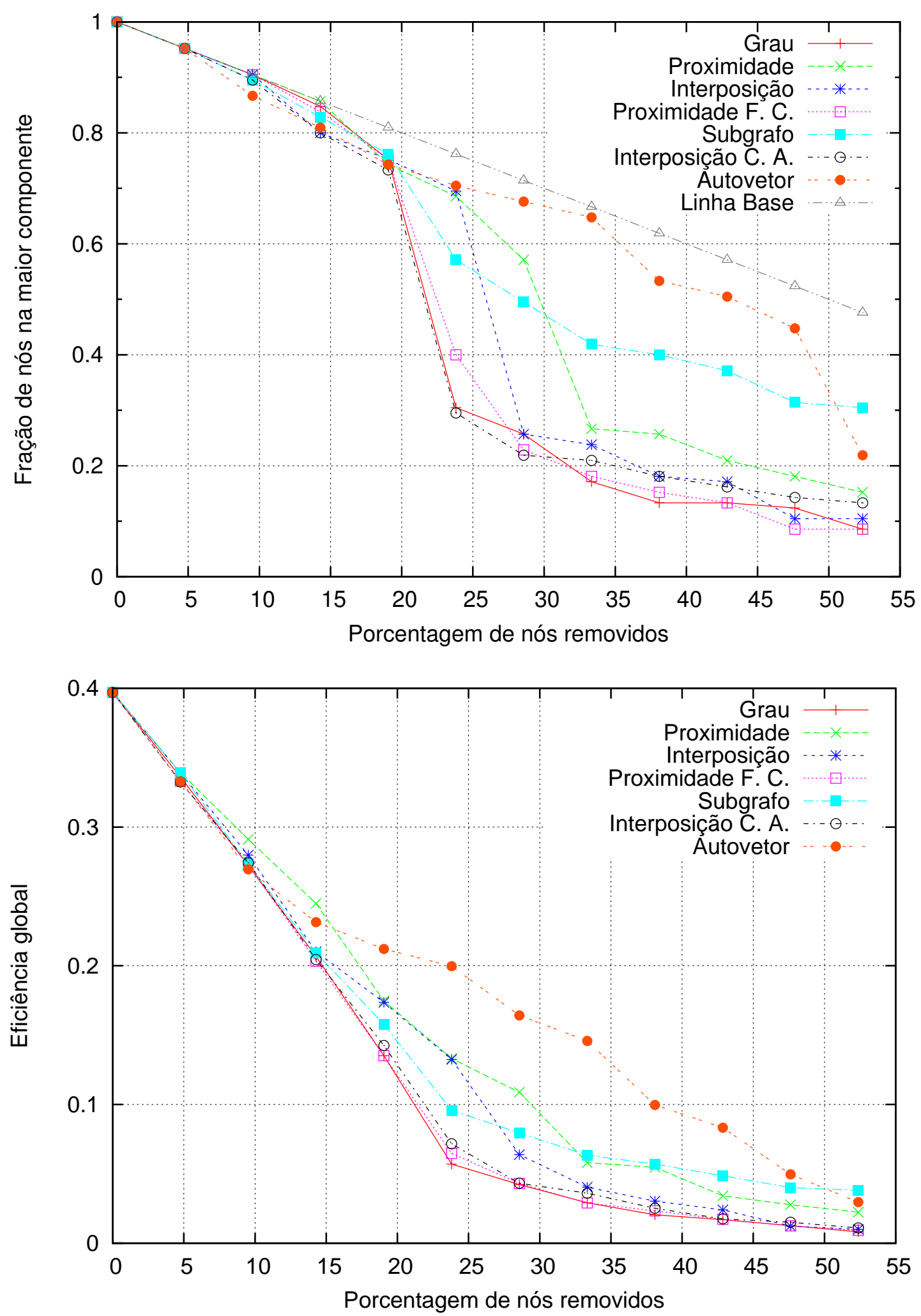

Figura 4.37 - Ataques realizados na rede dos livros sobre política. Os gráficos mostram como o tamanho da maior componente e eficiência da rede decaem com a remoção de seus nós para as diferentes medidas de centralidade consideradas. Fonte: Elaborada pelo autor. 

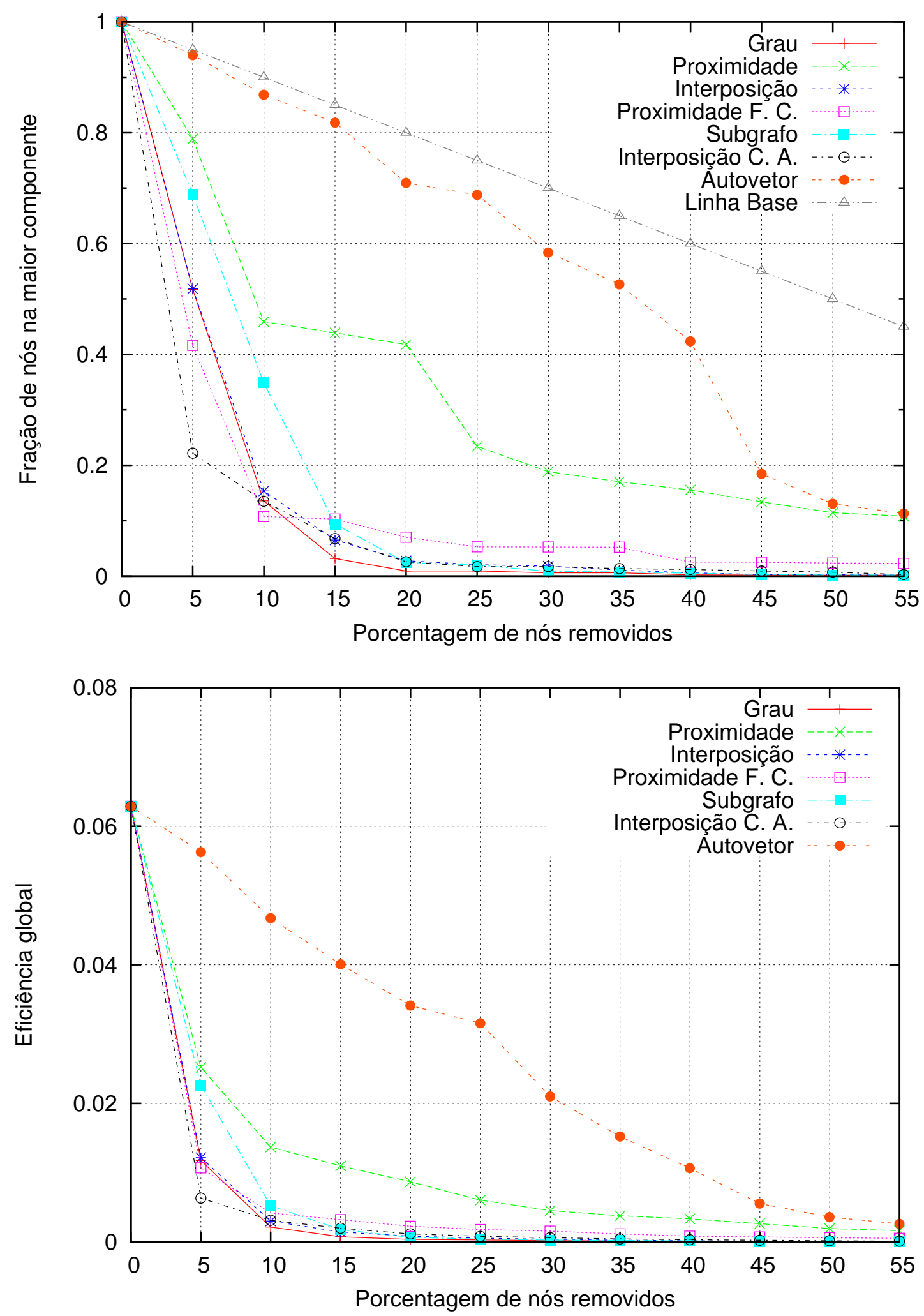

Figura 4.38 - Ataques realizados na rede de distribuição de energia. Os gráficos mostram como o tamanho da maior componente e eficiência da rede decaem com a remoção de seus nós para as diferentes medidas de centralidade consideradas. Fonte: Elaborada pelo autor. 


\subsubsection{Ataques utilizando centralidades das ligações}

As figuras de 4.39 a 4.44, mostram os resultados para os ataques das ligações das redes. De maneira semelhante aos ataques dos nós, para cada sistema, removemos as ligações e medimos como o tamanho da maior componente e a eficiência da rede diminuem. As ligações também foram removidas em passos de 5\%, e a sequência de remoção seguiu a ordem decrescente de importância fornecida pelas centralidades de ligação. Neste estudo, como nos demais, consideramos tanto as medidas originalmente definidas para ligações quanto as derivadas.

Dos gráficos dos ataques, observamos que as diferentes métricas apresentam desempenhos distintos, e que mesmo as centralidades de ligação derivadas das dos nós, demonstram resultados significativos, como as medidas derivadas de interposição e sua variante baseada em caminhada aleatória.

Também notamos que frequentemente as centralidades que não são derivadas apresentam melhor desempenho no decréscimo da maior componente e eficiência das redes, principalmente quando apenas uma pequena fração das ligações foi removida. As centralidades de ligação derivadas de medidas que são privilegiadas pelo número de conexões dos nós, como por exemplo grau e subgrafo, precisam que uma grande quantidade das ligações sejam removidas, para que o tamanho da maior componente diminua significativamente, além disso, essas medidas apresentam reduções lentas na eficiência das redes. Acreditamos que os fatos acima acontecem devido a quantidade de ligações, que conectam os nós com grande número de vizinhos, e por isso recebem valores elevados para estas centralidades derivadas, já que existe chance dos elementos com muitas conexões estarem relacionados com os outros, por diferentes caminhos. Assim, precisamos remover muitas ligações para que a rede se divida em mais de uma componente; já a eficiência diminui lentamente desde o início, pois as remoções dessas ligações aumentam os menores caminhos entre os nós.

Comparando os resultados dos ataques das conexões com os coeficientes de correlação entre os pares de centralidades das ligações, observamos que existem casos em que as medidas que estão correlacionadas apresentam a mesma eficiência nos ataques, como na rede dos livros de política onde as medidas com os quatro resultados mais semelhantes demonstram praticamente o mesmo desempenho, ou ainda, na rede de distribuição de energia para o par (interposição e interposição de ligação). A situação oposta também ocorreu: as medidas de interposição de ligação e sua variante baseada em caminhada aleatória, estão entre as mais correlacionadas para a rede dos golfinhos, entretanto sua efetividade nos ataques é bastante diferente. Os pares das centralidades que apresentaram os menores coeficientes de Pearson 
exibiram desempenhos distintos, o que indica que quanto menor a correlação, maior a diferença na maneira como as ligações selecionadas por ela afetam a rede.

Comparando os dois tipos de ataques realizados e os resultados apresentados pelas diversas centralidades, notamos que a performance das medidas é similar e que eles comportam-se da mesma maneira tanto no caso da eficiência quanto na redução da maior componente. 

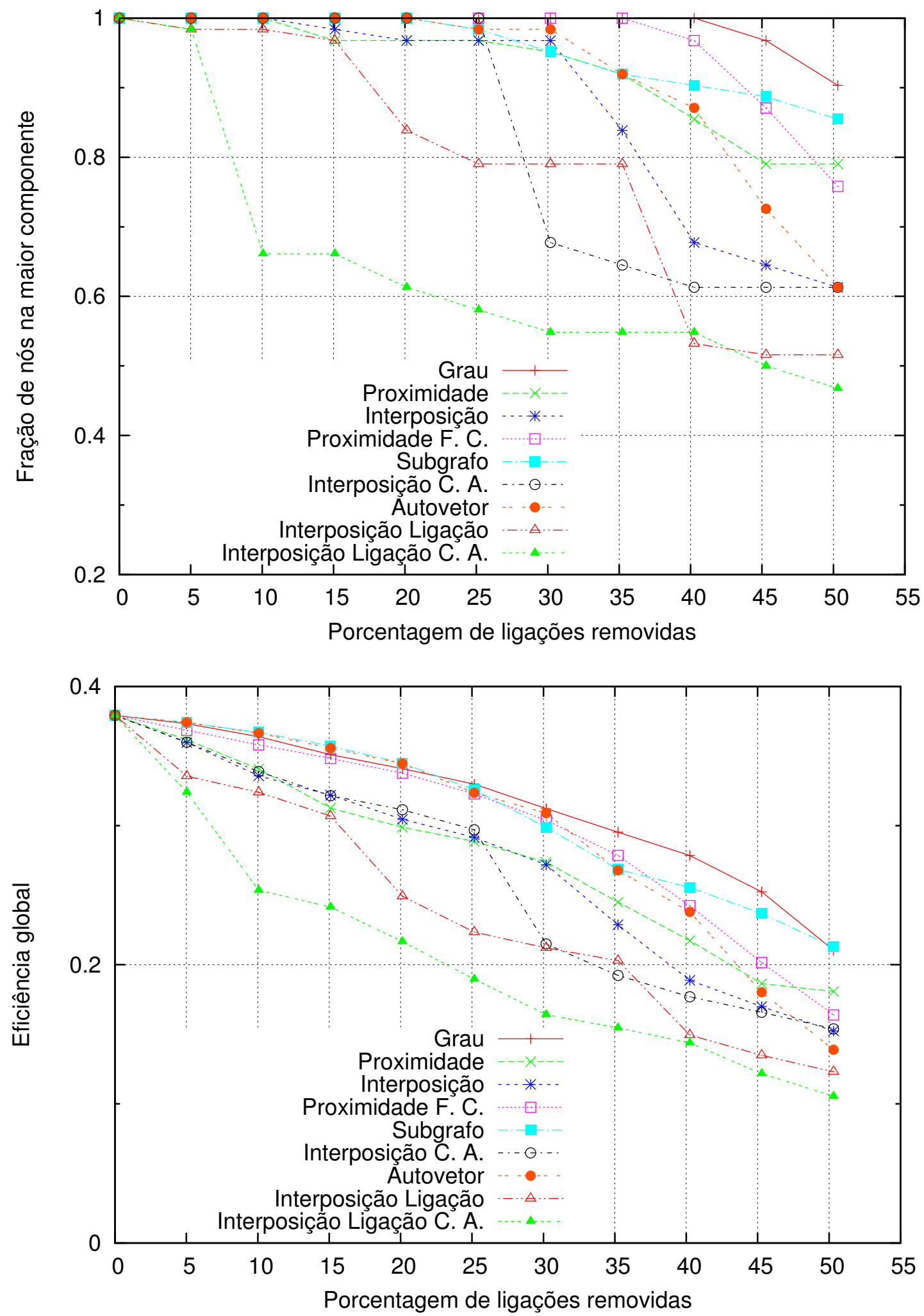

Figura 4.39 - Ataques realizados na rede golfinhos. Os gráficos mostram como o tamanho da maior componente e eficiência da rede decaem com a remoção de suas ligações para as diferentes medidas de centralidade consideradas. Fonte: Elaborada pelo autor. 

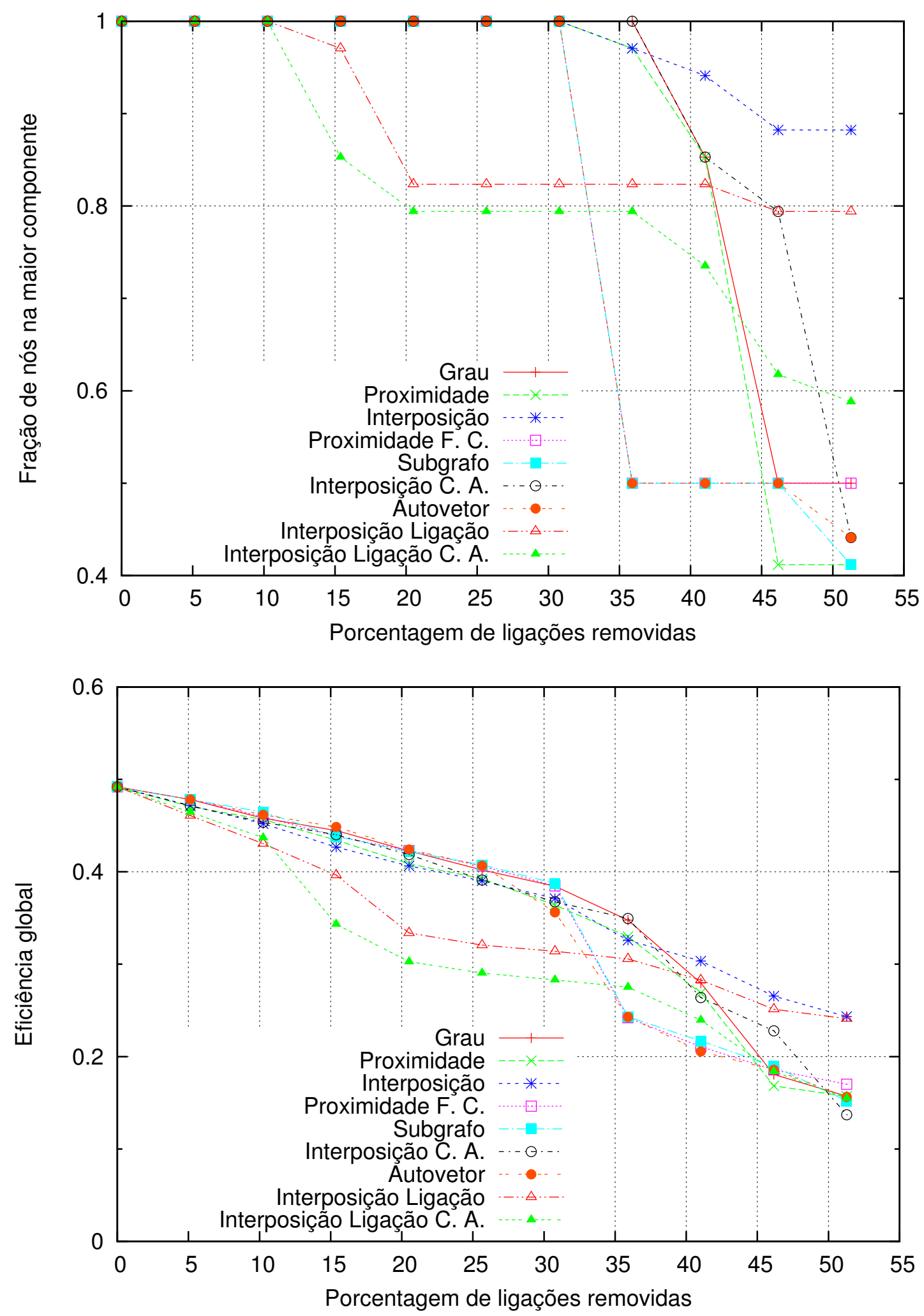

Figura 4.40 - Ataques realizados na rede do clube de caratê. Os gráficos mostram como o tamanho da maior componente e eficiência da rede decaem com a remoção de suas ligações para as diferentes medidas de centralidade consideradas. Fonte: Elaborada pelo autor. 

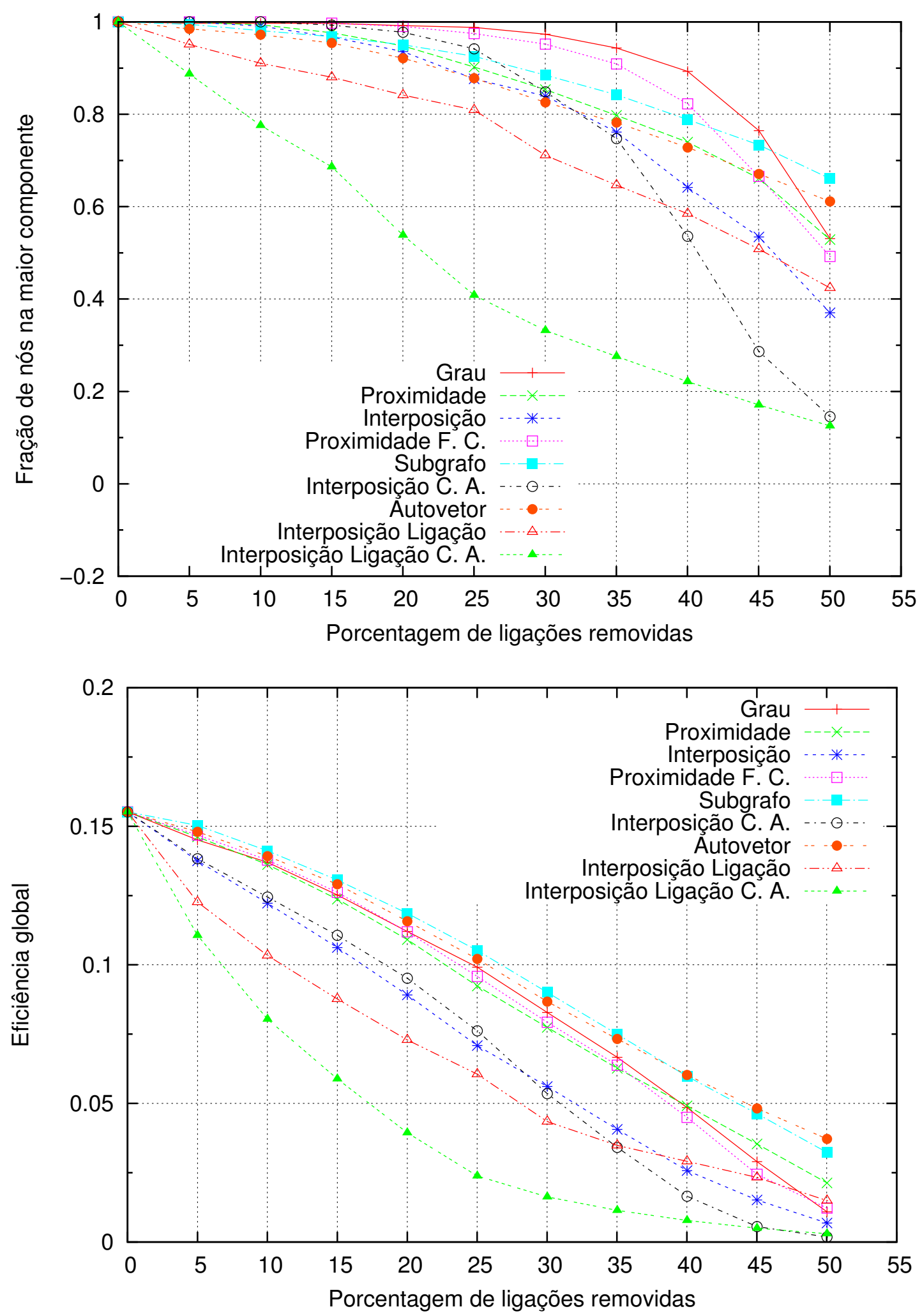

Figura 4.41 - Ataques realizados na rede de colaboradores em física de altas energias. Os gráficos mostram como o tamanho da maior componente e eficiência da rede decaem com a remoção de suas ligações para as diferentes medidas de centralidade consideradas. Fonte: Elaborada pelo autor. 

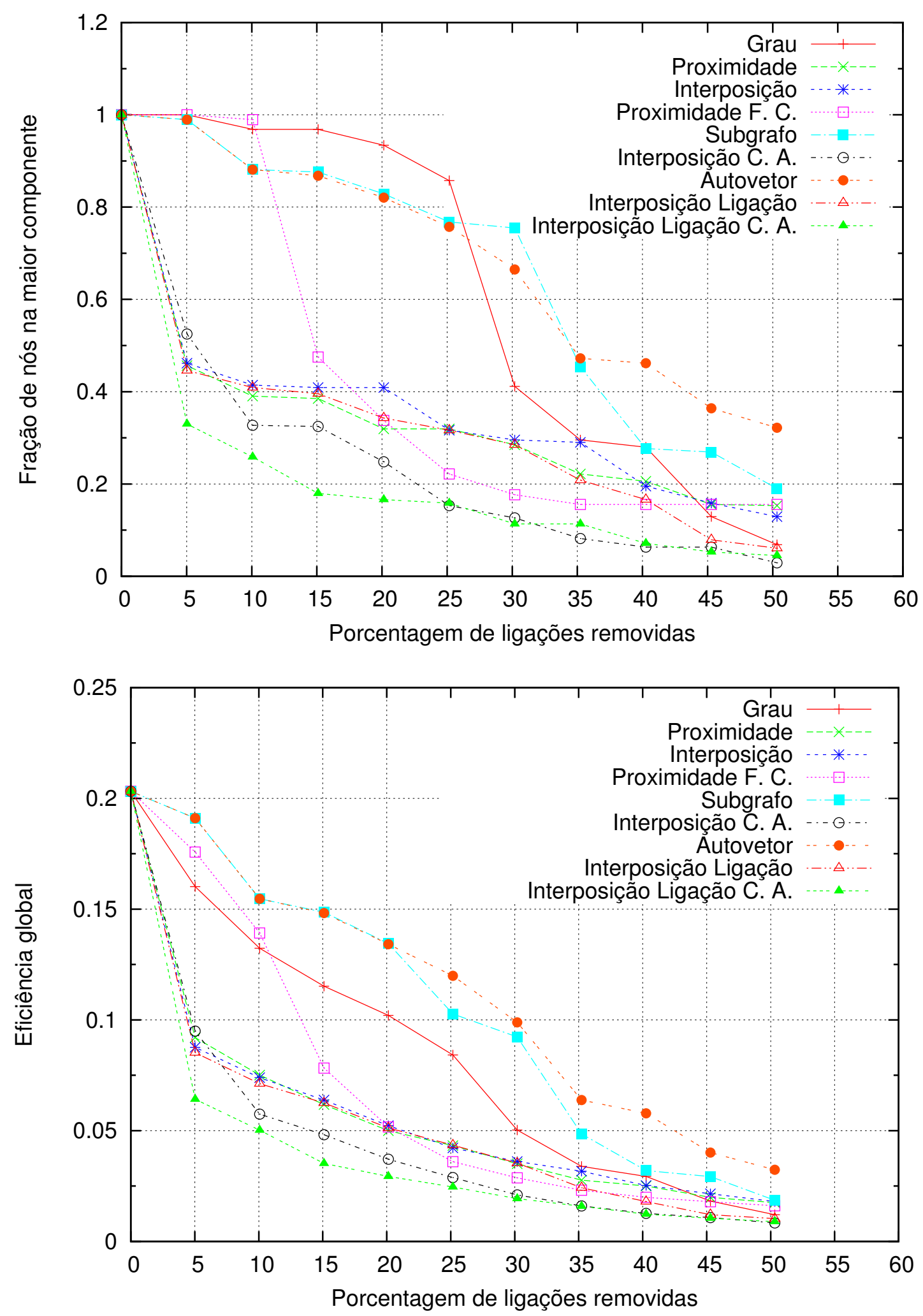

Figura 4.42 - Ataques realizados na rede de colaboradores em redes complexas. Os gráficos mostram como o tamanho da maior componente e eficiência da rede decaem com a remoção de suas ligações para as diferentes medidas de centralidade consideradas. Fonte: Elaborada pelo autor. 

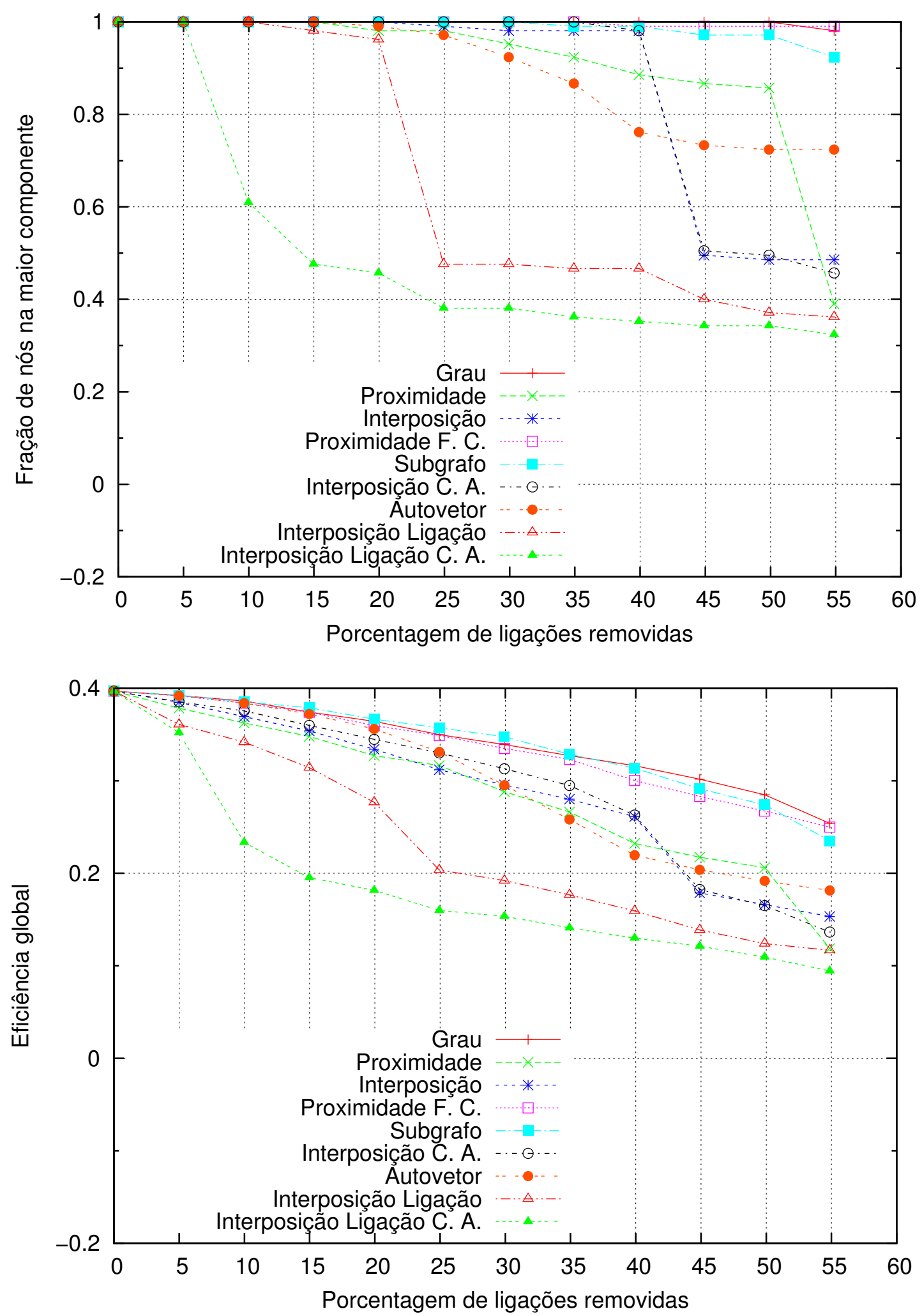

Figura 4.43 - Ataques realizados na rede dos livros sobre política. Os gráficos mostram como o tamanho da maior componente e eficiência da rede decaem com a remoção de suas ligações para as diferentes medidas de centralidade consideradas. Fonte: Elaborada pelo autor. 

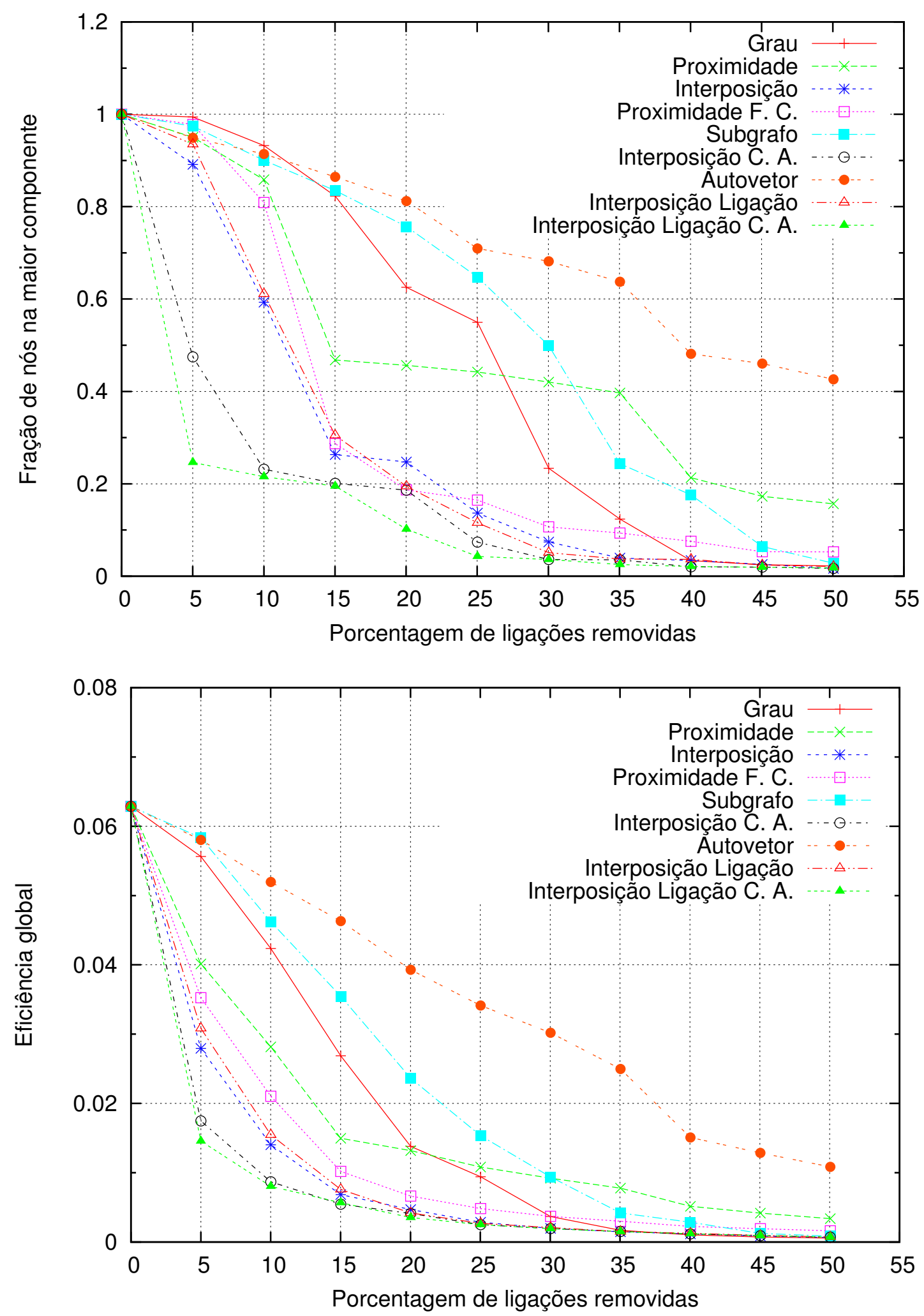

Figura 4.44 - Ataques realizados na rede de distribuição de energia. Os gráficos mostram como o tamanho da maior componente e eficiência da rede decaem com a remoção de suas ligações para as diferentes medidas de centralidade consideradas. Fonte: Elaborada pelo autor. 


\subsection{Caracterização de redes usando centralidades}

As medidas de centralidade refletem as características estruturais das redes complexas. Os resultados da seção 4.2 mostram que as correlações entre os pares de medidas mudam de um sistema para outro e não seguem um padrão. Será que esta diferença entre os resultados é suficiente para caracterizar as diversas redes? Estudamos se os valores dos coeficientes de Pearson entre os pares de centralidades pode ser utilizados como características das redes para diferenciá-las. Para isso realizamos uma análise de componentes principais (79) nos valores das correlações para as redes consideradas.

A análise de componentes principais é um método de redução de dimensionalidade, que mantém a maior variação possível no conjunto de medidas (neste caso as correlações entre as medidas de centralidade) obtidas para caracterizar um grupo de elementos. A ideia principal deste método é realizar uma rotação na base que em as medidas são obtidas, visando maximizar a variância e ao mesmo tempo reduzir a redundância (covariância) dos dados experimentais obtidos. Como a nova base que maximiza a variância das medidas é escrita como uma combinação linear da base original em que os dados foram obtidos, este método assume que exista linearidade entre as relações das medidas. Dessa forma, procuramos expressar nossos dados em uma nova base $\mathbf{Y}$ tal que as condições acima sejam satisfeitas. Essa rotação no sistema de coordenadas pode então ser escrita como:

$$
\mathbf{P X}=\mathbf{Y}
$$

onde $\mathrm{X}$ é o sistema de coordenadas original em que as medidas foram expressas, $\mathrm{Y}$ é o novo sistema que maximiza a variância, e $\mathbf{P}$ é a matriz de rotação.

A matriz de covariância é a matriz que mede o quão linearmente correlacionadas estão duas medidas; sua diagonal é composta pela variância de cada medida e os elementos fora da diagonal representam a covariância entre todos pares de medidas considerados. A matriz de covariância das medidas representadas por $\mathbf{X}$ (onde as linhas contém as medidas consideradas e as colunas são os dados de cada amostra) pode ser escrita como:

$$
\mathbf{C}(\mathbf{X})=\frac{1}{n-1} \mathbf{X X}^{\mathbf{T}}
$$

onde o $\mathbf{X}$ da equação (4.4.2) é o mesmo presente na equação (4.4.1). Podemos escrever uma expressão semelhante para o sistema de coordenadas $\mathbf{Y}$ : 


$$
\mathbf{C}(\mathbf{Y})=\frac{1}{n-1} \mathbf{Y Y}^{\mathbf{T}}
$$

Utilizando então a equação (4.4.1) na (4.4.3), obtemos a seguinte expressão para a matriz de covariância de $\mathbf{Y}$ :

$$
\mathbf{C}(\mathbf{Y})=\frac{1}{n-1} \mathbf{P Z P}^{\mathbf{T}}
$$

onde $\mathbf{Z}=\mathbf{X} \mathbf{X}^{\mathbf{T}}$, assim se diagonalizando-se a matriz $\mathbf{Z}$ encontramos o novo sistema de coordenadas que maximiza a variância entre as medidas ao mesmo tempo que reduz a redundância entre elas. Após a diagonalização da matriz $\mathbf{Z}$, os autovetores associados aos maiores autovalores são os que contém a melhor projeção dos dados.

\subsubsection{Análise de componentes principais utilizando centralidades dos nós}

Para verificar se é possível identificar as redes utilizando suas medidas de centralidade, realizamos uma análise de componentes principais das correlações entre elas. Consideramos todas as redes reais e algumas geradas pelos modelos de Barabási-Albert e Erdős-Rényi, e as correlações entre as medidas de seus nós.

A figura 4.45, mostra o resultado da análise das componentes principais. Notamos que, com exceção da rede do clube de caratê próxima das redes geradas com o modelo de ErdősRényi, as reais ficaram bastante espalhadas e distantes daquelas geradas pelos modelos, assim elas poderiam ser identificadas utilizando-se a análise de componentes principais. Outro ponto interessante é que as redes que geramos utilizando modelos distintos ficaram aglomeradas em regiões diferentes do espaço, e é clara a diferença entre os dois modelos.

Como os resultados obtidos indicam que podemos utilizar as correlações entre as medidas de centralidade das redes para caracterizá-las, realizamos uma segunda análise comparando cada sistema real com redes similares que possuem aproximadamente o mesmo número de nós e grau médio geradas, utilizando-se os modelos de Erdős-Rényi e Barabási-Albert. Nesta análise, incluímos também redes criadas através de um processo de reconexão (chamado de rewiring) da rede original (39). Nele, as ligações entre os nós da rede real são refeitas aleatoriamente, de modo que o grau de cada um deles não seja alterado.

Nas figuras de 4.46 a 4.51 apresentamos os resultados. Com exceção da rede do clube 


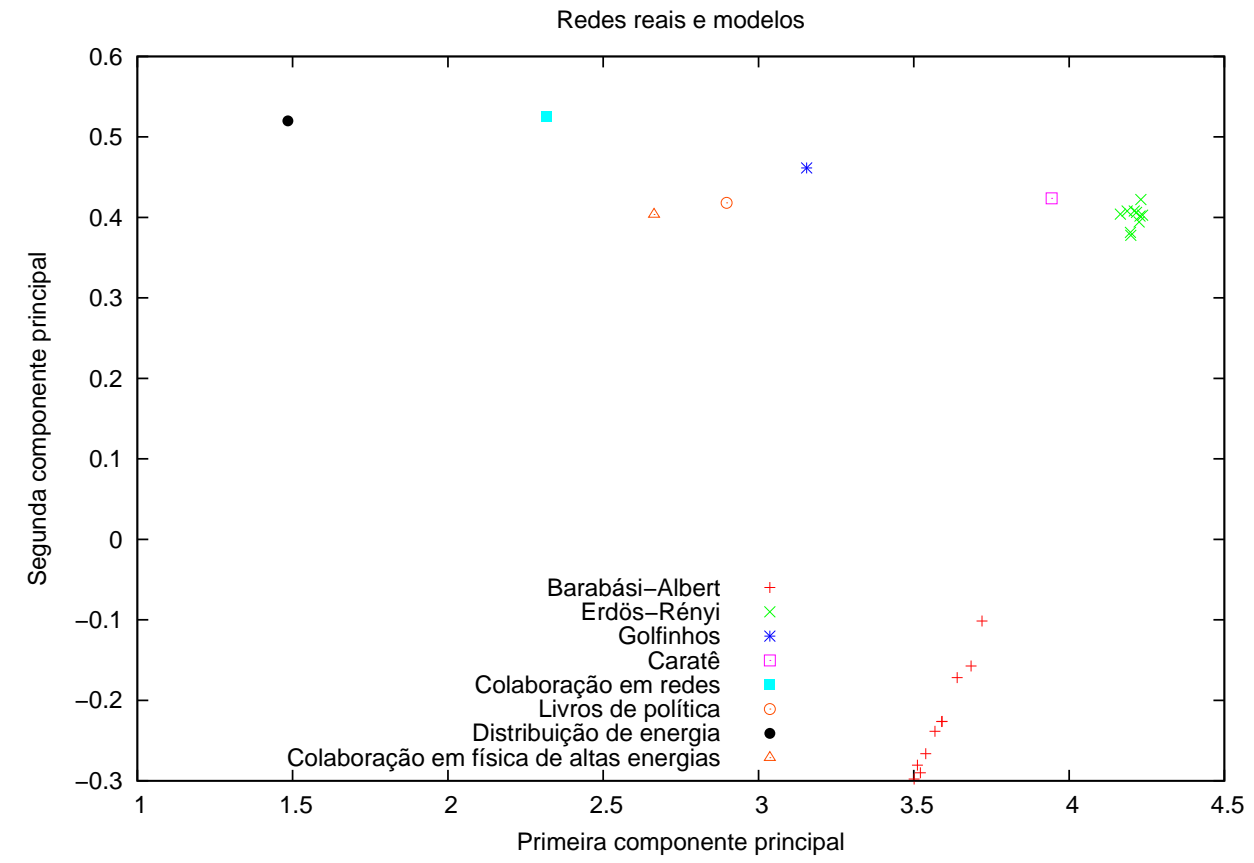

Figura 4.45 - Projeção das redes reais e modelos nas duas componentes principais mais significativas. Notamos que a maioria das redes reais pôde ser diferenciada dos modelos. Fonte: Elaborada pelo autor.

de caratê, todas as redes reais foram separadas dos modelos, confirmando a hipótese de que as correlações entre medidas de centralidade podem ser utilizadas como uma espécie de assinatura. No caso específico da rede do clube de caratê, também tentamos uma projeção em 3 componentes principais, mas mesmo assim não foi possível diferenciá-la. Os modelos de reconexão sempre ficam próximos de um dos outros modelos, o que nos indica que existem padrões importantes presentes nas ligações entre os nós das redes reais que não são totalmente representados por nenhum dos modelos considerados. 


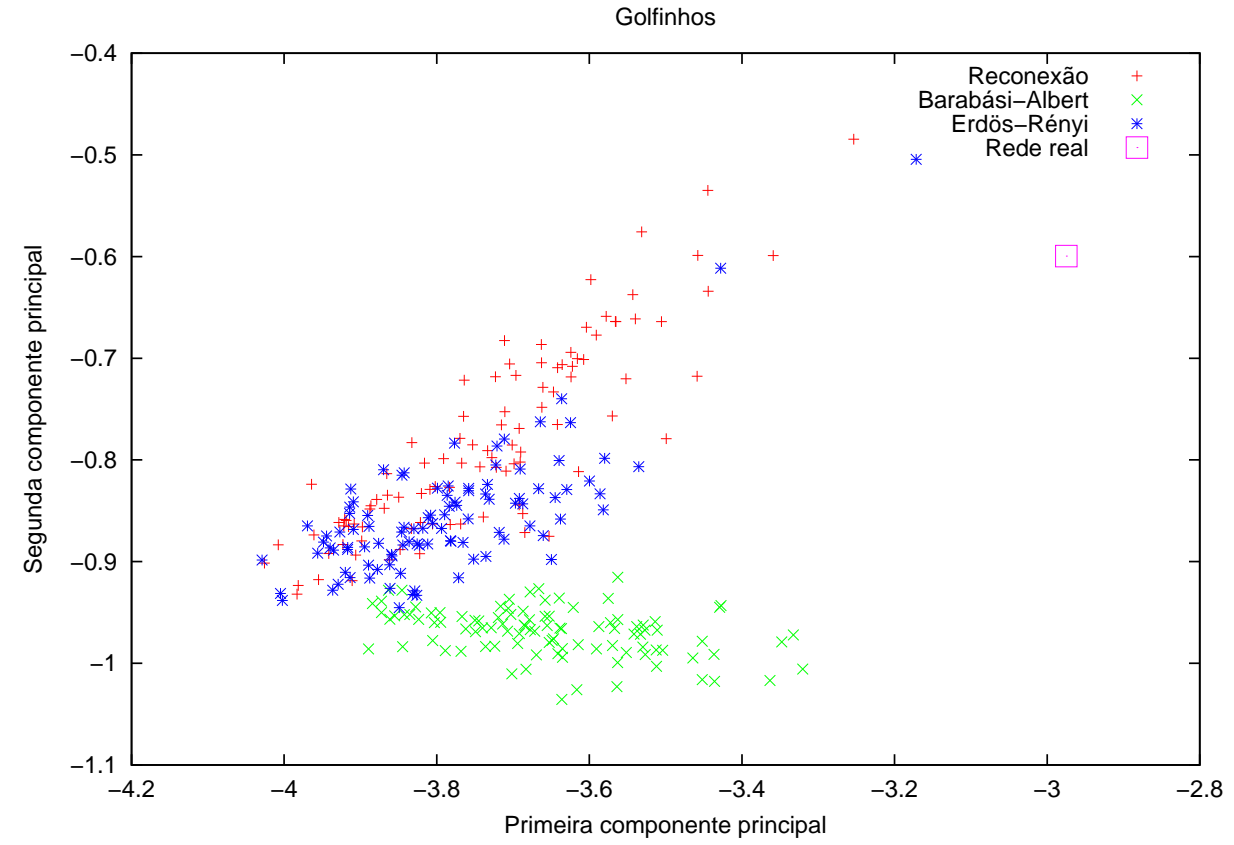

Figura 4.46 - Projeção das correlações entre os pares das medidas de centralidade dos nós da rede dos golfinhos nas duas componentes principais. Nesta figura também mostramos as projeções de redes geradas pelos modelos de Erdős-Rényi, Barabási-Albert e reconexão, utilizando características da rede real. Fonte: Elaborada pelo autor.

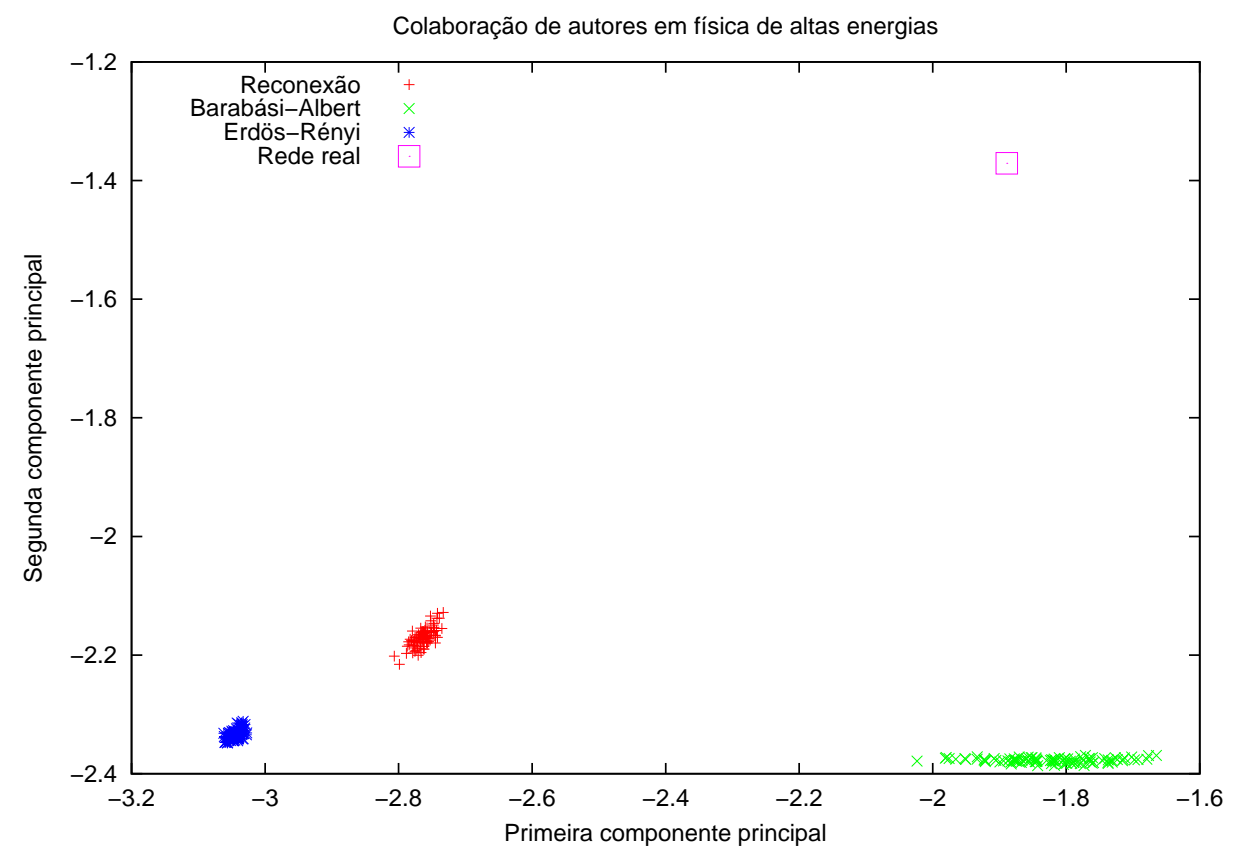

Figura 4.47 - Projeção das correlações entre os pares das medidas de centralidade dos nós da rede de colaboração em física de altas energias nas duas componentes principais. Nesta figura também mostramos as projeções de redes geradas pelos modelos de ErdősRényi, Barabási-Albert e reconexão, utilizando características da rede real. Fonte: Elaborada pelo autor. 


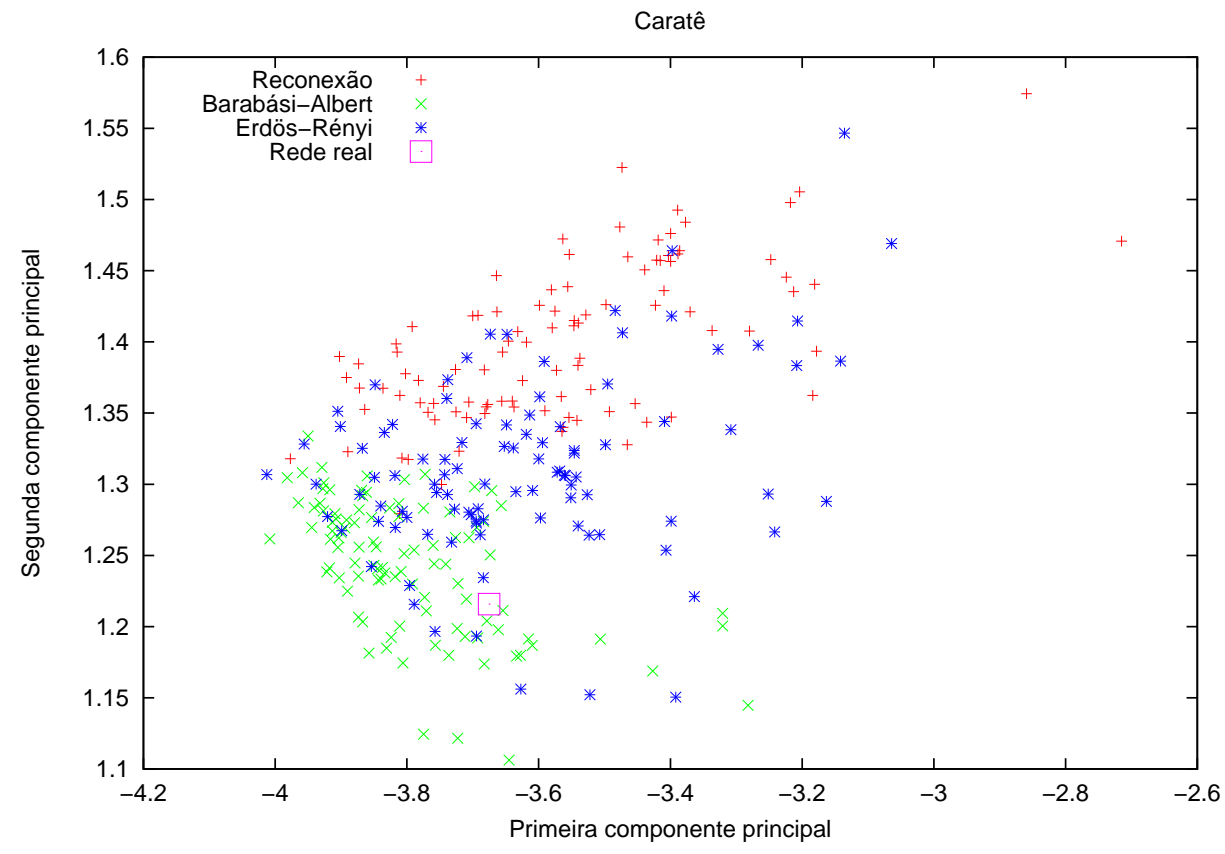

Figura 4.48 - Projeção das correlações entre os pares das medidas de centralidade dos nós da rede do clube de caratê nas duas componentes principais. Nesta figura também mostramos as projeções de redes geradas pelos modelos de Erdôs-Rényi, Barabási-Albert e reconexão, utilizando características da rede real. Fonte: Elaborada pelo autor.

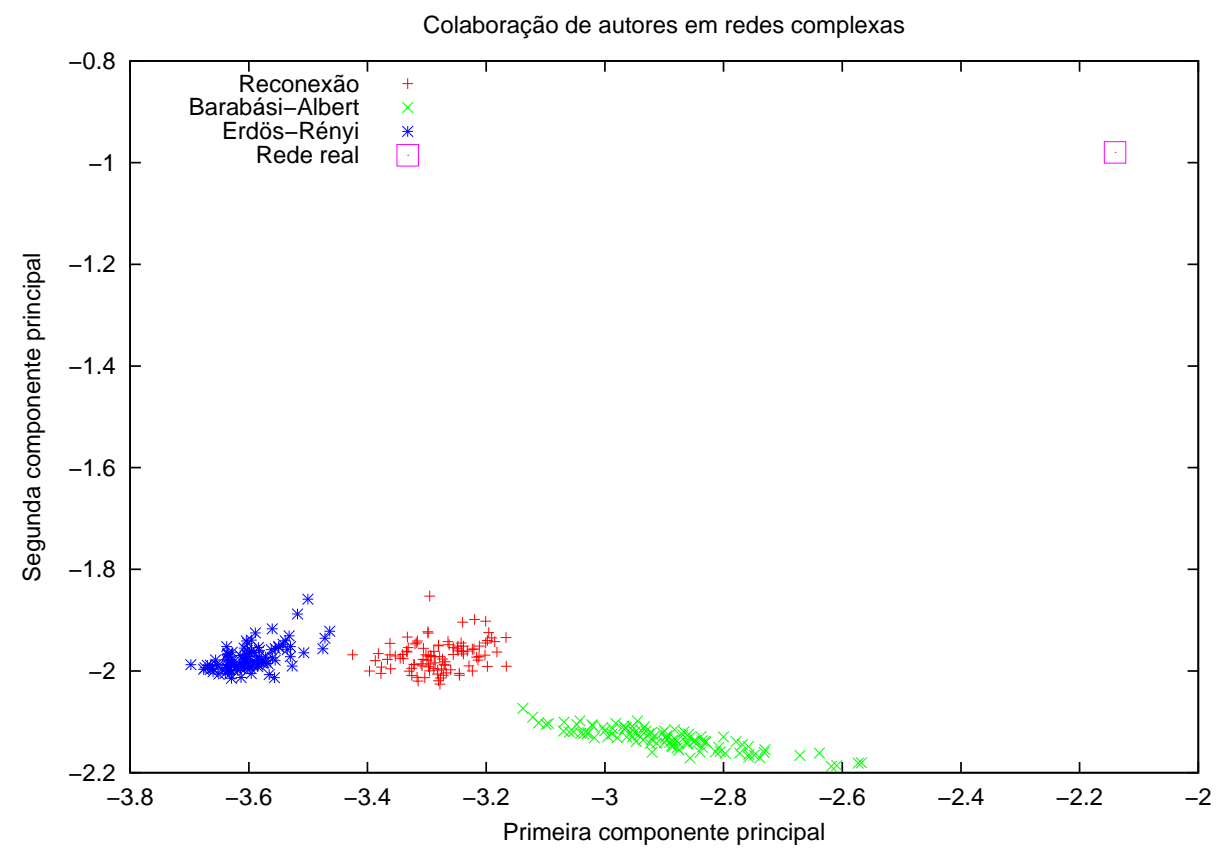

Figura 4.49 - Projeção das correlações entre os pares das medidas de centralidade dos nós da rede de colaboração entre autores de redes complexas nas duas componentes principais. Nesta figura também mostramos as projeções de redes geradas pelos modelos de Erdôs-Rényi, Barabási-Albert e reconexão, utilizando características da rede real. Fonte: Elaborada pelo autor. 


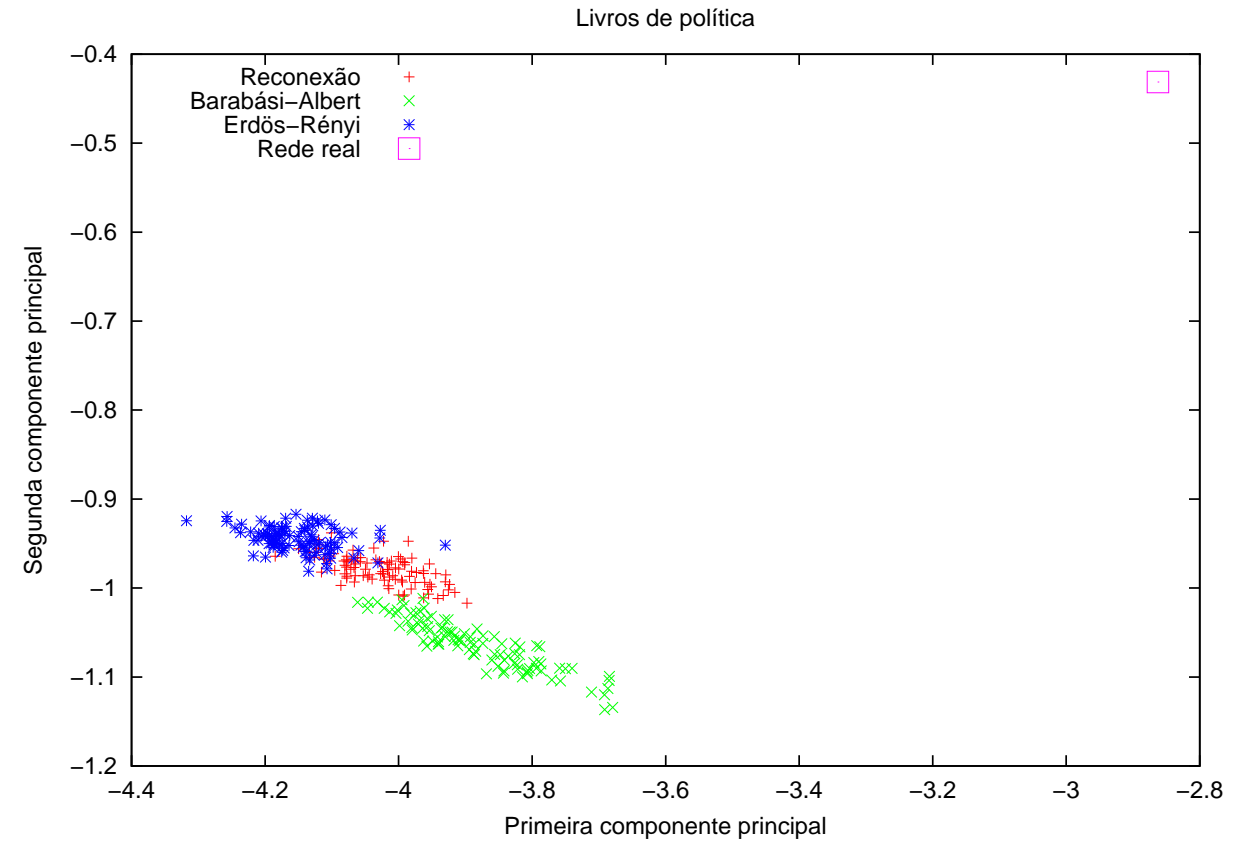

Figura 4.50 - Projeção das correlações entre os pares das medidas de centralidade dos nós da rede de livros sobre política nas duas componentes principais. Nesta figura também mostramos as projeções de redes geradas pelos modelos de Erdős-Rényi, Barabási-Albert e reconexão, utilizando características da rede real. Fonte: Elaborada pelo autor.

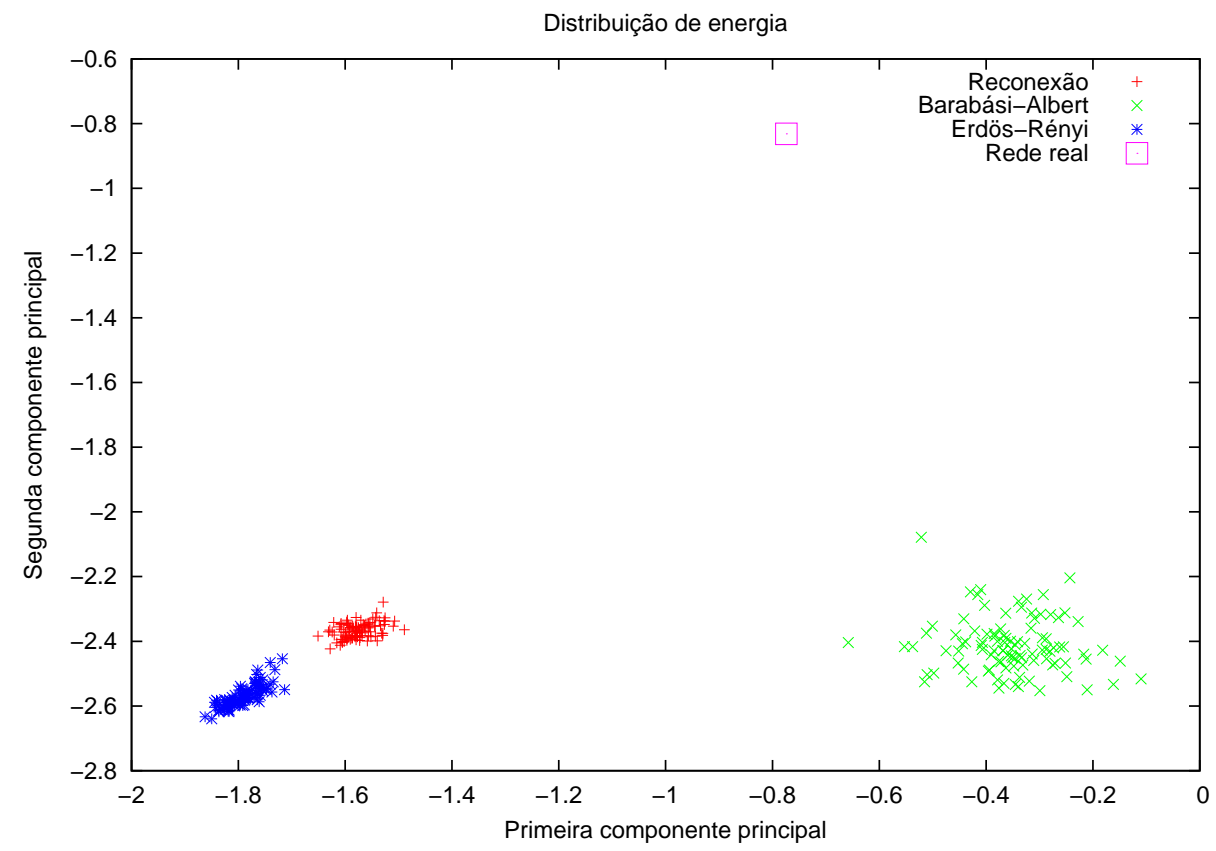

Figura 4.51 - Projeção das correlações entre os pares das medidas de centralidade dos nós da rede de distribuição de energia nas duas componentes principais. Nesta figura também mostramos as projeções de redes geradas pelos modelos de Erdős-Rényi, BarabásiAlbert e reconexão, utilizando características da rede real. Fonte: Elaborada pelo autor. 


\subsubsection{Análise de componentes principais utilizando centralidades de ligações}

Neste estudo, avaliamos a caracterização de redes utilizando as centralidades das ligações. Aqui, como nos experimentos anteriores, consideramos as medidas originalmente definidas para elas e as que são derivadas das dos nós da rede.

A figura 4.52 apresenta o resultado da análise de componentes principais utilizando as medidas de centralidade de ligação. Nela comparamos todas as redes reais e modelos. Observamos um resultado parecido ao obtido para as centralidades de nós, onde todas as redes reais utilizadas foram diferenciadas com sucesso dos modelos, incluindo a rede do clube de caratê, que não havia sido bem diferenciada pelas correlações de centralidades dos nós.

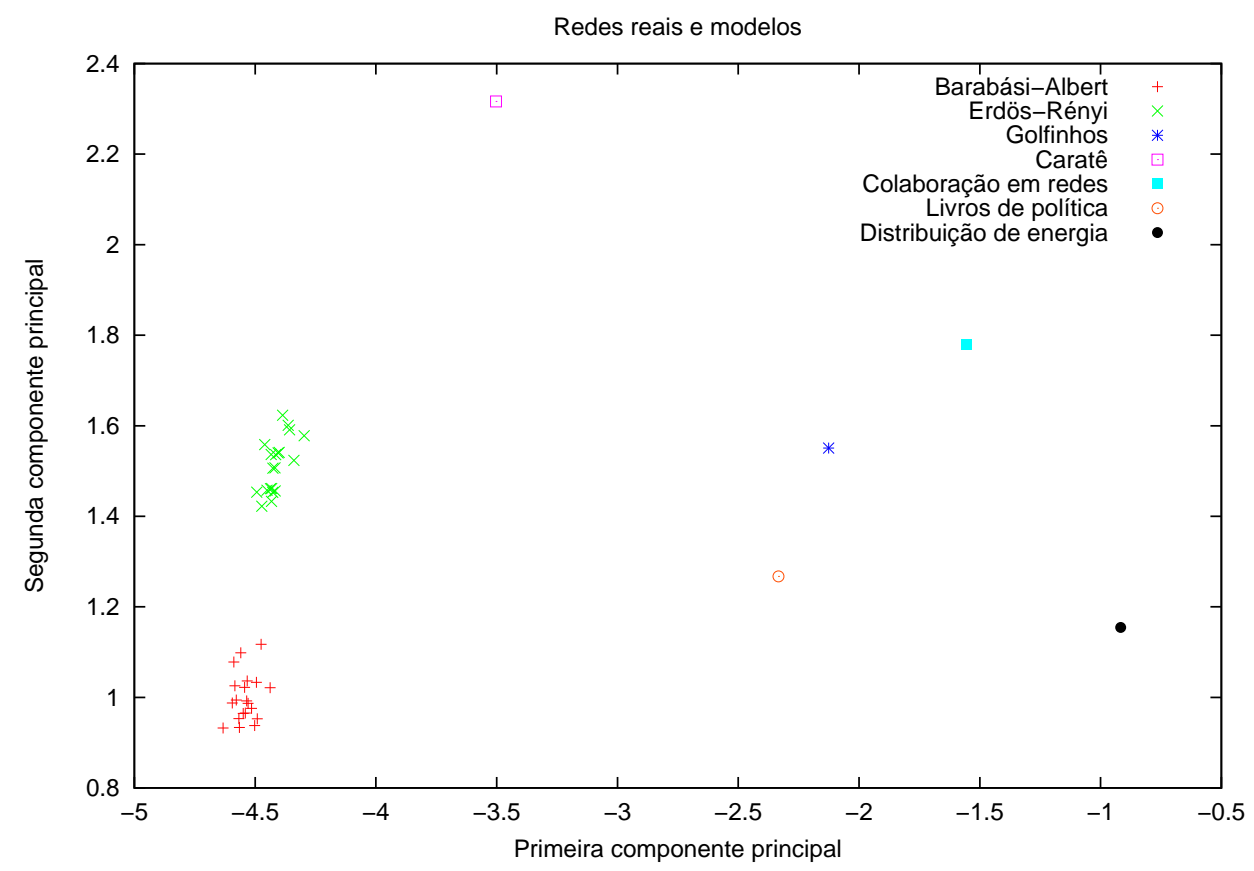

Figura 4.52 - Projeção das redes reais e modelos nas duas componentes principais mais significativas. Notamos que todas as redes reais foram diferenciadas dos modelos. Fonte: Elaborada pelo autor.

As figuras de 4.53 a 4.57 mostram os resultados individuais obtidos para a análise de componentes principais das redes. Igualmente ao estudo anterior, em cada análise comparamos a projeção, nas duas componentes mais significantes, do sistema real, e de redes geradas utilizando os modelos de reconexão, Barabási-Albert e Erdős-Rényi; todas com aproximadamente o mesmo número de nós e grau médio.

Com exceção da rede do clube de caratê, todas as demais foram caracterizadas utilizando este método e ficaram distantes dos modelos de rede. Neste caso também tentamos realizar 
a projeção da rede do clube de caratê em 3 componentes principais, mas mesmo neste caso a rede também ficou próximas das demais e não pôde ser diferenciada. As geradas com o modelo de reconexão geralmente ficaram próximas das Erdős-Rényi, porém existem casos em que elas estão perto das Barabási-Albert. Podemos concluir então que as correlações entre as medidas de centralidades das ligações, também podem ser utilizadas para caracterizar e diferenciar redes complexas, como uma espécie de assinatura. Além disso, esse resultado também sugere que a estrutura das redes reais não são completamente representadas por nenhum dos modelos considerados.

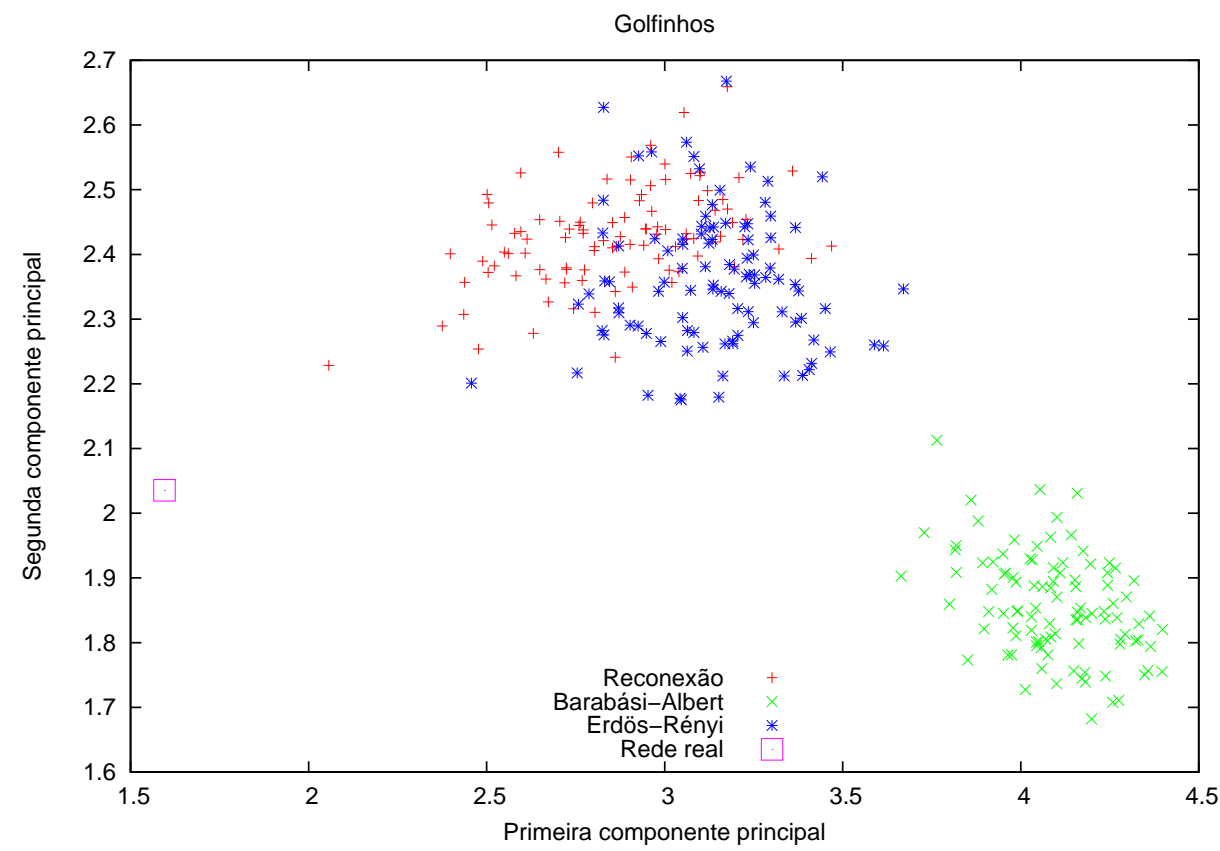

Figura 4.53 - Projeção das correlações entre os pares das medidas de centralidade das ligações da rede dos golfinhos nas duas componentes principais. Nesta figura também mostramos as projeções de redes geradas pelos modelos de Erdős-Rényi, Barabási-Albert e reconexão, utilizando características da rede real. Fonte: Elaborada pelo autor. 


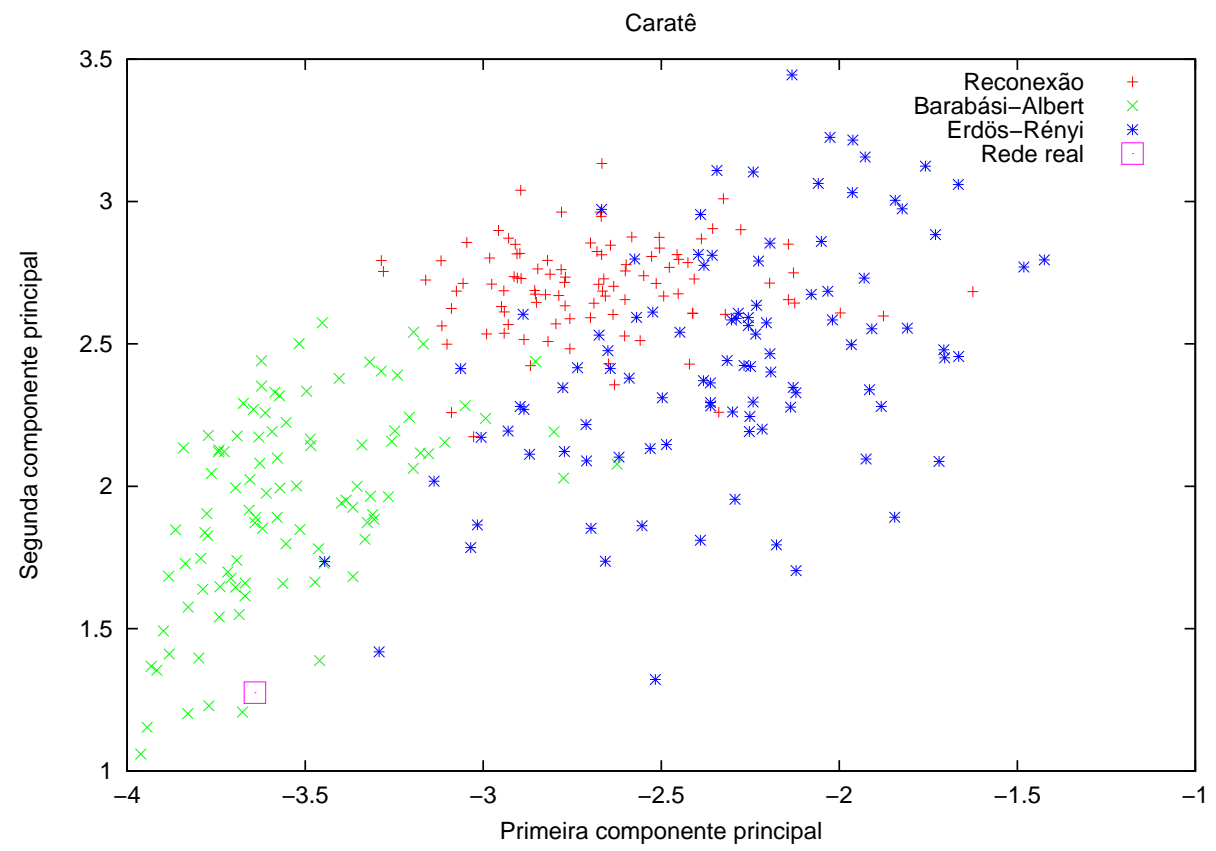

Figura 4.54 - Projeção das correlações entre os pares das medidas de centralidade das ligações da rede do clube de caratê nas duas componentes principais. Nesta figura também mostramos as projeções de redes geradas pelos modelos de Erdős-Rényi, BarabásiAlbert e reconexão, utilizando características da rede real. Fonte: Elaborada pelo autor.

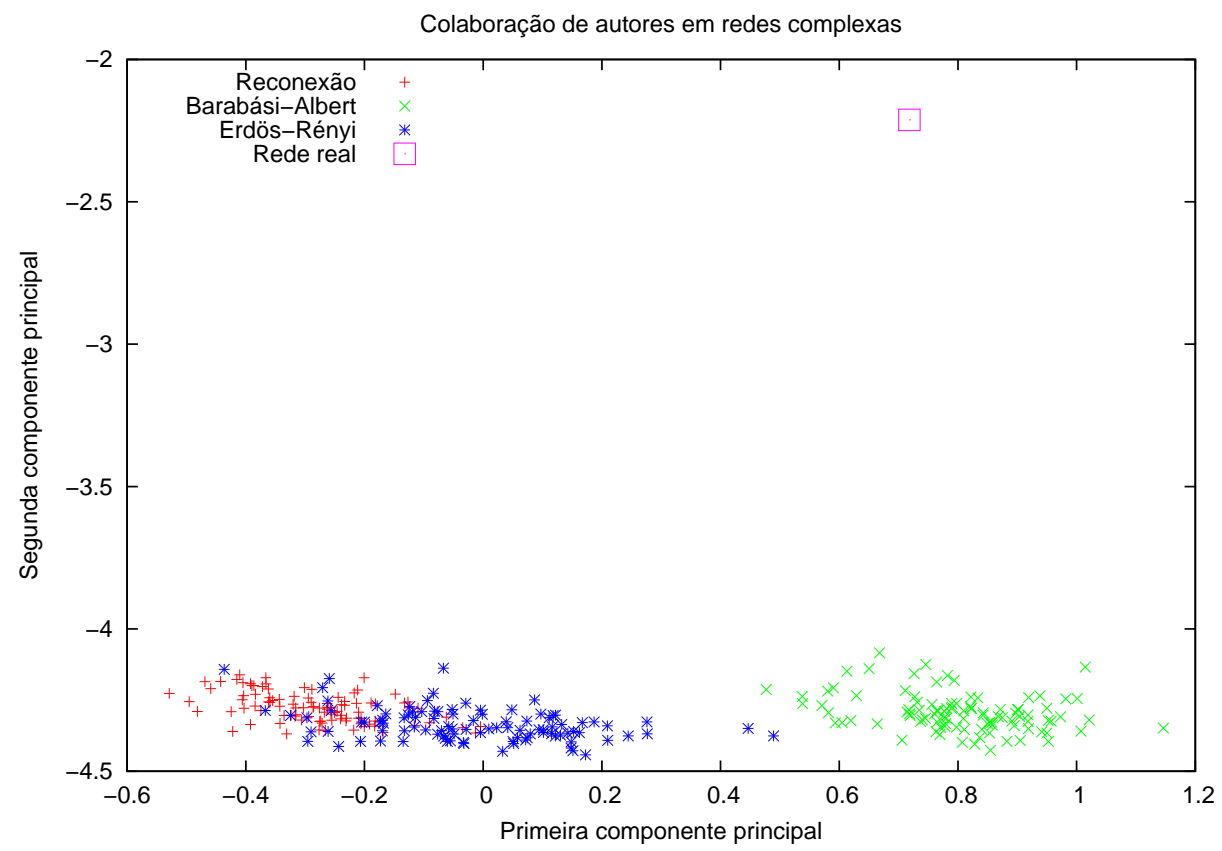

Figura 4.55 - Projeção das correlações entre os pares das medidas de centralidade das ligações da rede de colaboração entre autores de redes complexas nas duas componentes principais. Nesta figura também mostramos as projeções de redes geradas pelos modelos de ErdősRényi, Barabási-Albert e reconexão, utilizando características da rede real. Fonte: Elaborada pelo autor. 


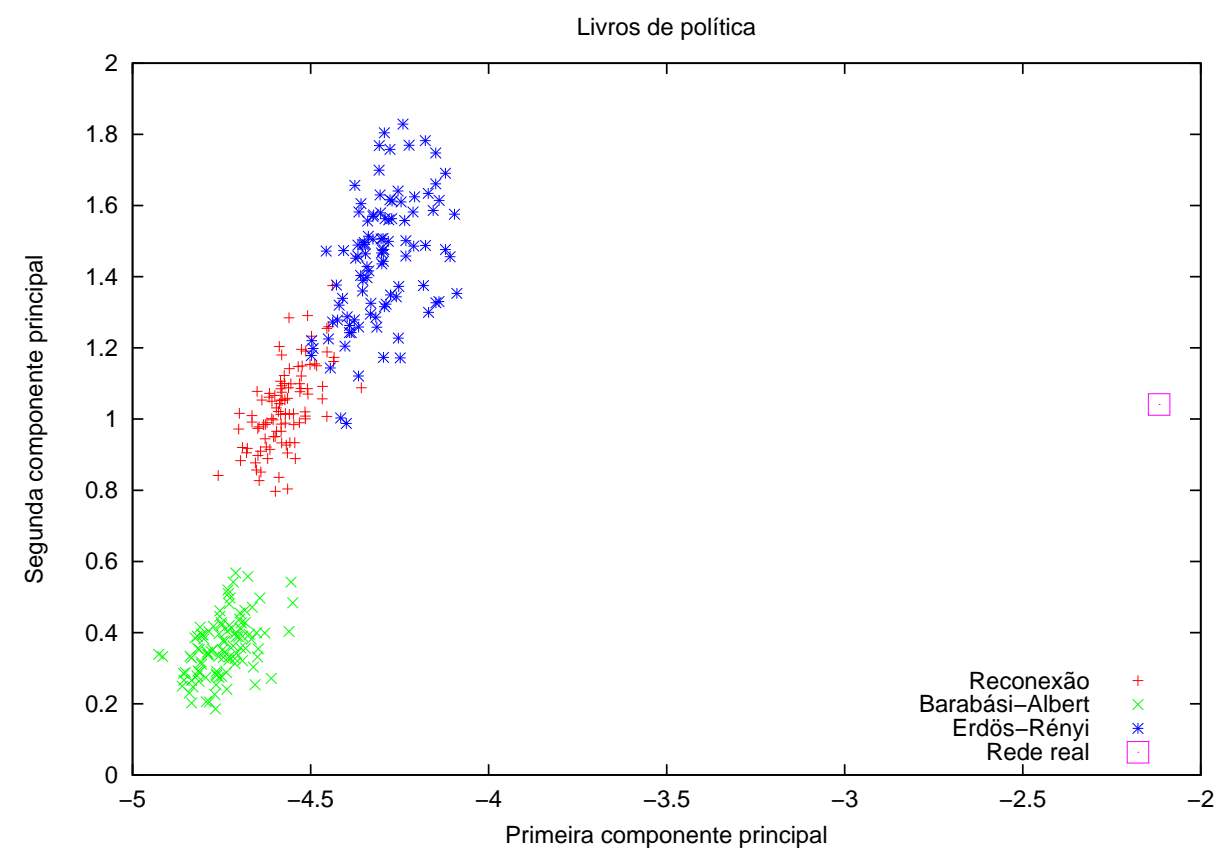

Figura 4.56 - Projeção das correlações entre os pares das medidas de centralidade das ligações da rede de livros sobre política nas duas componentes principais. Nesta figura também mostramos as projeções de redes geradas pelos modelos de Erdős-Rényi, BarabásiAlbert e reconexão, utilizando características da rede real. Fonte: Elaborada pelo autor.

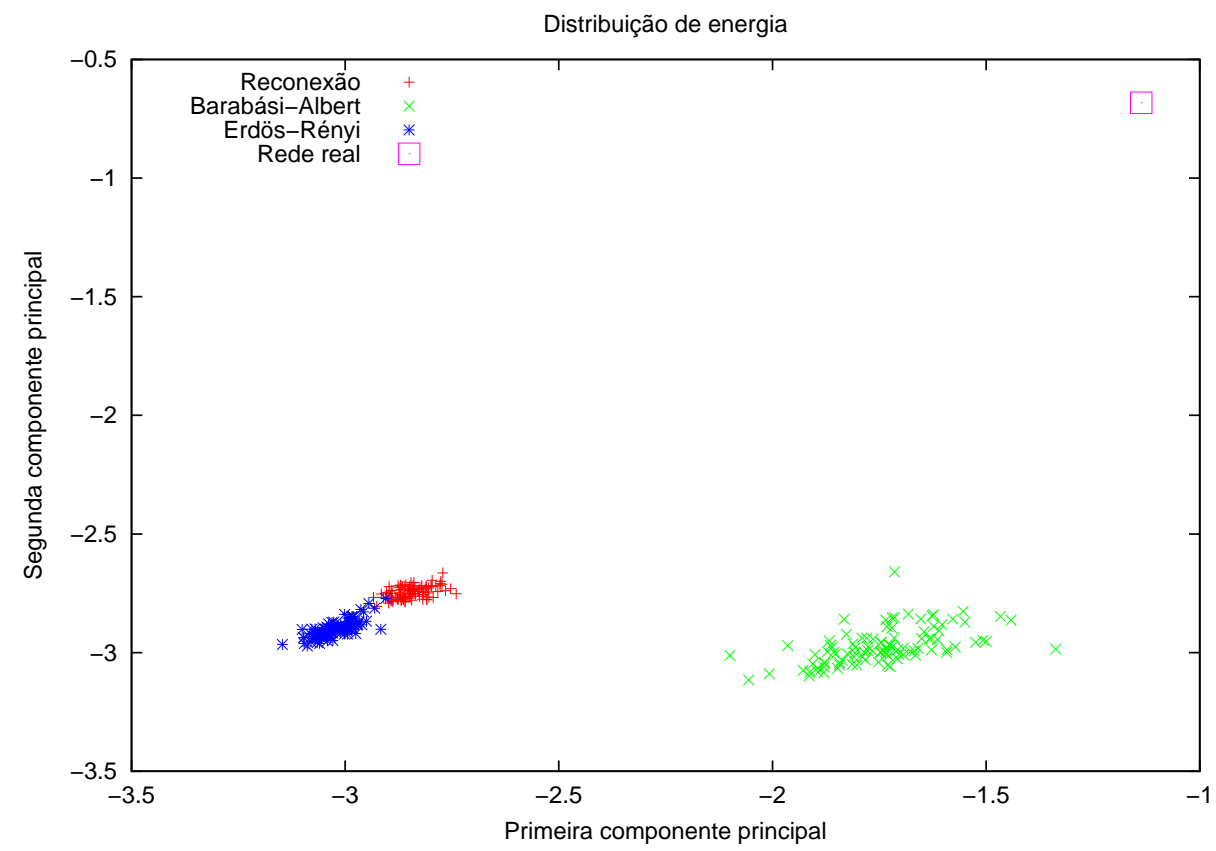

Figura 4.57 - Projeção das correlações entre os pares das medidas de centralidade das ligações da rede de distribuição de energia nas duas componentes principais. Nesta figura também mostramos as projeções de redes geradas pelos modelos de Erdős-Rényi, BarabásiAlbert e reconexão, utilizando características da rede real. Fonte: Elaborada pelo autor. 


\subsubsection{Avaliação de modelos com medidas de centralidades}

Para entender a estrutura das redes, existem diversos modelos que representam suas características. Como as correlações entre as medidas de centralidade conseguiram diferenciar as redes com sucesso, propomos utilizar este método para avaliar e comparar os diferentes modelos. Dessa forma, as projeções das medidas de centralidade das redes nos dois vetores mais significativos da análise de componentes principais são estudadas.

Para avaliarmos a eficiência deste método, utilizamos a rede Yeast e a comparamos com as geradas pelo modelo de Pastor-Satorras et al., desenvolvido para representar redes de interação de proteínas (80). Também incluímos as redes Barabási-Albert que possuem distribuição de grau livre de escala. O resultado está na figura 4.58. Nela, observamos que o modelo de Pastor-Satorras ficou mais próximo da rede original do que o modelo de Barabási-Albert. Ainda assim, o sistema real ficou fora da área ocupada pelas redes geradas com os modelos, indicando que suas características estruturais não são totalmente representadas por ele.

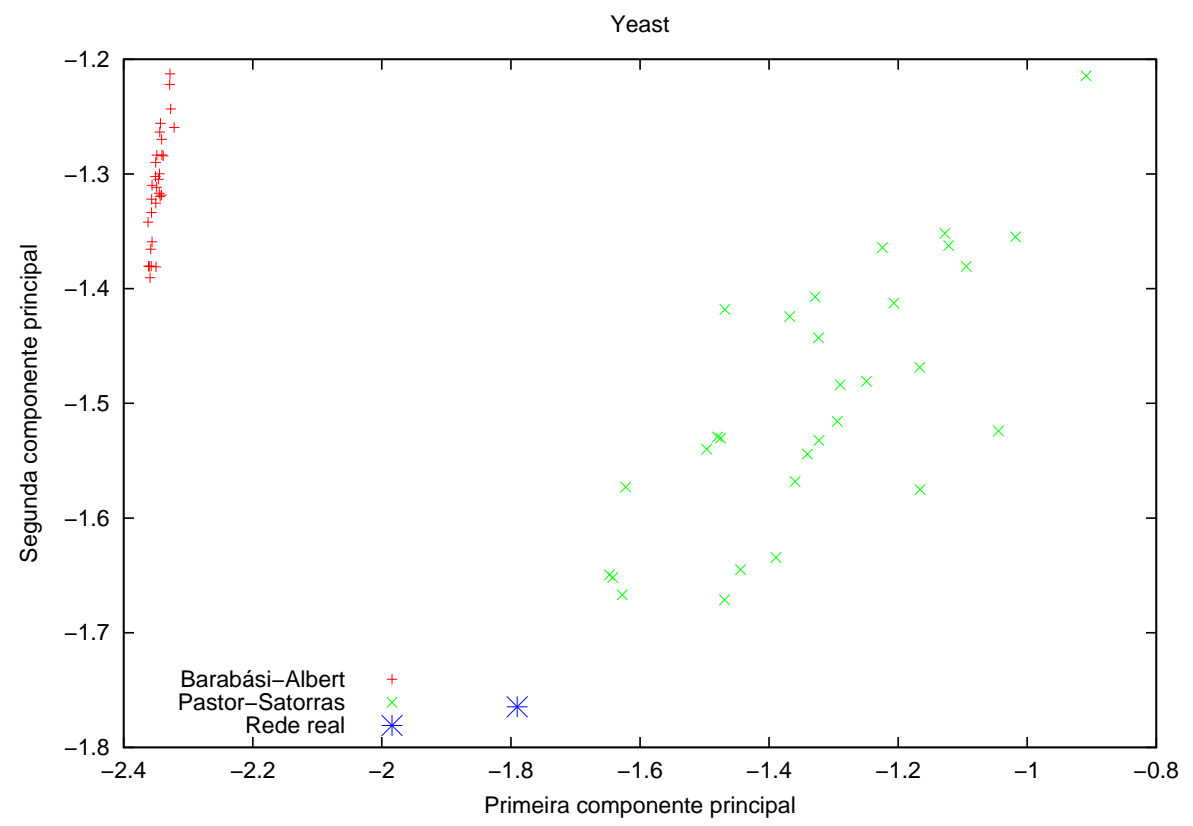

Figura 4.58 - Diferenciação entre uma rede de interação de proteínas e os modelos de BarabásiAlbert e Pastor-Satorras, utilizando as correlações entre as medidas de centralidade dos nós como características das redes. Fonte: Elaborada pelo autor. 


\section{Conclusões e trabalhos futuros}

As medidas de centralidade, utilizam a estrutura das redes complexas para classificar seus nós e ligações da rede por ordem de importância. Conhecendo os elementos essenciais, podemos entender melhor o seu funcionamento e através da sua estrutura, propor novos modelos além de estudar a resiliência dos diferentes tipos de rede.

Neste trabalho analisamos as centralidades e como se relacionam; para isso geramos gráficos scatter-plots em escala dilog dos pares de medidas onde observamos que eles se correlacionam como uma lei de potência especialmente para os valores de centralidade altos. $\mathrm{O}$ cálculo da correlação de Pearson indicou que em grande parte dos casos as medidas estão fortemente correlacionadas e que essas correlações são maiores nos modelos do que nas redes reais, mostrando que frequentemente os elementos essenciais são evidenciados pelas várias medidas.

Realizamos ataques aos sistemas reais removendo seus nós e ligações e avaliamos o decréscimo do tamanho da maior componente e da eficiência da rede; observamos que mesmo quando a correlação entre os pares de medidas está entre os mais fortes para uma dada rede, os resultados destes ataques podem ser diferentes, mostrando a importância do conjunto dos elementos selecionados pelas medidas para os sistemas. Isso mostra que uma análise apenas das correlações não é suficiente para dizer se duas medidas são semelhantes em um dado caso, mesmo quando as diferenças nos grupos de nós evidenciados pelas medidas é pequena, elas podem afetar a rede de maneiras bastante distintas e é necessário conhecer o sistema analisado na escolha das medidas que serão utilizadas.

Como as centralidades estão associadas a função e estrutura da rede, suas relações dependem do tipo de rede estudada, assim, utilizamos as correlações entre os pares de centralidades como características dos sistemas e realizamos uma análise de componentes principais nelas, com isso foi possível diferenciar as redes reais dos modelos na maioria dos casos, em outro estudo usamos este método para comparar modelos com uma rede real, onde observamos que podemos utilizar este método na proposição e comparação de novos modelos, dessa forma, capturando melhor as características mais importantes de cada tipo de rede o que implica uma maior compreensão sobre suas funções. 
Uma das dificuldades observadas foi encontrar centralidades de ligações que fossem amplamente utilizadas. O desenvolvimento de novas medidas para ligações é uma necessidade. Estudos aprofundados sobre as medidas de ligação derivadas das centralidades dos nós da rede também são importantes, já que elas mostram resultados significativos quando a fração de ligações removidas nos ataques é alta. Pesquisas semelhantes às realizadas, considerando redes do mesmo tipo como exemplo as de interação de proteínas ou sociais, também devem ser desenvolvidos para averiguar a existência de padrões nas correlações entre as redes representando um mesmo tipo de sistema. Como os pares de medidas frequentemente mostraram-se correlacionados, estudos sobre os nós e ligações da rede que receberam valor alto por uma centralidade e baixo por outra podem são interessantes, pois podem levar a uma melhor compreensão da estrutura da rede e do papel desempenhado por esses nós e ligações especiais. Finalmente podemos estender este trabalho, levando em consideração redes com direção e peso, e outras medidas de centralidade. 


\section{REFERÊNCIAS}

1 NEWMAN, M. Networks: an introduction. New York: Oxford University Press, Inc., 2010.

2 ESTRADA, E. The structure of complex networks: theory and applications. Oxford: Oxford University Press, 2011.

3 NEWMAN, M. The structure and function of complex networks. SIAM Review, v. 45, n. 2, p. 167-256, 2003. doi: $10.1137 /$ S003614450342480.

4 BOCCALETTI, S.; LATORA, V.; MORENO, Y.; CHAVEZ, M.; HWANG, D.-U. Complex networks: structure and dynamics. Physics Reports, v. 424, n. 4-5, p. $175-308$, 2006. doi: 10.1016/j. physrep.2005.10.009.

5 ALBERT, R.; BARABÁSI, A.-L. Statistical mechanics of complex networks. Reviews in Modern Physics, v. 74, p. 47-97, Jan 2002. doi: 10.1103/RevModPhys.74.47.

6 DOROGOVTSEV, S. N.; MENDES, J. F. F. Evolution of networks. Advances in Physics, London, v. 51, n. 4, p. 1079-1187, 2002. doi: 10.1080/00018730110112519.

7 DOROGOVTSEV, S. N.; GOLTSEV, A. V.; MENDES, J. F. F. Critical phenomena in complex networks. Reviews in Modern Physics, v. 80, p. 1275-1335, Oct. 2008. doi: 10.1103/RevModPhys.80.1275.

8 STROGATZ, S. H. Exploring complex networks. Nature, v. 410, p. 268-276, 2001. doi: $10.1038 / 35065725$.

9 COSTA, L. D. F.; OLIVEIRA, O. N.; TRAVIESO, G.; RODRIGUES, F. A.; VILLAS BOAS, P. R.; ANTIQUEIRA, L.; VIANA, M. P.; CORREA ROCHA, L. E. Analyzing and modeling real-world phenomena with complex networks: a survey of applications. Advances in Physics, London, v. 60, n. 3, p. 329-412, 2011. doi: 10.1080/00018732.2011.572452.

10 JEONG, H.; MASON, S. P.; BARABÁSI, A. L.; OLTVAI, Z. N. Lethality and centrality in protein networks. Nature, v. 411, n. 6833, p. 41-2, May 2001. doi: 10.1038/35075138.

$11 \mathrm{LEE}, \mathrm{T}$. I. et al. Transcriptional regulatory networks in saccharomyces cerevisiae. Science, v. 298, n. 5594, p. $799-804,2002$. doi: $10.1126 /$ science. 1075090.

12 DUNNE, J. A.; WILLIAMS, R. J.; MARTINEZ, N. D. Network structure and biodiversity loss in food webs: robustness increases with connectance. Ecology Letters, v. 5, n. 4, p. 558-567, 2002. doi: 10.1046/j.1461-0248.2002.00354.x. 
13 LILJEROS, F.; EDLING, C. R.; AMARAL, L. A.; STANLEY, H. E.; ABERG, Y. The web of human sexual contacts. Nature, v. 411, n. 6840, p. 907-8, June 2001. doi: 10.1038/35082140.

14 DODDS, P. S.; MUHAMAD, R.; WATTS, D. J. An experimental study of search in global social networks. Science, v. 301, n. 5634, p. 827-829, 2003. doi: 10.1126/science.1081058.

15 LUSSEAU, D. The emergent properties of a dolphin social network. Proceedings of the Royal Society of London. Series B: biological sciences, v. 270, p. S186-S188, 2003. Supplement 2. doi: $10.1098 / \mathrm{rsbl} .2003 .0057$.

16 GUIMERÀ, R.; MOSSA, S.; TURTSCHI, A.; AMARAL, L. A. N. The worldwide air transportation network: anomalous centrality, community structure, and cities' global roles. Proceedings of the National Academy of Sciences, v. 102, n. 22, p. 7794-7799, 2005. doi: 10.1073/pnas.0407994102.

17 DONGES, J. F.; ZOU, Y.; MARWAN, N.; KURTHS, J. Complex networks in climate dynamics. The European Physical Journal Special Topics, v. 174, n. 1, p. 157-179, 2009. doi: 10.1140/epjst/e2009-01098-2.

18 FALOUTSOS, M.; FALOUTSOS, P.; FALOUTSOS, C. On power-law relationships of the internet topology. SIGCOMM Computer Communication Review, v. 29, n. 4, p. 251-262, 1999.

19 MOTTER, A. E.; DE MOURA, A. P. S.; LAI, Y.-C.; DASGUPTA, P. Topology of the conceptual network of language. Physical Review E, v. 65, p. 065102, June 2002. doi: 10.1103/PhysRevE.65.065102.

20 COSTA, L. D. F.; RODRIGUES, F. A.; TRAVIESO, G.; VILLAS BOAS, P. R. Characterization of complex networks: A survey of measurements. Advances in Physics, London, v. 56, n. 1, p. 167-242, 2007. doi: 10.1080/00018730601170527.

21 ALBERT, R.; JEONG, H.; BARABASI, A. Error and attack tolerance of complex networks. Nature, v. 406, n. 6794, p. 378-82, July 2000. doi: $10.1038 / 35019019$.

22 GIRVAN, M.; NEWMAN, M. E. J. Community structure in social and biological networks. Proceedings of the National Academy of Sciences, v. 99, n. 12, p. 7821-7826, 2002. doi: $10.1073 /$ pnas. 122653799.

23 SEVEN bridges of Königsberg. Disponível em: <https://en.wikipedia.org/wiki/ File:7_bridges.svg>. Acesso em: 11 nov. 2013.

24 BIGGS, N.; LLOYD, E.; WILSON, R. Graph theory 1736-1936. Oxford: Clarendon Press, 1986. 
25 SYLVESTER, J. J. Chemistry and algebra. Nature, v. 17, p. 284, 1878 . doi: $10.1038 / 017284 a 0$.

26 SOLOMONOFF, R.; RAPOPORT, A. Connectivity of random nets. Bulletin of Mathematical Biophysics, v. 13, n. 2, p. 107-117, 1951. doi: 10.1007/BF02478357.

27 KÖNIGSBERG graph. Disponível em: <https://en.wikipedia.org/wiki/File: Konigsburg_graph.svg>. Acesso em: 11 nov. 2013.

28 MORENO, J.; JENNINGS, H. Who shall survive?: a new approach to the problem of human interrelations. Washington: Nervous and Mental Disease Publishing co., 1934.

29 MOODY, J. Race, school integration, and friendship segregation in america. American Journal of Sociology, v. 107, n. 3, p. 679-716, 2001. doi: 10.1086/338954.

30 AMARAL, L. A. N.; SCALA, A.; BARTHÉlÉMY, M.; STANLEY, H. E. Classes of small-world networks. Proceedings of the National Academy of Sciences, v. 97, n. 21, p. 11149-11152, 2000. doi: 10.1073/pnas.200327197.

31 WATTS, D. J.; STROGATZ, S. H. Collective dynamics of 'small-world' networks. Nature, v. 393 , n. 6684 , p. 440-2, June 1998. doi: 10.1038/30918.

32 DOBSON, I.; CARRERAS, B. A.; LYNCH, V. E.; NEWMAN, D. E. Complex systems analysis of series of blackouts: cascading failure, critical points, and self-organization. Chaos: an interdisciplinary journal of nonlinear science, v. 17, n. 2, p. 026103, 2007. doi: $10.1063 / 1.2737822$.

33 NOORDEN, R. van. Brazilian citation scheme outed. Nature, v. 500, n. 7464 , p. 510-1, Aug. 2013. doi: 10.1038/500510a.

34 DE SOLLA PRICE, D. J. Networks of scientific papers. Science, v. 149, n. 3683, p. 510-515, July 1965. doi: 10.1126/science.149.3683.510.

35 SPORNS, O. Networks of the brain. Cambridge, Massachusetts: The MIT Press, 2010.

36 PROULX, S. R.; PROMISLOW, D. E. L.; PHILLIPS, P. C. Network thinking in ecology and evolution. Trends in Ecology \& Evolution, v. 20, n. 6, p. 345-53, June 2005. doi: 10.1016/j.tree.2005.04.004.

37 ZHANG, A. Protein interaction networks: computational analysis. Cambridge, New York: Cambridge University Press, 2009.

38 OLIVER, S. Guilt-by-association goes global. Nature, v. 403, n. 6770, p. 601-3, Feb. 2000. doi: $10.1038 / 35001165$. 
39 MILO, R.; SHEN-ORR, S.; ITZKOVITZ, S.; KASHTAN, N.; CHKLOVSKII, D.; ALON, U. Network motifs: simple building blocks of complex networks. Science, v. 298, n. 5594, p. 824-827, 2002. doi: 10.1126/science.298.5594.824.

40 JOHNSON, N. F. Two's company, three is complexity: a simple guide to the science of all sciences. Oxford: Oneworld Pubns Ltd, 2007.

41 ZACHARY, W. W. An information flow model for conflict and fission in small groups. Journal of Anthropological Research, v. 33, n. 4, p. 452-473, 1977.

42 NEWMAN, M. E. J.; GIRVAN, M. Finding and evaluating community structure in networks. Physical Review E, v. 69, p. 026113, Feb. 2004. doi: 10.1103/PhysRevE.69.026113.

43 PAGE, L.; BRIN, S.; MOTWANI, R.; WINOGRAD, T. The pagerank citation ranking: bringing order to the web. Technical Report. Stanford InfoLab, Nov. 1999. Previous number = SIDL-WP-1999-0120. Disponível em: <http://ilpubs.stanford.edu: 8090/422/1/1999-66.pdf>. Acesso em: 9 jan. 2014.

44 MILGRAM, S. The small world problem. Psychology Today, v. 2, n. 1, p. 60-67, 1967.

45 NEWMAN, M. Power laws, pareto distributions and zipf's law. Contemporary Physics, v. 46, n. 5, p. 323-351, 2005. doi: 10.1080/00107510500052444.

46 SIMON, H. A. On a class of skew distribution functions. Biometrika, v. 42, n. 3-4, p. 425-440, 1955. doi: 10.2307/2333389.

47 LATORA, V.; MARCHIORI, M. Efficient behavior of small-world networks. Physical Review Letters, v. 87, p. 198701, Oct. 2001. doi: 10.1103/PhysRevLett.87.198701.

48 NEWMAN, M. E. J. Mixing patterns in networks. Physical Review E, v. 67, p. 026126, Feb. 2003. doi: 10.1103/PhysRevE.67.026126.

49 ERDÓS, P.; RÉNYI, A. On random graphs. Publicationes Mathematicae Debrecen, v. 6, p. 290-297, 1959. Disponível em: <http: //ftp.math-inst.hu/ p_erdos/1959-11.pdf>. Acesso em: 9 jan. 2014.

50 ERDŌS, P.; RÉNYI, A. On the evolution of random graphs. Publications of the Mathematical Institute of the Hungarian Academy of Sciences, v. 5, p. 17-61, 1960. Disponivel em: <http://www.renyi.hu/ p_erdos/1960-10.pdf>. Acesso em: 9 jan. 2014.

51 BOLLOBÁS, B. Random graphs. Cambridge, New York: Cambridge University Press, 2001.

52 DURRETT, R. Random graph dynamics. Cambridge, New York: Cambridge University Press, 2007. 
53 BARABÁSI, A.-L.; ALBERT, R. Emergence of scaling in random networks. Science, v. 286, n. 5439, p. 509-512, 1999. doi: 10.1126/science.286.5439.509.

54 BONACICH, P. Power and centrality: a family of measures. American Journal of Sociology, v. 92 , n. 5, p. pp. 1170-1182, 1987. doi: 10.1086/228631.

55 ANTHONISSE, J. M. The rush in a directed graph. Stichting Mathematisch Centrum., , n. BN 9/71, p. 1-10, 1971. Disponível em: <http://oai.cwi.nl/oai/asset/9791/ 9791A.pdf>. Acesso em: 9 jan. 2014.

56 FREEMAN, L. C. A set of measures of centrality based on betweenness. Sociometry, v. 40, n. 1, p. 35-41, 1977. doi: 10.2307/3033543.

57 BEAUCHAMP, M. A. An improved index of centrality. Behavioral Science, v. 10, n. 2, p. 161-163, 1965. doi: 10.1002/bs.3830100205.

58 STEPHENSON, K.; ZELEN, M. Rethinking centrality: methods and examples. Social Networks, v. 11, n. 1, p. 1 -37, 1989. doi: 10.1016/0378-8733(89)90016-6.

59 FREEMAN, L. C.; BORGATTI, S. P.; WHITE, D. R. Centrality in valued graphs: a measure of betweenness based on network flow. Social Networks, v. 13, n. 2, p. $141-154$, 1991.

60 NEWMAN, M. J. A measure of betweenness centrality based on random walks. Social Networks, v. 27, n. 1, p. $39-54,2005$.

61 BRANDES, U.; FLEISCHER, D. Centrality measures based on current flow. In: DIEKERT, V.; DURAND, B. (Ed.) STACS 2005. Berlin: Springer, 2005. p. 533-544. ( Lecture notes in computer science, v., 3404).

62 BOLLOBÁS, B. Modern graph theory. Heidelberg: Springer, 1998. (Graduate texts in mathematics, v. 184).

63 ESTRADA, E.; RODRÍGUEZ-VELÁZQUEZ, J. A. Subgraph centrality in complex networks. Physical Review E, v. 71, p. 056103, May 2005. doi: 10.1103/PhysRevE.71.056103.

64 FARKAS, I. J.; DERÉNYI, I.; BARABÁSI, A.-L.; VICSEK, T. Spectra of "real-world" graphs: beyond the semicircle law. Physical Review E, v. 64, p. 026704, July 2001. doi: 10.1103/PhysRevE.64.026704.

65 FARKAS, I.; DERZÉNYI, I.; JEONG, H.; NÉDA, Z.; OLTVAI, Z.; RAVASZ, E.; SCHUBERT, A.; BARABÁSI, A.-L.; VICSEK, T. Networks in life: scaling properties and eigenvalue spectra. Physica A: statistical mechanics and its applications, v. 314, n. 1-4, p. $25-34$, 2002. doi: 10.1016/S0378-4371(02)01181-0. 
66 LUSSEAU, D.; SCHNEIDER, K.; BOISSEAU, O.; HAASE, P.; SLOOTEN, E.; DAWSON, $\mathrm{S}$. The bottlenose dolphin community of doubtful sound features a large proportion of longlasting associations. Behavioral Ecology and Sociobiology, v. 54, n. 4, p. 396-405, 2003.

67 NEWMAN, M. E. J. Finding community structure in networks using the eigenvectors of matrices. Physical Review E, v. 74, p. 036104, Sept. 2006. doi: 10.1103/PhysRevE.74.036104.

68 KREBS, V. New political patterns. Disponível em: <http://www.orgnet.com/ divided.html>. Acesso em: 11 nov. 2013.

69 NEWMAN, M. E. J. The structure of scientific collaboration networks. Proceedings of the National Academy of Sciences, v. 98, n. 2, p. 404-409, 2001. doi: 10.1073/pnas.98.2.404.

70 NEWMAN, M. E. J. Scientific collaboration networks. i. network construction and fundamental results. Physical Review E, v. 64, p. 016131, June 2001. doi: 10.1103/PhysRevE.64.016131.

71 NEWMAN, M. E. J. Scientific collaboration networks. ii. shortest paths, weighted networks, and centrality. Physical Review E, v. 64, p. 016132, June 2001. doi: 10.1103/PhysRevE.64.016132.

72 NEWMAN, M. Network data. Disponível em: <http://www-personal.umich.edu/ mejn/netdata/>. Acesso em: 11 nov. 2013.

73 BU, D.; ZHAO, Y.; CAI, L.; XUE, H.; ZHU, X.; LU, H.; ZHANG, J.; SUN, S.; LING, L.; ZHANG, N.; LI, G.; CHEN, R. Topological structure analysis of the protein-protein interaction network in budding yeast. Nucleic Acids Research, v. 31, n. 9, p. 2443-2450, 2003. doi: $10.1093 /$ nar/gkg340.

74 PAJEK datasets. Disponível em: <http://vlado.fmf.uni-lj.si/pub/networks/ data/bio/Yeast/Yeast.htm>. Acesso em: 11 nov. 2013.

75 HOLME, P.; KIM, B. J.; YOON, C. N.; HAN, S. K. Attack vulnerability of complex networks. Physical Review E, v. 65, p. 056109, May 2002. doi: 10.1103/PhysRevE.65.056109.

76 LEE, C.-Y. Correlations among centrality measures in complex networks. 2006. Disponível em: <http://arxiv.org/pdf/physics/0605220v1.pdf>. Acesso em: 9 jan. 2014.

77 VALENTE, T. W.; CORONGES, K.; LAKON, C.; COSTENBADER, E. How correlated are network centrality measures? Connect (Tor), v. 28, n. 1, p. 16-26, Jan. 2008.

78 IYER, S.; KILLINGBACK, T.; SUNDARAM, B.; WANG, Z. Attack robustness and centrality of complex networks. PLoS ONE, v. 8, n. 4, p. e59613, Apr. 2013. 
79 JOLLIFFE, I. Principal component analysis. New York: Springer, 2002.

80 PASTOR-SATORRAS, R.; SMITH, E.; SOLÉ, R. V. Evolving protein interaction networks through gene duplication. Journal of Theoretical Biology, v. 222, n. 2, p. $199-210,2003$. 